\title{
DESIGN AND EVALUATION CRITERIA FOR ENERGY CONSERVATION IN NEW BUILDINGS
}

NBSIR 74-452

February 27, 1974

Revised February 26, 1976

U.S. DEPARTMENT OF COMMERCE

National Bureau of Standards

Washington, D.C. 20234

Prepared for:

NATONAL CONFERENCE OF STATES

ON BUILDING CODES AND STANDARDS 

February 27, 1974

National Conference of States for

Building Codes and Standards

c/o Mr. Bernard E. Cabelus, Chairman

State of Connecticut Delegate

State Office Building

Hartford, Connecticut 06115

Dear Mr. Cabelus:

The "Design and Evaluation Criteria for Energy Conservation in New Buildings" was developed in response to the July 12, 1973 request of the National Conference of States on Building Codes and Standards to provide the technical basis for a performance-type standard. Although this document is comprehensive in its technical scope, it is not practical at this time to develop a single document which would be universally applicable to all types of buildings in a uniform manner.

It is our recommendation that this document be used as the basis for the development of a consensus standard to apply to new construction for all building types except those excluded in the following paragraph. It is also our recommendation that the. States be advised not to use the document in its present form for regulatory purposes.

The following recommendations are made with respect to:

1. Residential buildings including manufactured housing (oneand two-family) --

- The Federal Housing Administration's Minimum Property Standard $51 \mathrm{lb}$ should be used as an interim standard.

- A consensus standard for one- and two-family housing should be developed using this document as a guideline to expand the scope covered by MPS 51b. It should include such factors as: air infiltration, usage of glass, illumination levels, and electrical distribution systems. It should seek to eliminate wasteful practices in heating, ventilation, air conditioning, and service water systems.

- As an interim measure, the States should investigate the possibility of initiating a voluntary labeling program for buildings which meet the requirements of this document. 
2. Mobile Homes --

- The Coordinating Committee of the National Mobile Home Standard should be requested to sponsor and appoint a new subcomittee to develop an energy conservation supplement to ANSI A119.1. This supplement should be completed by July 1, 1974, using this document as a guideline.

3. Industrial buildings, monument buildings, short-term periodic use buildings such as vacation shelters, or buildings containing special laboratories --

- Instead of using this document, special energy conservation measures applying to these buildings should be developed which take into consideration the special conditions which prevail.

As indicated in your November 19, 1973 letter to Dr. Richard Roberts, Director of the National Bureau of Standards, performance standards cannot be utilized without changes in the structure of the building regulatory system. It is recommended that NCSBCS at its February 27, 1974 meeting study what tasks need to be done to make performance standards workable and designate appropriate organizations to carry out the identified tasks. The completion of these tasks should be scheduled so that the regulatory system is capable of handling a performancetype standard when the consensus standard based on this document has been completed.

Sincerely,

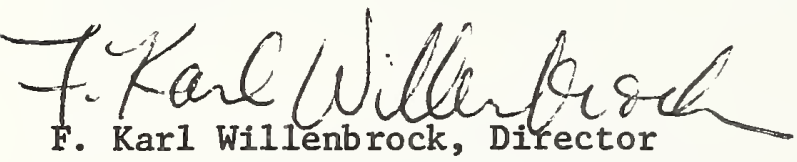

Institute for Applied Technology 
NBSIR 74-452

DESIGN AND EVALUATION CRITERIA FOR

ENERGY CONSERVATION IN NEW

BUILDINGS

Jim L. Heldenbrand, Editor

Center for Building Technology

Institute for Applied Technology

National Bureau of Standards

Wa shington, D. C. 20234

February 27, 1974

Revised February 1976

Prepared for

National Conference of States on Building Codes and Standards

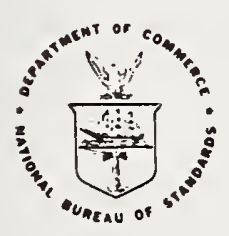

U.S. DEPARTMENT OF COMMERCE, Elliot L. Richardson, Socrotary James A. Baker, III, Under Secretary

Dr. Betsy Ancker-Johnson, Assistant Secretary for Science and Technology

NATIONAL BUREAU OF STANDARDS. Ernest Ambler, Acting Director 

This document is a set of design and evaluation criteria for energy conservation in most types of new buildings. The National Conference of States on Building Codes and Standards (NCSBCS) requested that the National Bureau of Standards (NBS) develop such a document with the intent that it could serve as a basis for a national standard developed through the voluntary consensus process.

Development of these design criteria required engineering value judgments in their preparation. Two Administration energy policy directives have served as quantitative goals for the engineering judgments that guided the formulation of these criteria: these are found in the President's 1971 and 1972 Energy Messages to Congress. In 1971, the President directed the Secretary of Housing and Urban Development to reduce maximum permissible energy loss by "about one-third for a typical 1200 square foot home--and by even more for larger (federally insured) homes." In the following year, the President directed the Secretary to "issue revised insulation standards for apartments and other multifamily structures not covered by the earlier revision. The new rules will cut maximum permissible (energy) loss by 40 percent." A third Administration statement appeared part way through the criteria's development which reinforced its conservation orientation. This was Atomic Energy Commission Chairman Dixy Lee Ray's report to the President (December 1, 1973) on a plan to commit $\$ 10$ billion to Federal energy research and development in fiscal 1975-79. In that report, entitled The Nation's Energy Future, conservation is central to the Federal Government's energy self-sufficiency strategy. Moreover, the Ray report ranks conservation of energy as the highest federal research and development priority.

The design and evaluation criteria focus on building subelements and service system arrangements. Special provisions offer added flexibility for both conventional and innovative designs. The technical portions of the document are organized into four complementary sections: requirements, criteria, evaluation and commentary. Existing standards and procedures promulgated by organizations such as the American Society of Heating, Refrigerating and Air Conditioning Engineers (ASHRAE), the American Society for Testing and Materials (ASTM) and the American National Standards Institute, Inc. (ANSI) are referenced whenever possible. The evaluation statements describe how to verify that candidate solutions meet the stipulated criteria. Finally, the commentary statements convey the intent of the criteria and, in a number of cases, explain how the criteria were selected.

We believe adherence to the criteria contained herein will result in significant energy savings while maintaining an acceptable level of habitability, thus advancing several national goals.

Paul R. Achenbach,

Chief

February 27, 1974

Building Environment Division

Center for Building Technology, IAT

National Bureau of Standards 


\section{CONTENTS}

Foreword

Task Group for Development of the Energy Document 1 /

Background of Project

Procedures Used in Development of the Energy Document

Application

Design Criteria with Evaluation and Commentary Statements

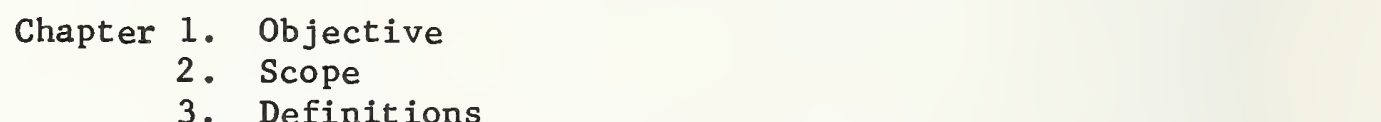

4. General Performance Requirements

5. Exterior Envelope Requirements 14

Appendix 1 Examples Illustrating the Application of Chapter 5 Criteria

Appendix 2 Heat Flux, Thermal Resistance and Thermal Transmittance Values for Ceilings, Roofs, and Opaque Walls

6. Heating, Ventilating and Cooling System Requirements

Appendix 1 Listing of Standards for HVAC Equipment Which Include Efficiency

Appendix 2 Procedure for Determining

Coefficient of Performance (COP), 6.5.8 75

7. Service Water Heating Requirements

Appendix 1 Listing of Standards for

Service Water Heating Equipment Which

Include Efficiency

8. Electrical Distribution and Power-Factor Requirements

9. Lighting Requirements

10. Energy Requirements for Building Designs Based on Dynamic Analys is

11. Requirements for Buildings Utilizing Solar or Wind Powered Energy Sources

Conversion Factors to Metric (SI) Units

Procedure for Determining Economic Efficiency

New Information Needed for Energy Conservation Criteria

I/ Wherever the term "document" is used in this publication it refers to these design and evaluation criteria unless the immediate context indicates another meaning. 
The energy document is the result of work by personnel of the National Bureau of Standards Center for Building Technology augmented by a group of advisors who met frequently over a period of three months. The following persons comprised the Task Group.

\section{NBS CENTER FOR BUILDING TECHNOLOGY}

Paul R. Achenbach, Program Manager, Task Group for Energy Document

Jim L. Heldenbrand, Project Manager

Robert W. Beausoliel

Adolfo A. Camacho

Peter F. Colwell

James E. Hill

Tamami Kusuda

Charles T. Mahaffey

Bradley A. Peavy

Clinton $W$. Phillips

Frank J. Powell (Chief, Thermal Engineering Systems Section)

Jack E. Snell (Ass't Chief, Building Environment Division)

Francis T. Ventre (Ass't Chief, Office of Building Standards and Codes Services)

Thomas W. Watson

Gary Yonemura

\section{ADVISORS*}

Samuel A. Bogen

Bogen Jenal Engineers, P.C.

Albertson, New York

Joseph A. Demkin

Dept. of Professional Practice, AIA

Washington, D. C.

Charles A. Hagberg

Hagberg and Associates

Madison, Wisconsin

Lawrence G. Spielvogel

Lawrence G. Spielvogel, Inc.

Wyncote, Pennsylvania

Joseph Stein

Tishman Research Corp.

New York, New York

\section{DESIGNATED BY}

American Consulting Engineers Council ( $\mathrm{ACEC}$ )

American Institute of Architects (AIA)

National Conference of States on Building Codes and Standards (NCSBCS)

American Society of Heating, Refrigerating, and Air Conditioning Engineers (ASHRAE)

National Conference of States on Building Codes and Standards (NCSBCS)

\footnotetext{
*Participation in the preparation of this document does not imply endorsement by the advisors or the organizations who designated them.
} 

Temporary shortages of gas, oil, and electricity have occurred during the last two years in various areas of the country. These shortages have caused temporary shutdowns of schools, offices, manufacturing, food processing, and military installations, and brought about requests to state and City executives for guidelines in the use of energy resources. Several State governments have initiated independent legislative action to control the use of limited energy resources in new buildings, thus raising the possibility that a wide variety of different requirements could be imposed on the building and equipment industries.

In an effort to provide uniformity in the requirements placed on building design by the various State and local governments, the National Conference of States on Building Codes and Standards (NCSBCS) in July 1973 requested the National Bureau of Standards (NBS) to develop an interim standard for energy conservation in new buildings which would be available for consideration by the States during their 1973-74 legislative sessjons. Although NBS does not promulgate or establish engineering Standards 1 , it strongly supports the concept of voluntary consensus standards. NBS agreed to develop design and evaluation criteria for energy conservation in new buildings which would be made available to a suitable organization for sponsorship through the consensus process. Toward this end NBS prepared altemative plans for expeditious promulgation of their criteria through the consensus process by such a sponsor.

NBS established a Task Group in the Center for Building Technology to develop the document. With the concurrence of NCSBCS, NBS invited three professional societies who are concerned in a broad way with the design of buildings and energy-using equipment, and NCSBCS itself to name advisors to work with the NBS Task Group. After receiving a preliminary draft, ASHRAE has offered to sponsor this document through to a national consensus voluntary standard. NCSBCS will act on this proposal at their meeting in Salt Lake City on February 27, 1974.

I) Exceptions to this generalization are the voluntary product standards and the limited number of mandatory standards covered by Congressional directives. 
NCSBCS requested that the document be performance oriented where practicable. Since the term "performance" is subject to various interpretations, a number of different approaches were studied. The following two categories of objectives for the energy document were developed by NBS and approved by NCSBCS, and the various performance approaches were rated for their ability to attain these objectives:

ESSENTIAL OBJECTIVES

1. Be available by January 1974 .

2. Effect significant energy savings.

3. Be applicable to a range of building construction, occupancies, climates, and equipment.

4. Be amenable to consistent interpretation.

5. Be compatible with existing health, safety, and environmental regulations.

6. Be useful as a design guide.

7. Be an improvement over existing documents.

8. Merit a high level of voluntary compliance.

DESIRABLE OBJECTIVES

1. Maximize energy savings.

2. Be an acceptable basis for a voluntary consensus standard.

3. Reflect due consideration of cost implications.

4. Permit design flexibility and choice of materials and equipment within given constraints.

5. Maintain acceptable standards of space, environmental conditions, and convenience.

6. Clearly differentiate requirements for each type of occupancy.

7. Suggest methods of preconstruction evaluation.

8. Include provision for different (emergency) conformance levels. 
The approach which rated the highest probability of attaining the above objectives can be described as a "framework of performance statements supported by performance requirements for subelements," and was followed in preparing this document.

The timeframe within which the document was developed permitted the use of state-of-the-art technology only. A public workshop was held on November 12 and 13, 1973, after announcement in the Commerce Business Daily and the issuance of written invitations to State officials and to a broad selection of professional and industrial associations for its provisions. During the preparation of this document, meetings were held at NBS between the Task Group and officials of various industry associations representing types of energy resources, mechanical equipment for buildings, the housing and mobile home industries, and building materials, to obtain their views and recommendations of building requirements. In advance of making the resulting design and evaluation criteria available for sponsorship through a consensus review process an opportunity was provided to selected industry, professional and government groups to review a working draft. In addition NBS contracted for economic and technical impact analyses of the draft document from nine architectural and engineering firms and industry associations. These comments and analyses have received consideration in the preparation of this document.

Design requirements were developed for only those features of energy-using equipment for which enough technical information was available to support a definitive criterion. Other parameters can be covered now by guidelines to designers on an advisory basis, and may be incorporated into future revisions of the document as the experience and technology of energy conservation expands. 
As illustrated in Figure 1, the document provides three paths to acceptance of a building's design energy requirement. Path 1 is basic since it provides the most direct approach and also provides the basis of comparison for establishing acceptable levels of energy usage for the alternative approaches afforded by Path 2 and Path 3.

By choosing only Path 1 in Figure 1, the building designer chooses to comply with the performance statements of Chapters 5 through 9 of this document.I/ These chapters contain a set of detailed performance requirements and criteria directed toward the saving of energy through design of building envelopes with good thermal resistance and low air leakage, and utilization of energy-saving practices in the design of mechanical and electrical systems. Provisions for acceptance of alternative designs for the building envelope are also included in Chapter 5. Conformance with Chapters 5 through 9 will result in energy conservation in buildings, and will provide design guidelines suitable for most building applications without the necessity for analysis of annual energy use.

In choosing Path 2 in Figure 1, the designer must perform a dynamic energy analysis on the building and service systems selected in Path 1. The resulting computed annual energy consumption becomes a reference energy budget. An alternative building design which does not necessarily meet each and every subelement requirement will be acceptable if an energy analysis of that design shows that the calculated annual energy use is equal to or less than the reference energy budget. Details regarding the Path 2 approach are given in Chapter 10 and illustrated in Figure 10-1.

Path 3 provides the designer with an allowable increase in total design annual energy consumed by the total building system, as a bonus for substituting solar or wind powered energy for part or all of the energy otherwise generated from mineral energy sources such as fossil fuel and uranium. The reference energy budget is based on a building designed to meet the requirements of Path 1 . The basis for claiming an energy bonus is a dynamic energy analysis to establish both the reference energy budget and the annual design energy contribution provided by the solar or wind powered energy source. Details regarding the Path 3 approach are given in Chapter 11 and are illustrated in Figure $11-1$ and the Commentary on Chapter 11.

I/ Chapters 1 through 4 apply to all three paths. 


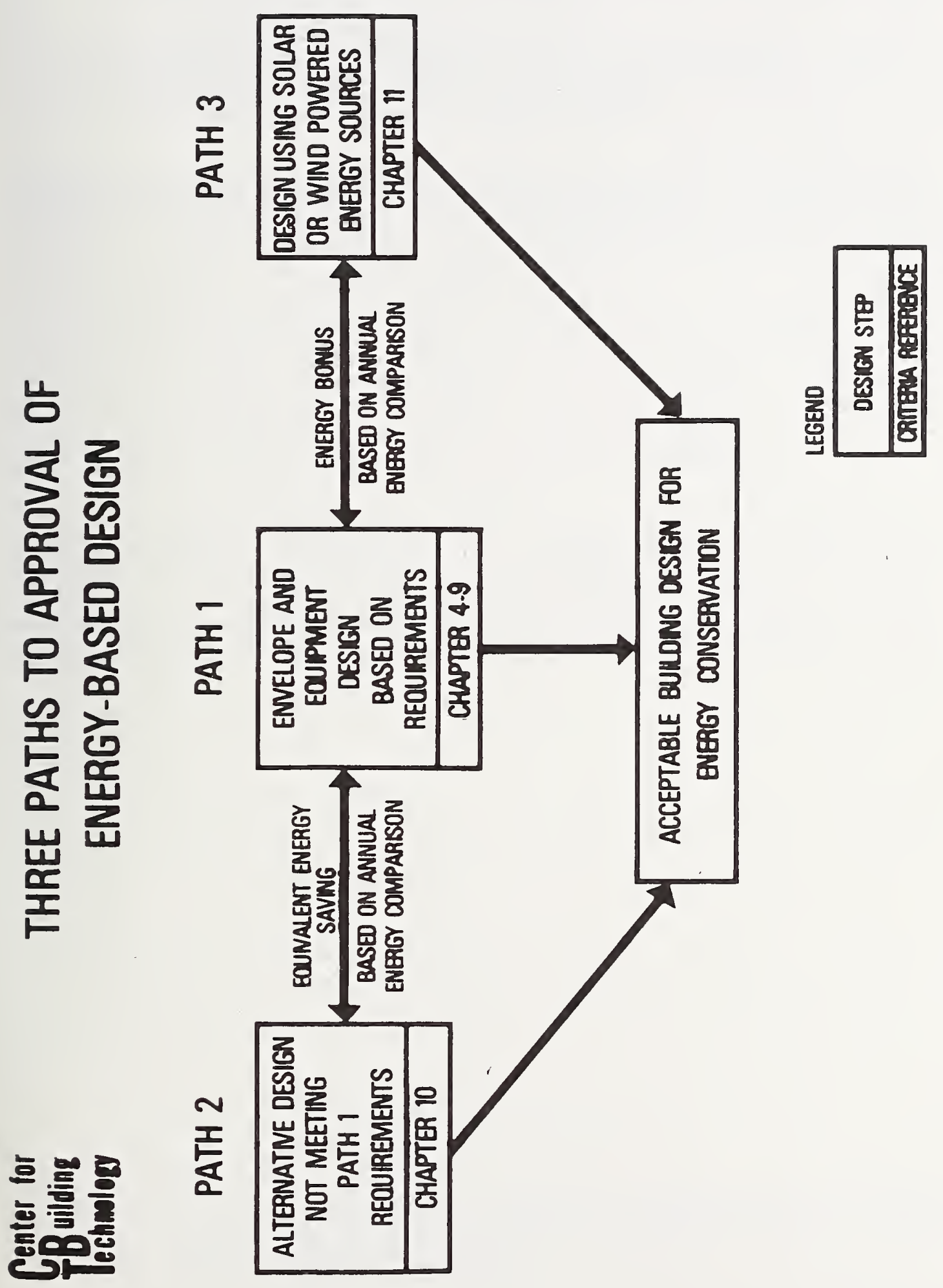




\section{DESIGN CRITERIA WITH \\ EVALUATION AND COMMENTARY STATEMENTS}

The Requirement and Criteria statements contained in this document are supplemented where necessary with Evaluation and Commentary statements.

The Evaluation statements are intended to identify suggested procedures for evaluating a building design for conformance with the Criteria. The Commentary statements provide examples and sample calculations to illustrate design options and procedures and, in some instances, provide rationale for the Criteria.

Where no Evaluation or Commentary statement is given, the Criteria statement is presumed to be self-explanatory. 


\section{OBJECTIVE}

These design and evaluation criteria contain performance-oriented requirements for energy conservation in buildings. This document $=$ was prepared in response to a request by the National Conference of States . on Building Codes and Standards to the National Bureau of Standards. It is intended to be the forerunner of a consensus standard to be promulgated by a national standards organization.

The document is performance-based to the extent permitted by present building design technology. The performance concept is applied at the subelement or subsystem level to synthesize an energy-efficient total system. The detailed performance requirements and criteria are directed toward the design of building envelopes with good thermal resistance and low air leakage, and toward requiring practices in the design of mechanical and electrical systems which conserve energy. Design flexibility is achieved by providing for acceptance of alternative design solutions that can be shown to save equivalent amounts of energy without following each and every detailed requirement. Such alternative designs, as well as those based on subelement requirements, must be supported by drawings, specifications, and calculations to demonstrate compliance.

The draft design and evaluation criteria can be made effective only by the application of its provisions in the design process, by review and evaluation of design proposals, and by the inspection of resulting construction. It is not the intent of this document to require tests and measurements of the completed building and its service systems to demonstrate compliance with its provisions except where explicitly stated.

I/ Wherever the term "document" is used in this publication, it refers to these proposed design and evaluation criteria unless the immediate context indicates another meaning. 
These design criteria are applicable to the design and construction of most new buildings for human occupancy except to buildings or portions thereof that are primarily an envelope over an industrial process; to buildings designed as monuments, to buildings intended for short-term periodic use, such as vacation shelters, or to portions of buildings containing special laboratories.

It is the intent of these design criteria to cover principally the features of a building and its equipment that determine its use of energy, and is not intended to abridge any safety or health requirements. The operation and use of buildings is not covered by this document, although some of the equipment requirements will inherently promote more efficient operation. 


\section{DEFINITIONS}

The following definitions are stipulated for the purposes of this document:

Building -- Any combination of materials, whether portable or fixed, which comprises a structure affording facilities or shelter for assembly, education, business, mercantile, institutional, or residential occupancies, as well as those portions of factory and industrial, and hazardous and storage occupancies which are used for office space. The word building shall be construed herein as if followed by the words "or part or parts thereof and all energy-significant equipment therein" unless the context clearly requires a different meaning. Unless otherwise stipulated, the term buildings as used in this document includes mobile homes and manufactured buildings.

Coefficient of Performance (COP) -- For cooling systems, the ratio of the rate of net heat removal to the rate of energy input, in consistent units. For heat pumps in the heating mode, the ratio of the rate of heat delivered to the rate of energy input, in consistent units.

Engineered System -- A system assembled at the point of application largely from standard components and packaged subsystems to meet a unique set of design requirements for a specific application, as contrasted with a mass produced system identified and sold as an integral product identified by a model number.

Energy Converting Equipment -- Equipment used principally to convert energy from one form to another, such as furnaces, electric motors, etc.

Energy Processing Equipment -- Equipment used principally to exchange energy, such as condensers, heat exchangers, etc. Specifically excluded are piping, ducting, and electrical distribution components.

Energy-Significant Equipment -- Means (1) central, unitary, or room space conditioning equipment, including but not limited to energy converting/ processing equipment used in engineered systems and energy converting/ processing packaged subsystems, and (2) service water-heating equipment.

Full-Load Fnergy-Utilization Efficiency $(n, f l)$-- The energy-utilization efficiency of energy-significant equipment, when operated at full-load rated capacity, computed as a ratio of useful output divided by energy input, including any auxiliaries, and converted to a percentage figure, as follows:

$$
n_{f l}=\frac{\text { Output }}{\text { Thermal Input } \mathrm{x}_{1}+\text { Electrical Input } \mathrm{xC}_{2}} \quad(100) \text {, percent. }
$$


Where: Output = Useful effect ( e.g., heating or cooling, shaft output energy, moisture added or removed, etc.) converted to Btu/hr.

Thermal Input = Thermal equivalent input of energy to direct fired equipment, in Btu/hr.

Electrical Input = Input to electrically energized equipment or components of equipment, in $\mathrm{kw}$.

$C_{7}=1.15$ for off-cycle draft (exfiltration) losses on fuel bưming equipment lacking devices to minimize air flow through the combustion chamber during burmer off-cycles. $C_{1}=1.0$ for equipment utilizing such controls.

$\mathrm{C}_{2}=12,000 \mathrm{Btu} / \mathrm{hr}(\mathrm{kw})$ for electrical generation and transmission to load.

HVAC System - A system that provides either collectively or individually the processes of comfort heating, ventilating, and/or cooling within or associated with buildings.

Manufactured Building -- Any building which is of closed construction and which is made or assembled in manufacturing facilities, on or off the building site; also any building of open construction for which certification under this document is sought by the manufacturer and which is made or assembled in manufacturing facilities away from the building site for installation, or assembly and installation on the building site. The term does not mean "mobile home."

Mobile Home -- A factory-assembled, movable dwelling designed and constructed to be towed on its own chassis, comprised of frame and wheels, usually used without a permanent foundation, and distinguishable from other types of dwellings in that the standards to which it is built include provisions for its mobility on that chassis as a vehicle.

New Energy -- Energy obtained by increasing the output of the basic energy conversion process as contrasted to energy recovered from or wasted by a primary energy-utilization system.

Opaque Areas -- All exposed areas of a building envelope which enclose conditioned space, except openings for windows, skylights, doors, and building service systems.

Recovered Energy -- Energy utilized which would otherwise be wasted (or rejected) from an energy-utilization system.

Reheat -- Sensible heat added to condition a zone to overcome cooling produced by expenditure of energy within the HVAC system serving that zone.

Solar Energy Sources -- Sources of thermal or photoelectric energy derived directly from conversion of incident solar radiation. 
Test Year -- A year of hourly weather data recommended by the ASHRAE Technical Cormittee on Weather Data and Design Conditions for the purpose of energy consumption analysis. It is a weather year chosen from past weather in a given locality in terms of frequency, duration, and severity of hot and cold spells and in terms of overall energy requirements for heating and cooling buildings. In the absence of ASHRAF recommendations the designer may designate a test year for the locality concerned.

Thermal Break -- A relatively poor conductor of heat used to interrupt the path of heat flux between the inner and outer surfaces of a building element.

Total Energy System -- A system in which electric power is generated on or near the building site by means of engines or turbines, with exhaust and jacket heat recovered and used for space heating, water heating, absorption air conditioning, and/or process applications. For the purposes of this document, a qualifying total energy system shall have a minimum annual energy-utilization efficiency of 50 percent, including energy inputs to necessary auxiliary equipment. Combination electric generating and district heating or district cooling plants which have a minimum annual energy-utilization efficiency of 50 percent are also defined as total energy systems for the purpose of this document.

Unheated Space -- Means a ventilated crawl space, an unheated attic, basement or garage, or the outdoors. A basement or unheated portion thereof within which a heating system is located, shall be considered heated space if no insulation is provided at the basement ceiling, and shall be considered unheated space if insulation is provided at the basement ceiling. In mobile homes, spaces shall not be considered unheated which fall within an insulated envelope which provides one-half or more or the total resistance to the flow of heat, as required by Chapter 5.

Unitary Air Conditioner -- Means one or more factory made assemblies which normally include an evaporator or cooling coil, a compressor and condenser combination, and may include a heating function as well. Where such equipment is provided in more than one assembly, the separated assemblies are to be designed to be used together.

Zone -- With respect to the temperature control requirements in this document, a zone is defined as a portion of the space within a building which, recognizing the nature of its heating/cooling loads, could be satisfactorily controlled to desired temperature limits under varying outdoor conditions by the operation of a single automatic temperature control at an appropriate location within the zone. For actual temperature control criteria, refer to 6.4 .2 and 6.4 .3 . 
Full-Load Finergy Utilization Efficiency -- This definition is provided in conjunction with paragraphs 6.3 and 6.4 to give system designers an interim basis for selection of efficient equipment. Efficiency information is needed for design of efficient systems, regardless of the nature of the energy source. Under the section on "New Information Needed for Energy Conservation Criteria" it is recognized that part-load efficiency data are not widely available at present for all types of energy-significant equipment. A requirement for part-load efficiency data should be incorporated in the criteria as soon as standard test procedures can be developed, in order to a) refine energy calculations affecting the design and selection of systems and equipment, and b) to avoid competitive pressures to optimize equipment efficiency at a load condition (such as $100 \%$ of design-rated load) which may not be typical of seasonal operation.

Referring to the constants used in the definition for Full-Load EnergyUtilization Efficiency, it is recognized that there are different values for energy conversion and transmission processes using direct-fired equipment. Because these factors are not all well documented at the present time, and because the order of magnitude of their values is nearest to unity, a value of one is assigned to $C_{1}$. Where off-cycle exfiltration is a factor, a 15-percent loss is assigned, pending receipt of better data. The $\mathrm{C}_{2}$ figure of $12,000 \mathrm{Btu} / \mathrm{kw} \mathrm{hr}$ was computed from national fuel consumption and energy production figures based on "Electric Power Statistics," Federal Power Commission, 1972, rounded to the nearest 1,000 . It is necessary to use constants representing national averages to simplify the manufacturer's task of answering requests for the efficiency information stipulated in 6.4 or of publishing such data in sales literature or catalogs. This approach provides a simple yet fair method of including relative comparisons of efficiency among the considerations for deciding between competitive equipment. 
The following general performance requirements shall be the basis for the more detailed statements of requirements and criteria which make up this performance document.

\subsection{REQUIREMENIT}

Buildings and their service systems shall be designed to use energy efficiently while maintaining an acceptable thermal and visual environment and preserving their essential functional characteristics. The constraints put on energy use shall allow flexibility in the choice of materials and subsystems in the design process.

\subsection{REQUIREMENTT}

The thermal resistance and air tightness of the exterior envelope of a building shall be designed to conserve energy under the applicable climate and occupancy conditions.

\subsection{REQUIREMENT}

The service systems in buildings used for heating, cooling, ventilation, domestic water heating, and lighting shail be designed for the efficient use of energy whether the energy conversion to useful effect occurs in the building or at some other location.

\subsection{REQUIREMENT}

Waste heat shall be recovered for useful purposes wherever practicable. 


\subsection{REQUIREMENT}

A building which is heated or cooled for comfort purposes shall be designed to restrict the flow of heat through the building exterior envelope.

\section{CRITERIA (DESIGN CONDITIONS)}

5.0.1 Combined Heating/Cooling -- A building designed to be both heated in winter and cooled in summer shall meet the higher of the summer and winter thermal resistance values for ceilings and roofs, opaque walls, foundation wa11s, slabs-on-grade, and the air leakage criteria requiring the greater airtightness. The winter design criteria shall be used to determine the area, heat transmission factors, and air leakage of doors and windows; water-vapor condensation control, and properties of caulking and sealants. The summer design criteria shall be used to determine shading requirements for windows. The preceding guidelines for selecting design criteria shal1 apply when establishing the reference energy budget for comparison with alternative designs provided for in Chapters 10 and 11.

\section{EVALUATION}

The design requirements for heating and cooling will be compared, where appropriate, to select the criteria which require the greater insulation resistance and airtightness.

\section{COMMENTARY}

This criterion is provided to require the designer and evaluator to design to the greatest need. For example, buildings in warm climates should restrict heat gain to minimize cooling loads, while buildings in cold climates should restrict heat loss to minimize heating loads. This criterion also requires more insulation in the coldest climates where it is most needed.

\section{CRITERIA}

5.0.2 Design Temperatures -- For the purpose of determining the therma1 resistance to the flow of heat, indoor and outdoor design temperatures sha 11 be used as specified below and in the ASHRAE Handbook of Fundamenta1s, 1972 .

\section{Design Temperatures, dry-bulb, ${ }^{\circ} \mathrm{F}$}

Indoor Outdoor*

Heating $70^{\circ} \mathrm{F}$ Heating -- see Column 4, subheading $97-1 / 2 \%$

Cooling $78^{\circ} \mathrm{F}$ Cooling -- see Column 6, subheading 2-1/2\% 
* For locations in the United States and Canada, values given in Table 1, page 669, 1972 American Society of Heating, Refrigerating and Air Conditioning Engineers (ASHRAE) Handbook of Fundamentals, shall be required.

\section{EVALUATION}

Engineering examination of design temperatures used in calculations.

\section{CRITERIA (HEATING)}

5.0.3 Opaque Ceilings/Roof - Heating -- The heat flow through opaque areas of roofs or ceilings facing heated interiors shall not exceed the values of $\mathrm{q} / \mathrm{A}$ (Btu/hr $\mathrm{ft}^{2}$ of ceiling area) given in Table 5.1 for regions classified by heating degree-days when calculated at the indoor and outdoor design temperatures specified in 5.0.2.

$$
\begin{aligned}
& q / A=U\left(t_{i}-t_{0}\right) \\
& U=\frac{q / A}{t_{i}-t_{0}}
\end{aligned}
$$

where $q / A=$ heat flux, $B t u / h r \mathrm{ft}^{2}$.

$\mathrm{U}=$ overall coefficient of heat transmission or thermal transmittance, air to air, Btu/hr $\mathrm{ft}^{2}{ }^{\circ} \mathrm{F}$.

$\mathrm{t}_{\mathrm{i}}=$ indoor design temperature, ${ }^{\circ} \mathrm{F}$.

$t_{0}^{i}=$ outdoor design temperature, ${ }^{\circ} \mathrm{F}$.

5.0.3.1 Degree-day Values -- For locations in the United States and Canada, yearly total heating degree-days values given in Table 2, page 433, American Society of Heating, Refrigerating and Air Conditioning Engineers 1973 Systems Handbook shall be required. For degree-day values falling between the values tabulated in Table 5.1, intermediate values of $\mathrm{q} / \mathrm{A}$ for ceilings and roofs may be read from Figure 5.1.

Table 5.1

Maximum Heat Flow Through Opaque Areas of Roofs or Ceilings at Design Conditions

Heating

$\frac{\text { Degree-days }}{0}$

1,000

2,000

3,000

4,000

5,000

6,000

7,000

8,000

9,000

10,000

12,000

14,000 or greater $\frac{\mathrm{g} / \mathrm{A}, \mathrm{Btu} / \mathrm{hr}}{4.2}\left(\mathrm{ft}^{2}\right.$ Roof or Ceiling Area)

3.7

3.5

3.5

3.5

3.5

3.5

3.6

3.6

3.7

3.8

4.0

4.4 


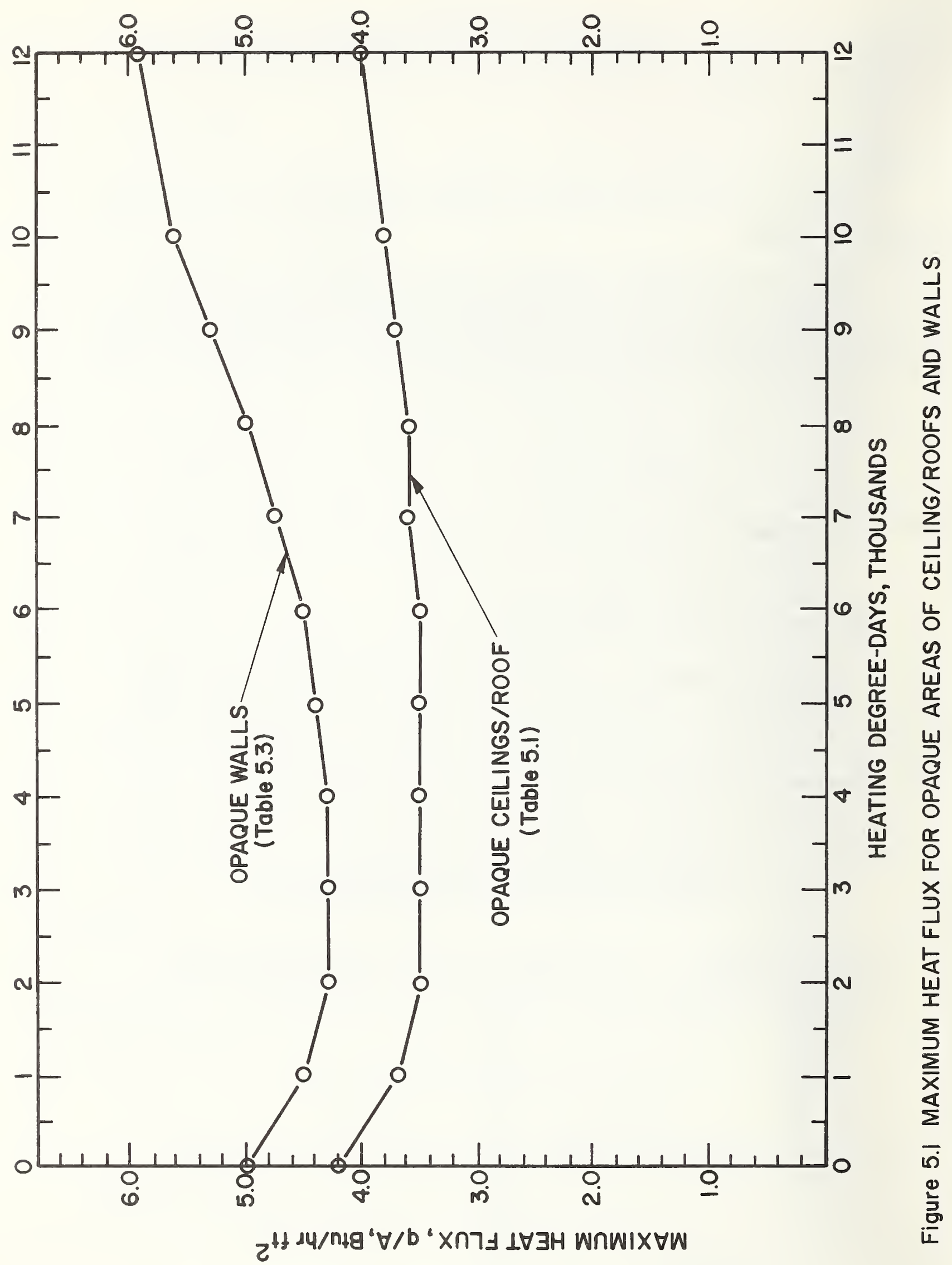


Engineering examination and evaluation of heat flow computations or test results. Design values of the thermal resistance of building materials as given on pages 357-363, ASHRAE 1972 Fundamentals Volume shall be used for evaluation.

\section{COMMENTARY}

A limit is placed on the heat flow through ceiling surface areas. The required overall thermal resistance of the ceiling/roof construction for each geographic area of the U. S. can be determined by the procedure used in the illustrative examples given in Appendix 1 to Chapter 5. A plot of q/A vs Heating Degree-days is shown in Figure 5.1. Design values of the thermal resistance of building materiais to be used for evaluation are given on pages 357-363, ASHRAE 1972 Fundamentals Volume.

Heating energy used in a building correlates more closely with heating degree days than with design temperature difference. Degree days are not precisely related to design temperature differences referenced in handbooks. Therefore the criteria for heat flux through building elements was made to correlate with heating degree days and tive thermal resistance was adjusted to meet the heat flux criteria at design temperature conditions. A building in a city having a greater design temperature difference but the same degree days as for an identical building in another city will have greater thermal resistance. This will result in somewhat less annual energy usage. The rationale for this approach is to maintain approximately equivalent comfort conditions for cities having lower extremes of design temperature.

\section{CR ITER IA}

5.0.4 Gross Exterior Wa11s (Including Opaque Wa11, Window, and Door Areas Heating -- The combined thermal transmittance value (U value) for the gross area of exterior walls consisting of opaque wall areas, window areas, and door areas, a11 facing a heated interior, sha11 not exceed the values given in Table 5.2 for regions as classified by heating degree-days (see 5.0.3.1) when calculated at the indoor and outdoor design temperatures specified in 5.0.2. For degree-day values falling between the values tabulated in Table 5.2, intermediate values of the combined thermal transmittance of exterior walls, $U_{0}$, shall be read from Figure 5.2 .

Table 5.3 provides guidelines for using equation (3) to select combinations of opaque wal1, fenestration, and door areas and thermal resistances to satisfy the requirements of Table 5.2. The thermal transmittance values for window areas and door areas, and the amount of wa11, window, and door area and its distribution in the periphery of the exterior walls of the building are at the option of the designer, providing the criteria for combines thermal transmittance are satisfied. For additional options see 5.0.9. For degree-day values falling between the values tabulated in Table 5.3, intermediate values of q/A for opaque walls shall be read from Figure 5.1. 
Table 5.2

$\underline{U}_{Q}$ Values, Gross Exterior Wall Area, Btu/hr $\mathrm{ft}^{2}{ }^{\circ} \mathrm{F}$

Heating

Degree-days

0
500
1,000
2,000
3,000
4,000
5,000
6,250
7,500
10,000
12,000

$$
\text { One- and Two-Family }
$$

Living Units and Mobile Homes

$$
\begin{aligned}
& 0.60 \\
& 0.48 \\
& 0.36 \\
& 0.29 \\
& 0.27 \\
& 0.25 \\
& 0.22 \\
& 0.20 \\
& 0.18 \\
& 0.17 \\
& 0.16
\end{aligned}
$$

A11 Other Buildings
0.63
0.51
0.40
0.37
0.36
0.34
0.32
0.30
0.28
0.27
0.26

Table 5.3

Guidelines for Maximum Heat Flow Through Opaque Areas of Walls at Design Conditions

\section{Heating \\ Degree-days}

0
1,000
2,000
3,000
4,000
5,000
6,000
7,000
8,000
9,000
10,000
12,000
14,000

q/A,
Btu/hr (ft ${ }^{2}$ Opaque Wall Area)

$$
\begin{aligned}
& 5.0 \\
& 4.5 \\
& 4.3 \\
& 4.3 \\
& 4.3 \\
& 4.4 \\
& 4.5 \\
& 4.8 \\
& 5.0 \\
& 5.3 \\
& 5.6 \\
& 5.9 \\
& 6.0
\end{aligned}
$$

For convenience of the user of this document, the heat flux (q/A), thermal resistance ( $R$ ), and thermal transmittance (U) values meeting the design criteria of Tables 5.1 and 5.3 for $243 \mathrm{U}$. S. cities are tabulated in Appendix 2, along with corresponding degree-day and winter design temperature data from the ASHRAE Fundamentals and Systems Volumes, 1972 and 1973, respectively. 


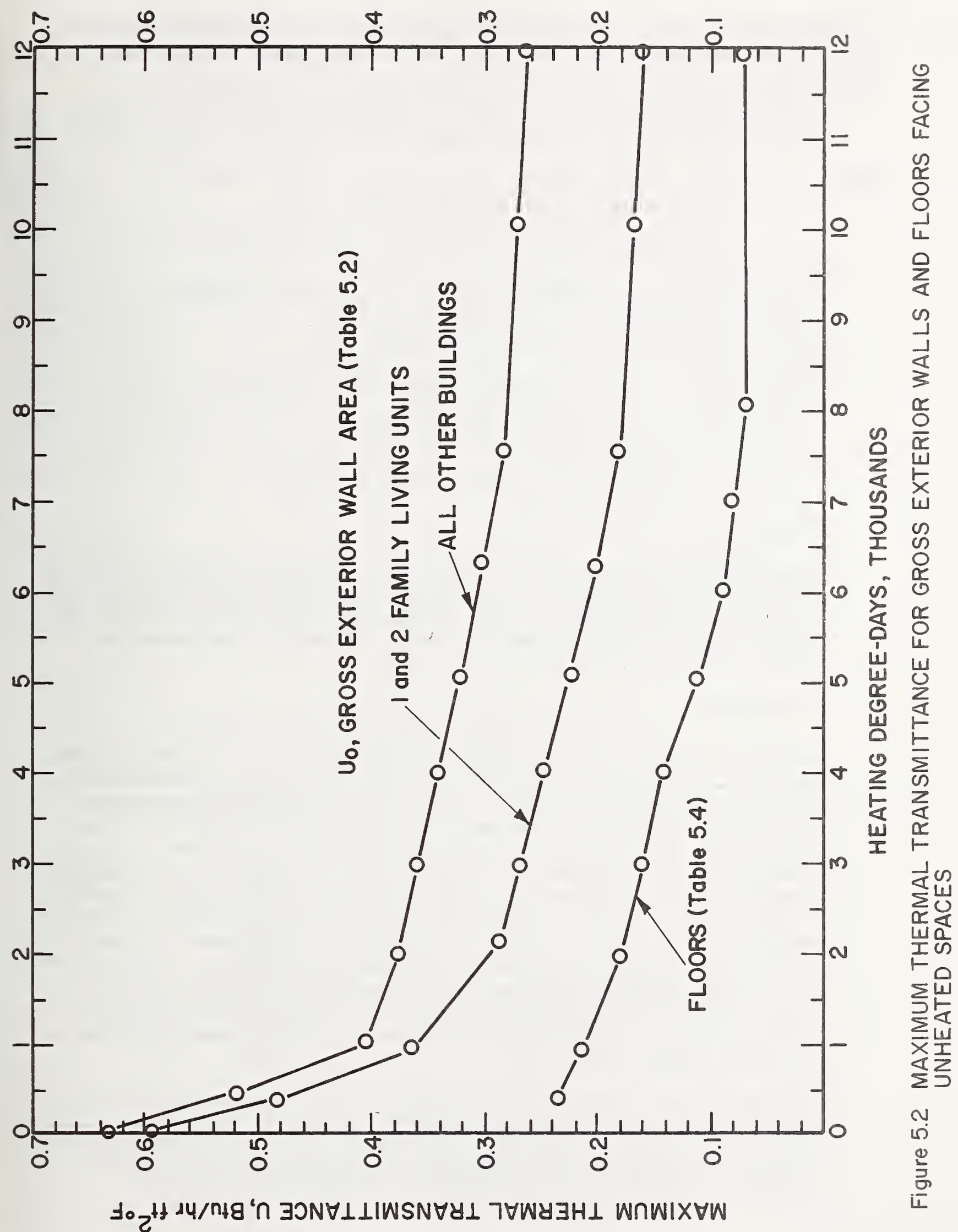


The following formula sha11 be used to determine acceptable combinations of wa11, window, and door areas, and thermal properties to meet the requirements of Table 5.3 .

$$
\mathrm{U}_{\mathrm{O}} \mathrm{A}_{\mathrm{O}}=\mathrm{U}_{\text {wa } 11} \mathrm{~A}_{\text {wa11 }}+\mathrm{U}_{\text {window }} \mathrm{A}_{\text {window }}+\mathrm{U}_{\text {door }} \mathrm{A}_{\text {door }}
$$

where: $U_{0}=$ the average thermal transmittance of the gross wal1 area and $\mathrm{A}_{0}=\mathrm{a}$ unit area of gross wall

$\mathrm{U}_{\text {wa11 }}=$ thermal transmittance of opaque wa11 area

$\mathrm{A}_{\text {wa11 }}=$ ratio of opaque wa11 area to gross wa11 area

$\mathrm{U}_{\text {window }}=$ thermal transmittance of window

$\mathrm{A}_{\text {window }}=$ ratio of window area to gross wall area

$\mathrm{U}_{\text {door }}=$ thermal transmittance of door

$\mathrm{A}_{\text {door }}=$ ratio of door area to gross wall area.

EVALUATION

Engineering examination and evaluation of overa11 U -value computations. Design values of the thermal resistance of building materials, thermal transmission for windows and slab doors as given on pages 357-363, Tables 8 and 9 on page 370, ASHRAE Fundamenta1s Volume, shal1 be used for evaluation.

\section{COMMENTARY}

A limit is placed on the thermal transmittance ( $U$ - value) of the gross wa11 area around the periphery of the building, including the wa11, window and door areas. The required therma 1 transmittance for the gross wa11 area for each geographic area of the U. S. can be determined by the procedure used in the illustrative examples given in Appendix 1 to Chapter 5. A plot of U vs Heating Degree-days is shown in Figure 5.2. Design coefficientS of therma 1 transmission for windows and slab doors are given in Tables 8 and 9, respectively, on page 370 of the ASHRAE 1972 Fundamentals Volume and for the thermal resistance of building materials on pages 357-363. A11 of the thermal resistance values required by Tables 5.1, 5.2, and 5.3 can be met throughout the United States, except Alaska, without using oversized studs and joists, by using available plastic or dense fibrous insulation.

The objective of Table 5.3 is twofold: (1) to provide criteria for designers wishing to prepare energy conserving designs without performing the trade-off analysis permitted in applying Table 5.2 and paragraph 5.09; and (2) to simplify the first trial step of a 
trade-off analysis for those designers using the alternative criteria of Table 5.3 or paragraph 5.9.9. The thermal resistance of the opaque wall construction for each geographic area of the U. S. can be determined by the procedure used in the illustrative examples given in Appendix 1 to Chapter 5. A plot of q/A vs Heating Degreedays is shown in Figure 5.1 .

\section{CRITERIA}

\subsubsection{Floors, Foundation Walls, and Slabs-on-Grade - Heating}

Floors/Heated Spaces -- For floors that face heated areas both above and below the floor line, there is no requirement for thermal resistance of the floor area, except that the peripheral edges of the floor must contain thermal resistance equivalent to that of the thermal transmittance values of Table 5.2 for Gross Exterior Wall Area above or below the floor and the thermal resistance must be continuous vertically. If the above thermal resistance criteria for the peripheral edge of a conventional structural floor system cannot be met, the peripheral edge shall be considered a part of the gross exterior wall area which is to be designed to meet the combined thermal transmittance values in Table 5.2.

Floors/Unheated -- For floors that face unheated spaces, the required maximum thermal transmittance is given in Table 5.4. For degree-day values falling between the values tabulated in Table 5.4, intermediate values of the maximum thermal transmittance, $U$, shall be read from. Figure 5.2.

Table 5.4

\begin{tabular}{cc}
$\begin{array}{c}\text { Maximum Thermal Transmittance } \\
\text { for Floors Facing Unheated Spaces }\end{array}$ \\
\hline $\begin{array}{c}\text { Heating } \\
\text { Degree-days }\end{array}$ & $\begin{array}{c}\text { Maximum U-value, } \\
\text { Btu/hr ft }{ }^{\circ} \mathrm{F}\end{array}$ \\
\cline { 2 - 2 } 0 & no requirement \\
500 & 0.23 \\
1,000 & 0.21 \\
2,000 & 0.18 \\
3,000 & 0.16 \\
4,000 & 0.14 \\
5,000 & 0.11 \\
6,000 & 0.09 \\
7,000 & 0.08 \\
8,000 or greater & 0.07
\end{tabular}

Foundation Walls -- Foundation walls and the windows and doors therein enclosing heated space and exposed to outdoor air shall contain thermal resistance equal to that required for gross exterior walls as specified in 5.0.4. The thermal resistance of foundation wall enclosing heated space below grade shall be not lower than $50 \%$ of that required for gross exterior walls above grade. 
Slab-on-Grade -- For slab-on-grade floors the thermal resistance of the insulation around the perimeter of the floor shall be equal to $50 \%$ of the thermal resistance of the opaque wall area above the floor and shall extend downward below the grade line to the footing or the design frost line, or an equivalent distance horizontally inward from the edge under the floor.

\section{EVALUATION}

Engineering examination and evaluation of U-value and thermal resistance computations. Design values of the thermal resistance of building materials to be used for evaluation are given on pages 357-363, ASHRAE 1972 Fundamentals Volume.

\section{COMMENTARY}

Heated space is considered to be space that is heated for human occupancy or for prevention of physical damage from freezing. The meaning of "unheated space" is given in Chapter 3, Definitions. The "U" value approach is used for Table 5.4, rather than q/A, because the temperature difference at design conditions across floors over unheated spaces is more uncertain than the design indoor-outdoor temperature difference.

\section{CRITERIA}

\section{0 .6 Air Leakage Contro1}

5.0.6.1 Overa11 Air Leakage - - The natural (not mechanically forced) leakage of air between indoors and outdoors shall not exceed 0.7 air change per hour for one- and two-family dwellings and 0.5 air change per hour for all other buildings and mobile homes.

Compliance with the overall air leakage requirement shall be determined by calculations from certified data furnished by the manufacturer or supplier on doors, windows, and exterior walls, and supplemented by calculations using the crack method given in the ASHRAE Handbook of Fundamentals, at the appropriate prevailing design wind conditions for the area of application. The 0.5 air change-per-hour criterion for all buildings other than one- and two-family dwellings and mobile homes contains an allowance for chimney effect in tall buildings.

5.0.6.2 Windows and Storm Windows -- Windows shal1 be designed to limit air leakage into or from the building. The air infiltration rate of aluminum, steel, and wood windows sha11 not exceed the rates specified in the following applicable national and jndustry standards, when tested at a pressure differential of $1.567 \mathrm{lb} / \mathrm{ft}^{2}$, equivalent to the impact pressure of a $25 \mathrm{mph}$ wind. 
ANSI A134.1-1972 Specifications for Aluminum Prime Windows

ANSI A134.3-1972 Specifications for Aluminum Combination

Vertically-sliding or Horizontally-operating

Storm Windows for External Application.

AAMA 303.2-Jan. 1973 Specifications for Aluminum Mobile Home

Windows (proposed ANSI 134.5)

Stee1 Window Institute Recommended Specifications for Steel

Windows - 1973

NAAMM Standard SW-1-71 Specifications for Metal Windows

NhMA Industry Standard for Wood Window Units I.S. 2-73

Compliance with the criteria for air leakage of al1 types of windows shal1 be determined by ASTM E283-73, Standard Method of Test for Rate of Air Leakage Through Exterior Windows, Curtain Wa11s, and Doors.

5.0.6.3 Doors -- All exterior doors shall be designed to limit air leakage into or from the building when in the closed position.

The air infiltration rates of aluminum and wood sliding glass doors shall not exceed the rates specified in the following national and indystry standards, when tested at a pressure differential of $1.567 \mathrm{lb} / \mathrm{ft}^{2}$.

ANSI A134.2-1972 Specifications for Aluminum Sliding Glass Doors. NWMA I.S. 3-70 Industry Standard for Wood Sliding Patio Doors.

The air infiltration rate of swinging doors shall not exceed $1 \mathrm{cfm}$ per foot of crack in the losed position, when tested at a pressure differential of $1.567 \mathrm{lb} / \mathrm{ft}^{2}$.

Compliance with the criteria for air leakage of all types of doors shall be determined by ASTM 283.73, Standard Method of Test for Rate of Air Leakage through Exterior Windows, Curtain Walls, and Doors.

5.0.6.4 Exterior Walls -- Panelized exterior walls shall be designed to limit air leakage at all joints between adjacent panels and at the joints between panels and other building elements.

The air infiltration rate of the exterior walls, excluding window elements, shal1 not exceed $3 \mathrm{ft}_{2}^{3} / \mathrm{hr} \mathrm{ft}^{2}$ of area, when tested at a pressure differential of $1.567 \mathrm{lb} / \mathrm{ft}^{2}$.

Compliance with the criteria for air leakage of all types of exterior walls shall be determined by ASTM E238-73, Standard Method of Test for Rate of Air Leakage through Exterior Windows, Curtain Wa1ls, and Doors.

5.0.6.5 Caulking and Sealants -- Caulking, sealants, or gasketing meeting the requirements of the specifications cited in the following paragraphs shall be used at the joints around all window and door frames, at the joints between walls and foundations, at the joints between walls and roof, around the frames of all other openings in the exterior envelope, and at the penetration of utility services through walls, floor, and ceiling. 
The properties of the sealants, caulking, and gaskets must meet the requirements of the following ASTM and Federal Government Specifications, as applicable, when tested as specified therein:

FS-TT-S-00227E (Com-NBS) Nov. 4, 1969

Interim Fed. Spec. "Sealing Compound: Elastomeric Type, Multi-Component (For Caulking, Sealing, and Glazing in Buildings and Other Structures)."

FS-S-00230C (Com-NBS) Feb . 2, 1970

Interim Fed. Spec. "Sealing Compound: Elastomeric Type, Single Component (For Caulking, Sealing, and Glazing in Buildings and Other Structures)."

FS-TT-C-00598C (Com-NBS) June 23, 19701/

Interim Fed. Spec. "Caulking Compound, Oi1 and Resin Base Type (For Building Construction)."

FS-TT-S-001657 (Com-NBS) Oct. 8, 1970

Interim Fed. Spec. "Sealing Compound: Single Component, Butyl Rubber Based, Solvent Release Type For Buildings and other Types of Construction)."

FS-TT-001543A (Com-NBS) June 9, 1971

Interim Fed. Spec. "Sealing Compound: Silicone Rubber Base (For Caulking, Sealing, and Glazing in Buildings and Other Structures)."

ASTM C509-70

"Standard Specification for Cellular Elastomeric Preformed Gasket and Sealing Material."

ASTM C542-71a

"Standard Specification for Lock-Strip Gaskets."

ASTM C570-72 2 /

"Oil and Resin-Base Caulking Compound for Building Construction."

1/ Same as ASTM C570-72

2/ Same as FS-TT-C00598C (Com-NBS) June 23, 1970 
Engineering examination and evaluation and test results data. Evaluation against materials and assemblies specifications as published by the Federal Government and the American Society for Testing and Materials. The crack method as given in the 1972 ASHRAE Handbook of Fundamentals shall be used as the basis for engineering evaluation.

\section{COMMENTARY}

The air leakage into and out of a building in winter is a significant portion of the energy requirement necessary to maintain indoor temperature. The process creating natural air leakage consists of the buoyancy or chimney pressure difference of the dense cold outdoor air and the lighter warmer indoor air plus the effect of wind velocity pressure on the building. The air leakage limitation specified is based on what is attainable in construction practice including allowance for exhaust fan openings fitted with self-closing devices when the fan is not in use. This criteria is not intended to cover purposely designed forced ventilation systems in buildings.

Weatherstripping and caulking are required to minimize the loss of heat energy from air infiltration and to protect the exterior envelope from the elements.

\section{CRITERIA}

5.0.7 Condensation Control - Heating -- The design of the building envelope shall provide protection against cold weather water-vapor condensation on or in roofs, attics, walls, windows, doors, and floors. For opaque areas of ceilings, roofs, floors, and walls containing dry thermal insulation, a continuous vapor barrier having a water vapor permeance not exceeding 0.5 perm (grains/hr ft (in.-Hg)) is required on the winter-time warm side of the insulation.

Slab-on-grade floors shall have a vapor barrier with lapped joints under the slab not exceeding 0.1 perm.

A vapor barrier not exceeding 0.1 perm sha11 be required to cover the ground area of a crawl space beneath floors.

Ceiling, roof, floor, and wall constructions shall contain thermal breaks to prevent excessive heat transmission through framing members.

\section{EVALUATION}

Engineering examination and evaluation of the design and design calculations. ASTM Recommended Practice E 241-68 for general design information, ASTM Test Methods E 96-66 (Procedures A - dry cup) for materials such as paper, plastic films and other sheet materials that are less than 1/8 inch thick, and C355-64 (dessicant method) for 
materials greater than $1 / 8$ inch thick such as fiberboards, gypsum and plaster products on wood products, shall be used to evaluate vapor barriers, when applicable. A simulated service test or comparison with systems known to be effective sha11 be used to evaluate complete wall, floor, ceiling or roof systems.

\section{COMMENTARY}

The purpose of these criteria is to prevent indoor water vapor from condensing on cool surfaces whose temperatures are below the dewpoint temperature of the indoor air and to prevent condensation within the construction of indoor water vapor that permeates through indoor surfaces.

\section{CRITERIA}

5.0.8 Orientation and Shape Analysis - Heating -- The proposed design sha11 show that energy conservation was among the considerations taken into account in determining building orientation and shape. The design submittal shall show that the following factors have been considered in the orientation analysis: (a) compass orientation of the building on the site; (b) aspect ratio (ratio of length to width); and (c) the number of stories for a given floor area requirement.

EVALUATION :

Engineering evaluation of heat loss and energy calculations. COMMENTARY

The intent of these criteria is to require analysis of the options available to the designer and owner of the building to conserve energy by taking into account prevalent solar and wind conditions. For example, if the predominant cold winds come from the north, the north wall of the building can be designed to reduce the heat flux, while the east, south, and west facades can be positioned to take advantage of winter solar heat and designed for minimum solar heat gain through windows in summer. The length-to-width ratio and the number of stories for a given building can sometimes be used as flexible design parameters. Subject to site constraints and user needs, the shape of the building that defines the amount of facade area can be varied and the energy consumption examined to select a minimum and yet allow the functional requirements of the building to be satisfied. 
5.0.9 Alternative Building Envelope Heat Transmission Design Criteria Heating - Alternate designs and methods of construction that show total building heat loss at design conditions to be equal to or less than designs developed to satisfy all of the above criteria shall be acceptable if submitted as certified by a registered engineer or architect. For the purpose of computing the total building heat loss of the building used as a basis for comparison, the heat transmitted through the ceiling/roof shal1 be based on the assumption of 100 percent opaque ceiling/roof area (not containing skylights or saw-tooth shaped roofs containing windows). The design heat loss calculation for any alternative building envelope or subelement construction proposed under this criterion shall be determined for the same indoor and outdoor design temperatures, common occupancy and use schedules, and equivalent useful floor area, perimeter, and building volume as for the design complying with all of the preceding criteria in this Chapter.

\section{EVALUATION}

Engineering evaluation of heat loss and energy consumption calculations.

\section{COMMENTARY}

The intent of these criteria is to allow a separate performance approach where maximum flexibility and innovation can be used that would result in overall conservation of energy from a process of trading off savings in one area of the building against losses that exceed the above criteria in other areas of the building. When this approach is used it is usually done with the aid of a computer where many options or changes can be examined rapidly and simultaneously for the building as a whole.

\section{CRITERIA (COOLING)}

5.0.10 Opaque Ceilings/Roof and Wa11 - Cooling -- The heat flow through opaque surface areas of roof/ceilings or walls facing cooled interiors shall not exceed $2.0 \mathrm{Btu} / \mathrm{hr} / \mathrm{ft}^{2}$ of ceiling or wall area when calculated at an indoor design temperature of $78^{\circ} \mathrm{F}$ and an outdoor sol-air temperature calculated as follows:

$$
t_{\text {ea }}=t_{o a}+\frac{\alpha}{h_{0}}\left(\frac{I_{D T}}{24}\right)-\frac{\epsilon \Delta R}{h_{0}}
$$

where:

$$
\begin{aligned}
& \alpha=\text { absorptance of the surface for solar radiation } \\
& h_{0}=\text { coefficient of heat transfer } 2 \text { by radiation and convection of } \\
& \text { the outer surface, Btu/hr } f t^{\circ} \mathrm{F}
\end{aligned}
$$

1/ Reference equation 42 of Chapter 22, ASHRAE Handbook of Fundamenta1s, 1972 . 


$$
\begin{aligned}
& t_{\text {ea }}=\text { average sol-air temperature, }{ }^{\circ} \mathrm{F} \\
& t_{\text {oa }}=\text { average summer design outdoor temperature, }{ }^{\circ} \mathrm{F} \\
& t_{\text {oa }}=t_{d}-\Delta t / 2 \text {, where } t_{d} \text { is the summer design dry-bulb temperature } \\
& \text { listed in Table 1, page 669, } 1972 \text { ASHRAE Funda- } \\
& \text { mentals Volume, Column } 621 / 2 \% \text {. } \Delta t \text { is the value } \\
& \text { given in Column 7, Outdoor Daily Range. } \\
& \epsilon=\text { hemispherical emittance of the surface. }
\end{aligned}
$$

The average equivalent temperature difference, $t_{\epsilon}$, is

$$
t_{\epsilon}=t_{e a}-t_{i}
$$

where $t_{i}$ is the indoor design temperature, $78^{\circ} \mathrm{F}$.

The minimum thermal resistance, $R$, of the opaque ceiling/roof or wall is

$$
R=\frac{t_{\epsilon}}{q / A} \text {. }
$$

Inclusion of the effect of the mass (weight) of the roof or wall in addition to the above procedures shall be allowed in meeting the heat flow criteria.

$R=$ the difference between the longwave radiation incident on the surface from the sky and surroundings, and the radiation emitted by a blackbody at outdoor air temperature Btu/hr ft ${ }^{2}$.

$\begin{aligned} \alpha / h_{0}= & 0.15 \text { for } 1 \text { ight colored surfaces } \\ & 0.30 \text { for dark colored surfaces }\end{aligned}$

$I_{\mathrm{DT}}=1.15$ times the maximum sum of the two half-day totals of solar heat gain factors for each wall as given in Tables 2 to 6 , pages 388-392, 1972 ASHRAE Handbook of Fundamentals, Btu/hr ft ${ }^{2}$.

$\begin{aligned} E \Delta R^{\prime} / h_{0} & =7^{\circ} \mathrm{F} \text { for horizontal surfaces } \\ & =0^{\circ} \mathrm{F} \text { for vertical surfaces. }\end{aligned}$

\section{EVALUATION}

Examination and evaluation of engineering calculations.

\section{COMMENTARY}

The average equivalent temperature difference, $t_{\epsilon}$, is used in the criterion instead of actual indoor air to outdoor air temperature differential to account for solar heating of outdoor surfaces to temperatures greater than the outdoor air temperature. The examples in Appendix 1 at the end of Chapter 5 will serve to illustrate the procedure for limiting the heat flux and determining the required overall thermal resistance and thermal transmittance (U-value). 
5.0.11 Window Heat Gain - Cooling -- The heat gain through transparent window areas of the exterior envelope shall be controlled during the cooling season in relation to the geographic location and the compass orientation of the building on its site. Plain glass without a shading device is not permitted (e.g., shades, venetian blinds, draperies, awnings, eyebrow reveals, or vertical/horizontal fins must be used). The windows shall be equipped with shading devices, interior or exterior, that will limit, during the cooling season, the maximum instantaneous combined solzr and air-to-air heat transmission at design conditions to $70 \mathrm{Btu} / \mathrm{hr} \mathrm{ft}^{2}$ of transparent window area, as an average for the entire window.

EVALUATION

Engineering examination and evaluation of calculations. For evaluation of design, calculation procedures given on pages 386 through 410 of the 1972 ASHRAE Handbook of Fundamentals shall be used.

\section{CRITERIA}

5.0.12 Doors - Cooling -- Heating criteria apply (see 5.0.4. and 5.0.6.3). EVALUATION

See Heating Evaluation, 5.0.4.

COMMENTARY

See Heating Commentary, 5.0.4.

\section{CRITERIA}

5.0.13 Floors, Foundation Walls, and Slabs-on-Grade - Cooling -. Heating criteria apply (see 5.0.5):

EVALUATION

See Heating Evaluation, 5.0.5.

COMMENTARY

See Heating Commentary, 5.0.5. 
5.0.14 Air Leakage Control - Cooling -- Heating criteria apply except that the natural (not forced) leakage of air from cooled spaces to the outdoors shall not exceed 0.5 volume air change per hour at design conditions for one- and two-family dwellings. (See 5.0.6.1)

\section{EVALUATION}

See Heating Evaluation following 5.0.6.5

\section{COMMENTARY}

See Heating Commentary following 5.0.6.5

\section{CRITERIA}

5.0.15 Orientation on Site - Cooling -- The proposed design shall show that energy conservation was among the considerations taken into account in determining building orientation and shape. The design submittal shall show that the following factors have been considered in the orientation ana1ysis: (a) compass orientation of the building on the site; (b) aspect ratio (ratio of length to width); and (c) the number of stories for a given floor area requirement.

\section{EVALUATION}

See Heating Evaluation, 5.0.8

COMMENTARY

See Heating Commentary, 5.0.8

\section{CRITERIA}

5.0.16 Alternative Building Envelope Heat Transmission - Cooling -Alternative designs and methods of construction that show design total building heat gains equal to or less than designs developed to satisfy a11 of the above criteria shall be acceptable if submitted as certified by a registered engineer or architect. The purpose of these criteria is to allow energy trade-offs that would result in equivalent overall conservation of energy, even though the criteria for selected subelements of the building may not precisely meet the specified requirements. For the purpose of computing the total heat gain of the basic building used for comparison, the heat gain through the ceiling/rood shall be based on the assumption of 100-percent opaque ceiling/roof area (not containing skylights or saw-tooth shaped roofs containing window:).

The design cooling load calculation for any alternative building envelope or subelement construction proposed under this criterion shall be determined for the same indoor and outdoor design temperatures, common occupancy and use schedules, and equivalent useful floor area, perimeter, and 
building volume as for the design complying with all of the preceding criteria in this Chapter that are applicable to cooling.

EVALUATION

See Heating Evaluation, 5.0.9.

COMMENTARY

See Heating Commentary, 5.0.9. 


\subsubsection{Opaque Ceilings/Roof - Heating}

1) Location, Duluth, Minnesota

Heating Degree-Days, 10,000 (from p.43.5 ASHRAE 1973 Systems Vol)

Required $\mathrm{g} / \mathrm{A}, 3.8 \mathrm{Btu} / \mathrm{hr}$. $\mathrm{ft}^{2}$ of ceiling area from Criteria 5.0.3.

Design Temperatures

Indoor, $70^{\circ} \mathrm{F}$ (from Criteria 5.0.2)

Outdoor, $-15^{\circ} \mathrm{F}$ (from p.674 ASHRAE 1972 Fundamentals Volume)

Design Temperature Difference, $[70-(-15)]=85^{\circ} \mathrm{F}$

Overall Thermal Resistance, $R$

$$
R=\frac{\text { Design Temperature Difference }}{q / A}=\frac{85}{3.8}=22.37
$$

Overall Thermal Transmittance, (U-value)

$$
\mathrm{U}=\frac{1}{\mathrm{R}}=\frac{1}{22.37}=0.0447 \mathrm{Btu} / \mathrm{hr} \mathrm{ft}^{2}{ }^{\circ} \mathrm{F}
$$

2) Location - Scranton/Wilkes-Barre, Pennsylvania

Heating Degree-Days - 6254

Required q/A - 3.52

Design Temperature Difference $-[70-6]=64$

Overall Thermal Resistance $-\frac{64}{3.52}=18.18$

Overall Thermal Transmittance $-\frac{1}{18.18}=0.055$

3) Location - Atlanta, Georgia

Heating Degree-Days - 2961

Required $\mathrm{q} / \mathrm{A}-3.5$

Design Temperature Difference $-[70-23]=47$

Overall Thermal Resistance - $\frac{47}{3.5}=13.43$

Overall Thermal Transmittance $-\frac{1}{13.43}=0.074$

4) Location - San Diego, California

Heating Degree-Days - 1458

Required $q / A-3.59$ 
Design Temperature Difference $-[70-44]=26$

Overall Thermal Resistance $-\frac{26}{3.59}=7.24$

Overall Thermal Transmittance $-\frac{1}{7.24}=0.14$

5) Location - Key West, Florida

Heating Degree-Days - 108

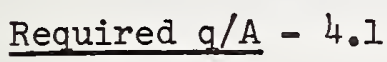

Design Temperature Difference $-[70-58]=12$

Overall Thermal Resistance $-\frac{12}{4.1}=2.93$

Overall Thermal Transmittance $-\frac{1}{2.93}=0.34$ 
5.0.4 Gross Exterior Walls (Including Opaque Walls, Window, and Door Areas) Heating $-\infty$ Table 5.2

1) Duluth, Minnesota, 10,000 heating degree-days

Single-Family

$\mathrm{U}_{\mathrm{wall}}=0.066$ from Opaque wall criteria

Assume $10 \%$ single glass and $4 \%$ metal storm doors

$$
\begin{aligned}
\mathrm{U}_{\mathrm{O}} \mathrm{x} I & =0.065 \times 0.86+1.13 \times 0.1+0.33 \times 0.04 \\
& =0.057+0.113+0.013 \\
& =0.183 \text { will not meet } 0.17 \text { Criteria }
\end{aligned}
$$

Assume 10\% storm windows and $4 \%$ metal storm doors

$$
\begin{aligned}
\mathrm{U}_{\mathrm{O}} \mathrm{x} I & =0.066 \times 0.86+0.56 \times 0.1+0.33 \times 0.04 \\
& =0.057+0.056 \times 0.013 \\
& =0.126 \text { will meet } 0.17 \text { Criteria }
\end{aligned}
$$

Assume $\mathrm{U}_{\text {wall }}=0.1110 \%$ storm windows and $4 \%$ metal storm doors

$$
\begin{aligned}
\mathrm{U}_{0} \mathrm{XI} & =0.11 \times 0.86+0.56 \times 0.1+0.33 \times 0.04 \\
& =0.095+0.056+0.013 \\
& =0.164 \text { will meet } 0.17 \text { Criteria }
\end{aligned}
$$

Assume $15 \%$ storm windows and $4 \%$ metal storm doors

$$
\begin{aligned}
\mathrm{U}_{0} \mathrm{x} I & =0.066 \times 0.81+0.56 \times 0.15+0.33 \times 0.04 \\
& =0.053+0.084+0.013 \\
& =0.15 \text { will meet } 0.17 \text { Criteria }
\end{aligned}
$$

Assume $20 \%$ storm windows and $4 \%$ metal storm doors

$$
\begin{aligned}
\mathrm{U}_{\mathrm{O}} \mathrm{x} I & =0.066 \times 0.76+0.56 \times 0.2+0.33 \times 0.04 \\
& =0.05+0.112+0.013 \\
& =0.175 \text { will not meet } 0.17 \text { Criteria }
\end{aligned}
$$

\section{All other buildings}

Assume 10\% insulating glass area and 1\% insulated steel door

$$
\begin{aligned}
U_{0} \times 1 & =0.066 \times 0.89+0.65 \times 0.1+0.59 \times 0.01 \\
& =0.059+0.065+0.006 \\
& =0.13 \text { will meet } 0.27 \text { Criteria }
\end{aligned}
$$

Assume $30 \%$ insulating glass area and $1 \%$ insulated steel door

$$
\begin{aligned}
\mathrm{U}_{\mathrm{O}} \mathrm{x} I & =0.066 \times 0.69+0.65 \times 0.3+0.59 \times 0.01 \\
& =0.046+0.195+0.006 \\
& =0.247 \text { will meet } 0.27 \text { Criteria }
\end{aligned}
$$


Assume $30 \%$ single glass area and $1 \%$ insulated steel door

$$
\begin{aligned}
U_{0} \times I & =0.066 \times 0.69+1.13 \times 0.3+0.59 \times 0.01 \\
& =0.046+0.339+0.006 \\
& =0.39 \text { will not meet } 0.27 \text { Criteria }
\end{aligned}
$$

Assume $\mathrm{U}_{\text {wall }}=0.16$, $10 \%$ single glass and $1 \%$ insulated steel door

$$
\begin{aligned}
\mathrm{U}_{0} \mathrm{XI} & =0.16 \times 0.89+1.13 \times 0.1+0.59 \times 0.01 \\
& =0.142+0.113+0.006 \\
& =0.261 \text { will meet } 0.27 \text { Criteria }
\end{aligned}
$$

Assume 50\% insulating glass emissivity coating $=0.2$ and $1 \%$ insulated steel door

$$
\begin{aligned}
\mathrm{U}_{\mathrm{O}} \mathrm{XI} & =0.066 \times 0.49+0.38 \times 0.5+0.59 \times 0.01 \\
& =0.032+0.19+0.006 \\
& =0.23 \text { meets } 0.27 \text { Criteria }
\end{aligned}
$$

2) Scranton/Wilkes-Barre, Pennsylvania, 6254 heating degree-days $\mathrm{U}_{\text {wall }}=0.072$ from opaque wall criteria

\section{Single-Family}

Assume 5\% single-glass, $10 \%$ storm windows and $4 \%$ metal storm door

$$
\begin{aligned}
U_{0} \times 1 & =0.072 \times 0.81+1.13 \times 0.05+0.56 \times 0.1+0.33 \times 0.04 \\
& =0.058+0.057+0.056+0.013 \\
& =0.184 \text { meets } 0.20 \text { Criteria }
\end{aligned}
$$

Assume $\mathrm{U}_{\text {wall }}=0.12,15 \%$ storm windows and $4 \%$ metal storm doors

$$
\begin{aligned}
U_{0} \times I & =0.12 \times 0.81+0.56 \times 0.15+0.33 \times 0.04 \\
& =0.097+0.084+0.013 \\
& =0.194 \text { will meet } 0.20 \text { Criteria }
\end{aligned}
$$

\section{All other buildings}

Assume 30\% insulating glass area and 1\% insulated door area

$$
\begin{aligned}
\mathrm{U}_{0} \mathrm{x} I & =0.072 \times 0.69+0.65 \times 0.3+0.59 \times 0.01 \\
& =0.050+0.195+0.006 \\
& =0.251 \text { meets } 0.30 \text { Criteria }
\end{aligned}
$$

Assume 50\% insulating glass area emissivity coating, 0.6 , and $1 \%$ insulating steel doors

$$
\begin{aligned}
U_{0} \times 1 & =0.072 \times 0.49+0.52 \times 0.5+0.59 \times 0.01 \\
& =0.035+0.26+0.006 \\
& =0.30 \text { meets } 0.30 \text { Criteria }
\end{aligned}
$$


Assume $U_{\text {wall }}=0.20,10 \%$ single glass and $1 \%$ insulating steel
doors

$$
\begin{aligned}
U_{0} \times I & =0.20 \times 0.89+1.13 \times 0.1+0.59 \times 0.01 \\
& =0.178+0.113+0.006 \\
& =0.297 \text { meets } 0.30 \text { Criteria }
\end{aligned}
$$

3) Atlanta, Georgia, 2961 heating degree-days

$U_{\text {wall }}=0.091$ from opaque wall criteria

\section{Single-Family}

Assume $15 \%$ single glass and $4 \%$ metal storm doors

$$
\begin{aligned}
U_{0} \times I & =0.091 \times 0.81+1.13 \times 0.15+0.33 \times 0.04 \\
& =0.074+0.17+0.013 \\
& =0.257 \text { meets } 0.27 \text { Criteria }
\end{aligned}
$$

\section{AlI other buildings}

Assume $25 \%$ single glass and $1 \%$ insulated door area

$$
\begin{aligned}
U_{0} \times I & =0.091 \times 0.74+1.13 \times 0.25+0.59 \times 0.01 \\
& =0.067+0.283+0.006 \\
& =0.356 \text { meets } 0.36 \text { Criteria }
\end{aligned}
$$

Assume $U_{\text {walI }}=0.27,10 \%$ single glass and $1 \%$ insulated door area

$$
\begin{aligned}
U_{0} X I & =0.27 \times 0.89+1.13 \times 0.1+0.59 \times 0.01 \\
& =0.24+0.113+0.006 \\
& =0.359 \text { meets } 0.36 \text { Criteria }
\end{aligned}
$$

Assume $45 \%$ insulating glass and $1 \%$ insulated door area

$$
\begin{aligned}
U_{0} X I & =0.091 \times 0.54+0.65 \times 0.45+0.59 \times 0.01 \\
& =0.049+0.293+0.006 \\
& =0.348 \text { meets } 0.36 \text { Criteria }
\end{aligned}
$$

4) San Diego, California, 1458 heating degree-days

$$
U_{\text {wall }}=0.17 \text { from opaque wall criteria }
$$

\section{Single-Family}

Assume $15 \%$ single glass and $4 \%$ wood doors

$$
\begin{aligned}
U_{0} \times I & =0.17 \times 0.81+1.13 \times 0.15+0.49 \times 0.04 \\
& =0.137+0.169+0.02 \\
& =0.32 \text { meets } 0.32 \text { Criteria }
\end{aligned}
$$


Assume $20 \%$ single glass, $1 \%$ insulated door area

$$
\begin{aligned}
\mathrm{U}_{0} \mathrm{x} I & =0.17 \times 0.79+1.13 \times 0.2+0.59 \times 0.01 \\
& =0.134+0.226+0.006 \\
& =0.37 \text { meets } 0.38 \text { Criteria }
\end{aligned}
$$

Assume $40 \%$ insulating glass and $1 \%$ insulated door area

$$
\begin{aligned}
\mathrm{U}_{0} \mathrm{XI} & =0.17 \times 0.59+0.65 \times 0.4+0.59 \times 0.01 \\
& =0.10+0.26+0.006 \\
& =0.37 \text { meets } 0.38 \text { Criteria }
\end{aligned}
$$

5) Key West, Florida, 108 heating degree-days

$$
U_{\text {wall }}=0.41 \text { from opaque wall criteria }
$$

\section{Single-Family}

Assume $25 \%$ single glass and $4 \%$ wood doors

$$
\begin{aligned}
U_{0} \times I & =0.41 \times 0.71+1.13 \times 0.25+0.49 \times 0.04 \\
& =0.29+0.283+0.02 \\
& =0.59 \text { meets } 0.60 \text { Criteria }
\end{aligned}
$$

\section{All other buildings}

Assume $30 \%$ single glass and $1 \%$ insulated door area

$$
\begin{aligned}
U_{0} \times I & =0.41 \times 0.69+1.13 \times 0.3+0.59 \times 0.01 \\
& =0.283+0.339+0.006 \\
& =0.628 \text { meets } 0.63 \text { Criteria }
\end{aligned}
$$

Assume 50\% insulating glass and 1\% insulated door area

$$
\begin{aligned}
\mathrm{U}_{0} \mathrm{X} I & =0.41 \times 0.49+0.65 \times 0.5+0.59 \times 0.01 \\
& =0.20+0.325+0.006 \\
& =0.53 \text { meets } 0.63 \text { Criteria }
\end{aligned}
$$


5.0.4 Opaque Walls - Heating, Table 5.3

(1) Location - Duluth, Minnesota

Heating Degree-Days - 10,000 (from p. 43.5 ASHRAE 1973 Systems Volume)

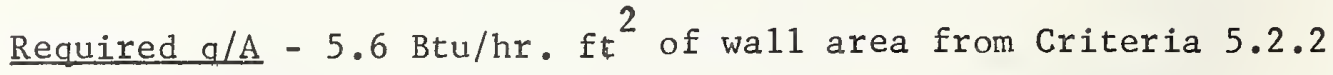

Design Temperatures

Indoor, $70^{\circ} \mathrm{F}$ (from Criteria 5.1.2)

Outdoor, $-15^{\circ} \mathrm{F}$ (from p. 674 ASHRAE 1972 Fundamentals Volume)

Design Temperature Difference $-[70-(-15)]=85^{\circ} \mathrm{F}$

Overa11 Therma1 Resistance, $\underline{\mathrm{R}}$

$$
\mathrm{R}=\frac{\text { Design Temperature Difference }}{\mathrm{q} / \mathrm{A}}=\frac{85}{5.6}=15.18
$$

Overa11 Therma1 Transmittance, (U-value)

$$
\mathrm{U}=\frac{1}{\mathrm{R}}=\frac{1}{15.18}=0.066
$$

(2) Location - Scranton/Wilkes-Barre, Pennsylvania

Heating Degree-Days - 6254

Required $\mathrm{g} / \mathrm{A}-4.58$

Design Temperature Difference $-[70-6]=64$

Overa11 Therma1 Resistance - $\frac{64}{4.58}=13.97$

Overa11 Therma 1 Transmittance $-\frac{1}{13.97}=0.072$

(3) Location - Atlanta, Georgia

Heating Degree-Days - 2961

Required q/A -4.3

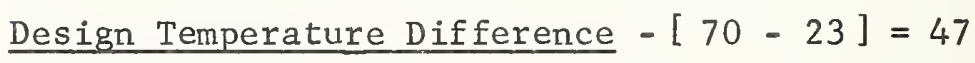

Overal1 Therma1 Resistance $-\frac{47}{4.3}=10.93$

Overa11 Therma1 Transmittance $-\frac{1}{10.93}=0.091$ 
(4) Location - San Diego, California

Heating Degree-Days - 1458

Required q/A -4.41

Design Temperature Difference $-[70-44]=26$

Overal1 Thermal Resistance - $\frac{26}{4.41}=5.9$

Overa11 Therma1 Transmittance $-\frac{1}{5.9}=0.17$

(5) Location - Key West, Florida

Heating Degree-Days - 108

Required q/A -4.95

Design Temperature Difference $-[70-58]=12$

Overall Thermal Resistance $-\frac{12}{4.95}=2.42$

Overal1 Thermal Transmittance $-\frac{1}{2.42}=0.41$ 


\subsubsection{Opaque Ceilings/Roof and Wa11-Cooling}

1) Key West, Florida

From Table 1, p. 671, 1972 ASHRAE Handbook of Fundamentals

Latitude $=24^{\circ} 3^{\prime \prime}$

Design dry-bulb temperature, $\Delta t_{d}=89^{\circ} \mathrm{F}$

Outdoor daily range, $\Delta t=9^{\circ} \mathrm{F}$

From Table 2, p. 388, 1972 ASHRAE Handbook of Fundamenta1s

Horizontal Roofs, the maximum half-day total value occurs on June 21, and is equal to 1095

For walls, maximum half-day totals are:

North, $282 \mathrm{a} \cdot \mathrm{m}$. and $282 \mathrm{p} \cdot \mathrm{m}$. on June 21

East, $936 \mathrm{a} \cdot \mathrm{m}$. and $176 \mathrm{p} \cdot \mathrm{m}$. on June 21

South, $451 \mathrm{a} \cdot \mathrm{m}$. and $451 \mathrm{p} \cdot \mathrm{m}$. on September 21

West, $176 \mathrm{a} \cdot \mathrm{m}$. and $936 \mathrm{p} \cdot \mathrm{m}$. on June 21

$$
t_{\text {ea }}=t_{\text {oa }}+\frac{\alpha}{h_{0}}\left(\frac{I_{D T}}{24}\right)-\frac{\varepsilon \Delta R}{h_{0}}
$$

\section{For Roofs}

$$
\begin{aligned}
& \text { 1ight colored, } t_{e a}=\left(89-\frac{9}{2}\right)+0.15\left[\frac{1.15(1095+1095)}{24}\right]-7 \\
& \qquad t_{e a}=93.2^{\circ} \mathrm{F} \\
& \begin{aligned}
\Delta t_{\varepsilon} & =t_{e a}-t_{i} \\
& =93.2-78 \\
& =15.2
\end{aligned} \\
& R=\frac{\Delta t_{E}}{q / A}=\frac{15.2}{2.0}=7.6 \\
& \begin{array}{l}
U=0.13
\end{array}
\end{aligned}
$$


dark colored,

$$
\begin{aligned}
& t_{\text {ea }}=\left(89-\frac{9}{2}\right)+0.3\left[\frac{1.15(1095+1095)}{24}\right]-7=109 . \\
& \begin{aligned}
\Delta t_{\varepsilon} & =t_{\text {ea }}-t_{i} \\
& =109-78 \\
& =31
\end{aligned} \\
& R=\frac{\Delta t}{q / A}=\frac{31}{2.0}=15.5 \\
& U=0.065
\end{aligned}
$$

For walls

light colored

$$
\begin{aligned}
& \text { North, } t_{\text {ea }}=\left(89-\frac{9}{2}\right)+0.15\left[\frac{1.15(282+282)}{24}\right]-0=88.6^{\circ} \mathrm{F} \\
& \Delta t_{t}=t_{\text {ea }}-t_{i} \\
& =88.6-78 \\
& =10.6 \\
& R=\frac{\Delta t_{q}}{q / A}=\frac{3.0 .6}{2.0}=5.3 \\
& \mathrm{U}=0.19 \\
& \text { East, } t_{\text {ea }}=\left(89-\frac{9}{2}\right)+0.15\left[\frac{1.15(936+176)}{24}\right]-0=92.5^{\circ} \mathrm{F} \\
& \Delta t_{t_{0}}=t_{\text {ea }}-t_{i} \\
& =92.5-78 \\
& =14.5 \\
& R=\frac{\Delta t_{\varepsilon}}{q / A}=\frac{14.5}{2.0}=7.25 \\
& \mathrm{U}=0.14
\end{aligned}
$$

$$
\text { South, } \begin{aligned}
t_{\text {ea }} & =\left(89-\frac{9}{2}\right)+0.15\left[\frac{1.15(451+451)}{24}-0=90 .{ }^{\circ} \mathrm{F}\right. \\
\Delta t_{t} & =t_{e a}-t_{i} \\
& =90-78 \\
& =12 \\
R & =\frac{\Delta t_{\varepsilon}}{q ! A}=\frac{12}{2.0}=6.0 \\
U & =0.17
\end{aligned}
$$




$$
\text { West, } \begin{aligned}
t_{\text {ea }} & =\left(89-\frac{9}{2}\right)+0.15 \frac{1.15(176+936)}{24}-0=92.4{ }^{\circ} \mathrm{F} \\
\Delta t_{\varepsilon} & =t_{\text {ea }}-t_{i} \\
& =92.4-78 \\
& =14.4 \\
R & =\frac{\Delta t_{\hat{\varepsilon}}}{\mathrm{q} / \mathrm{A}}=\frac{14.4}{2.0}=7.2 \\
\mathrm{U} & =0.14
\end{aligned}
$$

\section{dark colored}

$$
\begin{aligned}
& \text { North, } t_{\text {ea }}=\left(89-\frac{9}{2}\right)+0.30\left[\frac{1.15(282+282)^{-}}{24}\right]-0=92.7^{\circ} \mathrm{F} \\
& \Delta t_{\varepsilon}=92.7-78=14.7 \\
& \mathrm{R}=\frac{\Delta \mathrm{t}_{\mathrm{C}}}{\mathrm{q} / \mathrm{A}}=\frac{14.7}{2.0}=7.35 \\
& \mathrm{U}=0.14 \\
& \text { East, } t_{\text {ea }}=\left(89-\frac{9}{2}\right)+0.30\left[\frac{1.15(936+176)}{24}-0=100.5\right. \\
& \Delta t_{\varepsilon}=t_{\text {ea }}-t_{i} \\
& =100.5-78 \\
& =22.5 \\
& \mathrm{R}=\frac{\Delta \mathrm{t}_{\mathcal{\varepsilon}}}{\mathrm{q} / \mathrm{A}}=\frac{22.5}{2.0}=11.25 \\
& \mathrm{U}=0.09 \\
& \text { South, } t_{\text {ea }}=\left(89-\frac{9}{2}\right)+0.30\left[\frac{1.15(451+451)}{24}\right]-0=97.5^{\circ} \mathrm{F} \\
& \Delta t_{\varepsilon}=t_{\text {ea }}-t_{i} \\
& =97.5-78 \\
& =19.5 \\
& R=\frac{\Delta t}{q / A}=\frac{19.5}{2.0}=9.75 \\
& \mathrm{U}=0.10
\end{aligned}
$$




$$
\begin{aligned}
& \text { West, } t_{\text {ea }}=\left(89-\frac{9}{2}\right)+0.30\left[\frac{1.15(176+936)}{24}\right]-0=100.3^{\circ} \mathrm{F} \\
& \Delta \mathrm{t}_{\varepsilon}=\mathrm{t}_{\mathrm{ea}}-78 \\
& =100.3-78 \\
& =22.3 \\
& R=\frac{\Delta t_{\varepsilon}}{q / A}=\frac{22.3}{2.0}=11.15 \\
& \mathrm{U}=0.09
\end{aligned}
$$

(2) San Diego, California

Latitude $=32^{\circ} 4^{\prime}$

Design dry-bulb temperature, $t_{d}=83^{\circ} \mathrm{F}$

Outdoor daily range, $\Delta t=12$ of

Horizonta 1 Roofs, $\max$. half-day total = 1119 on June 21

For walls, max. half-day totals are:

North, 252 a.m. and $252 \mathrm{p} \cdot \mathrm{m}$. on June 21

East, $972 \mathrm{a} \cdot \mathrm{m}$. and $180 \mathrm{p} \cdot \mathrm{m}$. on June 21

South, 844 a.m. and 844 p.m. on December 21

West, $172 \mathrm{a} . \mathrm{m}$. and $983 \mathrm{p} . \mathrm{m}$. on May 21

$t_{\text {ea }}=t_{o a}+\frac{\alpha}{h_{o}}\left(\frac{I_{D T}}{24}\right)-\frac{\varepsilon \Delta R}{h_{o}}$

\section{For Roofs}

$$
\text { light colored, } \begin{aligned}
\mathrm{t}_{\text {ea }} & =\left(83-\frac{12}{2}\right)+0.15\left[\frac{1.15(1119+1119)}{24}\right]-7=86^{\circ} \mathrm{F} \\
\Delta \mathrm{t}_{\varepsilon} & =\mathrm{t}_{\text {ea }}-\mathrm{t}_{\mathrm{i}} \\
& =86^{\circ}-78 \\
& =8^{\circ} \mathrm{F} \\
\mathrm{R} & =\frac{\Delta \mathrm{t}_{\varepsilon}}{\mathrm{q} / \mathrm{A}}=\frac{8}{2.0}=4.0 \\
\mathrm{U} & =0.2 .5
\end{aligned}
$$


dark colored, $t_{\text {ea }}=\left(83-\frac{12}{2}\right)+0.3\left\lceil\frac{1.15(1119+1119)}{24}\right]-7=102{ }^{\circ} \mathrm{F}$

$$
\begin{aligned}
\Delta t_{\varepsilon} & =t_{\text {ea }}-t_{i} \\
& =102-78 \\
& =24^{\circ} \mathrm{F} \\
\mathrm{R} & =\frac{\Delta t_{\varepsilon}}{\mathrm{q} / \mathrm{A}}=\frac{24}{2.0}=12.0 \\
U & =0.08
\end{aligned}
$$

For wa11s

light colored

$$
\begin{aligned}
& \text { North, } t_{\text {ea }}=\left(83-\frac{12}{2}\right)+0.15\left[\frac{1.15(252+252)}{24}\right]-0=80.6^{\circ} \mathrm{F} \\
& \Delta t_{\varepsilon}=t_{e a}-t_{i} \\
& =80.6-78 \\
& =2.6 \\
& \mathrm{R}=\frac{\Delta t_{\varepsilon}}{\mathrm{q} / \mathrm{A}}=\frac{2.6}{2.0}=1.3 \\
& \mathrm{U}=0.77 \\
& \text { East, } t_{\text {ea }}=\left(83-\frac{12}{2}\right)+0.15 \frac{1.15(972+180)}{24}-0=85.3^{\circ} \mathrm{F} \\
& \Delta t_{\xi}=t_{e a}-t_{i} \\
& =85.3-78 \\
& =7.3^{\circ} \mathrm{F} \\
& \mathrm{R}=\frac{\Delta \mathrm{t}_{\mathrm{q}}}{\mathrm{q} / \mathrm{A}}=\frac{7.3}{2.0}=3.65 \\
& \mathrm{U}=0.27
\end{aligned}
$$


South, $t_{\text {ea }}=\left(83-\frac{12}{2}\right)+0.15\left[\frac{1.15(844+844)}{24}\right]-0=89.1{ }^{\circ} \mathrm{F}$

$$
\begin{aligned}
& \begin{aligned}
\Delta t_{\varepsilon} & =t_{e a}-t_{i} \\
& =89.1-78 \\
& =11.1
\end{aligned} \\
& R=\frac{\Delta t_{\varepsilon}}{q / A}=\frac{11.1}{2.0}=5.55 \\
& U=0.18
\end{aligned}
$$

$$
\begin{aligned}
& \text { West, } \mathrm{t}_{\text {ea }}=\left(83-\frac{12}{2}\right)+0.15\left[\frac{1.15(983+172)}{24}\right]-0=85.3{ }^{\circ} \mathrm{F} \\
& \Delta t \varepsilon=t_{e a}-t_{i}=85.3-78=7.3 \\
& R=\frac{\Delta t_{\varepsilon}}{q / A}=\frac{7.3}{2.0}=3.65 \\
& U=0.27
\end{aligned}
$$

\section{dark colored}

$$
\text { North, } \begin{aligned}
\mathrm{t}_{\text {ea }} & =\left(83-\frac{12}{2}\right)+0.30\left[\frac{1.15(252+252)}{24}\right]-0=90.2{ }^{\circ} \mathrm{F} \\
\Delta \mathrm{t}_{\varepsilon} & =\mathrm{t}_{\mathrm{ea}}-\mathrm{t}_{\mathrm{i}} \\
& =90.2-78 \\
& =12.2 \\
\mathrm{R} & =\frac{\Delta \mathrm{t}_{\varepsilon}}{\mathrm{q} / \mathrm{A}}=\frac{12.2}{2.0}=6.1 \\
\mathrm{U} & =0.16
\end{aligned}
$$

$$
\text { East, } \begin{aligned}
\mathrm{t}_{\mathrm{ea}} & =\left(83-\frac{12}{2}\right)+0.30 L \frac{1.15(972+180)}{24}-0=93.6{ }^{\circ} \mathrm{F} \\
\Delta \mathrm{t} \varepsilon & =\mathrm{t}_{\mathrm{ea}}-\mathrm{t}_{\mathrm{i}} \\
& =93.6-78=15.6 \\
\mathrm{R} & =\frac{\Delta \mathrm{t}_{\varepsilon}}{\mathrm{q} / \mathrm{A}}=\frac{15.6}{2.0}=7.8 \\
\mathrm{U} & =0.13
\end{aligned}
$$




$$
\begin{aligned}
\text { South, } t_{\text {ea }} & =\left(83-\frac{12}{2}\right)+0.30\left[\frac{1.15(844+844)}{24}\right]-0=101.2{ }^{\circ} \mathrm{F} \\
\Delta t_{\varepsilon} & =t_{\text {ea }}-t_{i}=101.2-78=23.2 \\
R & =\frac{\Delta t_{\varepsilon}}{q / A}=\frac{23.2}{2.0}=11.6 \\
U & =0.09 \\
\text { West, } t_{e a} & =\left(83-\frac{12}{2}\right)+0.30\left[\frac{1.15(983+172)}{24}\right]-0=93.6{ }^{\circ} \mathrm{F} \\
\Delta t & =t \\
\text { ea } & -t_{i}=93.6-78=15.6 \\
R & =\frac{\Delta t_{\varepsilon}}{q / A}=\frac{1}{2} \frac{1.6}{0}=7.8 \\
U & =0.13
\end{aligned}
$$


APPENDIX 2

HEAT FLUX, THERMAL RESISTANCE, AND THERMAL

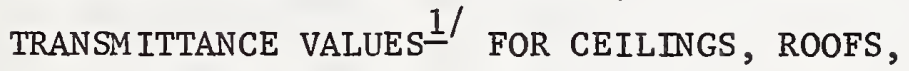
AND OPAQUE WALLS MEETING THE DESIGN CRITERIA OF TABLES 5.1 AND 5.3 FOR 243 U. S. CITIES

1/ The degree-day and winter outside design temperature in this Appendix are taken from ASHRAE Systems Volume (1973) and the ASHRAE Fundamentals Volume (1972), respectively. 
APPENDIX 2

\begin{tabular}{|c|c|c|c|c|c|c|c|c|c|c|}
\hline \multirow[t]{2}{*}{ STATE } & \multirow[t]{2}{*}{ STATION } & \multirow{2}{*}{$\begin{array}{c}\text { DEGREE } \\
\text { TAY }\end{array}$} & \multirow{2}{*}{$\begin{array}{l}\text { DESIGN } \\
\text { TEMP. }\end{array}$} & \multirow{2}{*}{$\begin{array}{c}D E S I G N \\
\Delta^{T}\end{array}$} & \multicolumn{3}{|c|}{ CFILING/ROJF } & \multicolumn{3}{|c|}{ WALL } \\
\hline & & & & & $D / A$ & $R$ & $u$ & $Q / A$. & $R$ & $u$ \\
\hline \multirow[t]{4}{*}{$A L A$. } & $A \perp F M \| N G H A M$ & 2551 & 22 & 48 & 3.52 & 13.71 & .07 & 4.30 & 11.16 & .09 \\
\hline & HLATSVILLE & 35.75 & 17 & 53 & 3.57 & $15 \cdot 14$ & .07 & 4.30 & 12.33 & 8 \\
\hline & MOEILE & $156 ?$ & 29 & 41 & 3.59 & 11.43 & . & $4 \cdot 39$ & 9.34 & .11 \\
\hline & MONTEOMERY & 2291 & 26 & 44 & 3.57 & 12.57 & .08 & 4.30 & 10.23 & .10 \\
\hline \multirow[t]{4}{*}{$A L \perp S K A$} & ANCHCRAGE & 10864 & -20 & 99 & 3.89 & $23 \cdot 16$ & .04 & 5.73 & 15.71 & .06 \\
\hline & FAIKQANKS & 14279 & -50 & 120 & 4.40 & 27.27 & .04 & 6.0 .3 & 20.00 & .05 \\
\hline & JUNEAU & $9: 75$ & -4 & 74 & 3.71 & 19.96 & .05 & $5 \cdot 32$ & 13.90 & .07 \\
\hline & NCNE & 14171 & -28 & 98 & 4.40 & 22.27 & .04 & 6.00 & 16.33 & .06 \\
\hline \multirow[t]{5}{*}{$\triangle F I Z$. } & $F L A G S T A F F$ & 7152 & 5 & 65 & 3.69 & 18.96 & .06 & 4.83 & 13.46 & .07 \\
\hline & PHOENIX & 1765 & 34 & 36 & 3.55 & $10 \cdot 15$ & .10 & $4 \cdot 35$ & 8.28 & .12 \\
\hline & TUCSON & 1800 & 32 & 38 & 3.54 & 15.73 & .09 & $4 \cdot 34$ & 8.76 & .11 \\
\hline & WISLLOW & 4782 & 13 & 57 & 3.52 & 16.29 & .06 & $4 \cdot 38$ & 13.02 & .08 \\
\hline & YUMA & 974 & 40 & 30 & 3.71 & 8.78 & .12 & 4.51 & 6.65 & .15 \\
\hline \multirow[t]{3}{*}{$A F K$. } & FCRT SMITH & 3292 & 19 & 51 & 3.50 & 14.57 & .07 & $4 \cdot 30$ & 11.86 & .08 \\
\hline & LITTLF ROCK & 3219 & 23 & 47 & 3.50 & 13.43 & .07 & $4 \cdot 30$ & 10.93 & .09 \\
\hline & TEXAEKANA & 2533 & 26 & 44 & 3.50 & 12.57 & .08 & $4 \cdot 30$ & 10.23 & .10 \\
\hline \multirow[t]{11}{*}{$C A \perp F$. } & DAKE OSFIELD & 2127 & 33 & 37 & 3.50 & 10.57 & .09 & 4.30 & 8.60 & .12 \\
\hline & BUKBANK & 1646 & 38 & 32 & 3.57 & 8.96 & .11 & $4 \cdot 37$ & 7.32 & .14 \\
\hline & EURFKA & 4643 & 35 & 35 & 3.52 & $1 ก$ & .10 & $4 \cdot 36$ & 8.02 & .12 \\
\hline & FFESAC & 2611 & 31 & 39 & $3.5 \mathrm{C}$ & 11.14 & .09 & $4 \cdot 30$ & 9.07 & .11 \\
\hline & LOAGEEACH & 1803 & 38 & 32 & 3.54 & 9.04 & .11 & $4 \cdot 34$ & 7.37 & .14 \\
\hline & LOS A AGELES & $2[661$ & 43 & 27 & 3.50 & $7.7 !$ & .13 & 4.30 & 6.29 & .16 \\
\hline & $\cap \Delta K L A N D$ & $2 P 7 C$ & 37 & 33 & 3.50 & 9.43 & .11 & $4 \cdot 30$ & 7.67 & .13 \\
\hline & SACKANENTO & 2502 & 32 & 38 & 3.50 & 10.96 & .09 & $4 \cdot 30$ & 8.84 & .11 \\
\hline & SAN T IEGO & 1458 & 44 & 26 & $3 \cdot 61$ & 7.21 & .14 & 4.41 & 5.90 & .17 \\
\hline & SAP: FRANCISCO & 3015 & 37 & 33 & 3.50 & 9.43 & .11 & $4 \cdot 30$ & 7.67 & .13 \\
\hline & SAMTI MARIA & 2967 & 34 & 36 & 3.50 & 10.29 & .10 & $4 \cdot 30$ & 8.37 & .12 \\
\hline \multirow[t]{4}{*}{$\cot \theta$} & CCLOPADO SPRINGS & 6423 & 4 & 66 & 3.54 & 18.63 & .05 & 4.63 & 14.26 & .07 \\
\hline & DEA VEF & 628.3 & 3 & 67 & 3.53 & 18.99 & .05 & 4.58 & 14.61 & .07 \\
\hline & GFA IC JUNCTION & 5641 & 11 & 59 & $3.5 n$ & 16.96 & .06 & 4.46 & 13.22 & .08 \\
\hline & $P L E F L O$ & 5462 & -1 & 71 & 3.50 & 20.79 & .05 & 4.45 & 15.97 & .06 \\
\hline \multirow[t]{3}{*}{ CNA . } & RFITGEPORT & 5617 & 8 & 62 & 3.50 & 17.71 & .06 & 4.46 & 13.90 & .07 \\
\hline & HAFTFDRE & b235 & 5 & 65 & 3.52 & 18.45 & .05 & 4.57 & 14.22 & .07 \\
\hline & NEP HAVEP: & 59.97 & 9 & $t 1$ & $3 \cdot 50$ & 17.43 & .06 & 4.49 & 13.59 & .07 \\
\hline CEL. & VILA JPGTCN & 4930 & 15 & 45 & 3.50 & 15.71 & .06 & 4.39 & 12.52 & .08 \\
\hline o.r. & WASH 1 NGTON & 4224 & 19 & 51 & 3.50 & 14.57 & .07 & 4.32 & 11.80 & .08 \\
\hline \multirow{12}{*}{ FLA } & DAYTCINA BEACH & 879 & 36 & 34 & 3.76 & 9.34 & .11 & 4.56 & 7.46 & .13 \\
\hline & FOKT MYERS & 442 & 42 & 28 & 3.09 & $7 . \Gamma 4$ & .14 & 4.78 & 5.86 & .17 \\
\hline & JACKCENVILLE & 1239 & 32 & 38 & 3.65 & 10.40 & .10 & 4.45 & 9. 54 & .12 \\
\hline & KEY :FST & $10^{\circ}$ & 58 & 12 & $4 \cdot 15$ & 2.89 & .35 & 4.95 & 2.43 & .41 \\
\hline & LAKELAND & 661 & 39 & 31 & 3.87 & $8 \cdot n 1$ & .12 & 4.67 & 6.64 & .15 \\
\hline & $M 1 \& M T$ & 214 & 47 & 23 & 4.99 & 5.62 & .18 & 4.89 & 4.70 & .21 \\
\hline & MIAH"I BEACH & $14 !$ & 48 & 22 & 4.13 & $5 \cdot 3.3$ & .19 & 4.93 & 4.46 & .22 \\
\hline & $O F L A A C O$ & 766 & 37 & 33 & 3.82 & 8.65 & .12 & 4.62 & 7.15 & .14 \\
\hline & PEACECOLA & 1463 & 32 & 38 & 3.61 & 10.53 & .09 & 4.41 & 8.62 & .12 \\
\hline & TLLL:HASSEE & 1485 & 29 & 41 & $3 \cdot 60$ & 11.39 & .09 & 4.40 & 9.31 & .11 \\
\hline & TAPAA & 683 & 39 & 31 & 3.86 & 8.93 & .12 & 4.66 & 6.65 & .15 \\
\hline & WEST PALM BEACH & 253 & 44 & 26 & 4.07 & 6.38 & .16 & 4.87 & 5.33 & .19 \\
\hline \multirow[t]{2}{*}{ GA. } & ATRFA'S & 2929 & 21 & 49 & 3.50 & 14. חn & .07 & 4.30 & 11.40 & .09 \\
\hline & ATLAMTA & 2961 & 23 & 47 & 3.50 & 13.47 & .07 & 4.30 & 10.93 & .09 \\
\hline
\end{tabular}


STATE STHTION

AUGUSTA

COLLIPAUS

MACCN

POOHF

SAVAP P!AH

HATA I TONOI ULU

HILO

IDEHO ROISE

LEV: STON

PCCATELLO

ILI. (HISAGO (OHARE)

CHICAGO (MIDNAY)

CHICAGO

MOLITEE

PEOPIA

ROCKFORD

SFRINGFIELD

JNR. FVANSVILLE

FORT WAYPE

IPDIANAPOLLIS

SUUTH BENO

IOVA RURLINGTON

DES M:CINES

DUEI!OUE

SIOIX CITY

WITFFLDO

KANS. DCIRE CITY

GOONLAND

TOFFYA

HiCH:Ta

Kr. COVIAistTON

LEXINGTON

LOUIGVILLE

LA. ALEYPNDRIA

AATRP, RDUGE

LAKF CHARLES

NE' ${ }^{\circ}$ TPLEANS

SHFEVFPRIT

MPIIE CARILCU

DCFTLANC

MD. BALTINORE

FFFFFFICK

MAES. DOSTRM

DITTSFIELD

HOFCF STER

MICH. OETPOIT

ESCEAARA

FL! $: T$

GFAI R RAPIDS

LANS:NG
DEGREE DESIGN DESIGN CFILING/ROOF

DAY TEMP. $\triangle T$ TIA R U

$\begin{array}{llllll}2397 & 23 & 47 & 3.50 & 13.43 & .07\end{array}$

2383

2136

3326

1819

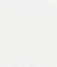

5809

5542

7 C.33

6639

6155

5882

6408

6025

6830

5429

4435

6265

5699

6430

6114

6586

$737 h$

6951

$732 r$

4986

6141

518 ?

$462 \mathrm{C}$

5265

4682

$466 \mathrm{C}$

1921

$156 r$

$145^{\circ}$

1385

2184

9767

7511

4654

5087

5634

7578

6064

6232

8481

7377

4894

609
$3.50 \quad 12.57$

$3.50 \quad 12.29$

$3.50 \quad 14.29$

$3.54 \quad 12.16$

4.201 .90

$4.20 \quad 2.14$

$3.50 \quad 17.14$

$3.50 \quad 16.57$

$3.60 \quad 20.00$

$3.56 \quad 19.64$

$3.52 \quad 19.63$

$3.50 \quad 19.71$

3.5420 .6 ?

$3.50 \quad 19.41$

$3.58 \quad 20.37$

3.5018 .86

3.5017 .14

$3.52 \quad 18.46$

3.5018 .86

$3.54 \quad 18.91$

3.5119 .94

$3.56 \quad 2 \pi .51$

$3.60 \quad 21.39$

$3.60 \quad 21.14$

$3.60 \quad 21.67$

$3.5 n 18.00$

3.5118 .78

$3.50 \quad 18.29$

$3.50 \quad 17.43$

$3.50 \quad 17.71$

$3.5 \mathrm{C} \quad 17.14$

3.5016 .57

$3.52 \quad 11.66$

$3.59 \quad 11.15$

$3.61 \quad 10.25$

3.67 0.66

$3.50 \quad 12.57$

$3.78 \quad 22.24$

$3.60 \quad 19.44$

$3.5 n \quad 15.71$

3.5016 .84

3.5017 .14

3.6019 .72

3.6019 .18

3.5 ? 17.60

$3.65 \quad 20.01$

$3.60 \quad 18.61$

$3.59 \quad 17.0 .3$

3.5917 .8 ?
.08

.08

.07

.08

.52

.47

.06

.06

.05

.05

.05

.05

.05

.05

.05

.05

.06

.05

.05

.05

.05

.05

.05

.05

.05

.06

.05

.05

.06

.06

.06

.06

.09

.09

.10

.10

.08

.04

.05

.06

.06

.06

.05

.05

.06

.05

.05

.06

.06
WALL

$Q / A \quad R \quad U$

$\begin{array}{lll}4.30 & 10.93 \quad .09\end{array}$

$4.3010 .23 \quad .10$

$4.30 \quad 10.00 \quad .10$

$4.30 \quad 11.63 \quad .09$

$4.34 \quad 9.92 \quad .10$

$5.00 \quad 1.60 \quad .63$

$5.00 \quad 1.80 \quad .56$

$\begin{array}{lll}4.48 & 13.39 & .07\end{array}$

$\begin{array}{llll}4.45 & 13.02 & .08\end{array}$

$\begin{array}{llll}4.81 & 14.98 & .07\end{array}$

$\begin{array}{llll}4.69 & 14.92 \quad .07\end{array}$

$\begin{array}{lll}4.55 & 15.18 & .07\end{array}$

$\begin{array}{lll}4.49 & 15.37 & .07\end{array}$

$4.62 \quad 15.79 \quad .06$

$\begin{array}{llll}4.51 & 15.09 & .07\end{array}$

$\begin{array}{llll}4.75 & 15.37 & .07\end{array}$

$\begin{array}{llll}4.44 & 14.86 & .07\end{array}$

$4.3413 .8 ! \quad .07$

$\begin{array}{llll}4.56 & 14.25 & .07\end{array}$

$\begin{array}{lll}4.47 & 14.77 & .07\end{array}$

$\begin{array}{llll}4.63 & 14.47 & .07\end{array}$

$4.53 \quad 15.44 \quad .06$

$4.68 \quad 15.61 \quad .06$

$4.88 \quad 15.79 \quad .06$

$\begin{array}{lll}4.79 & 15.88 & .06\end{array}$

$4.86 \quad 16.04 \quad .06$

$\begin{array}{llll}4.40 & 14.32 & .07\end{array}$

$\begin{array}{llll}4.54 & 14.53 \quad .07\end{array}$

$\begin{array}{lll}4.42 & 14.49 & .07\end{array}$

$\begin{array}{lll}4.36 & 13.98 & .07\end{array}$

$\begin{array}{llll}4.43 & 14.01 & .07\end{array}$

$\begin{array}{llll}4.37 & 13.74 & .07\end{array}$

$\begin{array}{llll}4.37 & 13.28 & .08\end{array}$

$4.329 .50 \quad .11$

$4.39 \quad 9.12 \quad .11$

$4.418 .39 \quad .12$

$4.42 \quad 7.91 \quad .13$

$4.30 \quad 10.23 \quad .10$

$\begin{array}{llll}5.53 & 15.19 & .07\end{array}$

$\begin{array}{lll}4.90 & 14.28 & .07\end{array}$

$4.37 \quad 12.60 \quad .08$

$4.4113 .38 \quad .07$

$4.46 \quad 13.44 \quad .07$

$4.92 \quad 14.44 \quad .07$

$\begin{array}{lll}4.79 & 14.40 \quad .07\end{array}$

$\begin{array}{llll}4.57 & 13.57 & .07\end{array}$

$5.14 \quad 14.19 \quad .07$

$\begin{array}{llll}4.88 & 13.74 \quad .07\end{array}$

$\begin{array}{llll}4.77 & 13.42 & .07\end{array}$

$\begin{array}{lll}4.77 & 13.41 \quad .07\end{array}$ 
DEGREF DFSIGN DFSIGN CEILING/RNOF
TAY TEMF.

MARTLETTE

MUSKF GON

SAUIT STE. MARIE

MI:AI. DULI!?H

MINMFAPOLIS

ROCHESTER

MISS. JACKECM

AEPJDIAN

VICKCPURG

MO. COLLIMEIA

KANSAS CITY

ST. JCSEPH

ST. LOUIS

ST. LOUIS

SFP.IP,GF IELD

NCM? RILLINGS

GLASROW

GPEAT FALLS

HAVRE

HELFI:

KLI S SPELL

MILES CITY

M ISSOULA

NER. GRAND ISLAND

LINCOLA:

NORFCLK

NURTH PLATTE

OMAHA

SCOT ISRLUFF

NEVIFDA FLKC

ELY

I. AS YEGAS

RENF:

WINHL MUCA

N.H. CORECRD

N.J. ATLL:ITIC CITY

NEW $\triangle P$ P

TRFPTCN

N.ll. ALRLILLERQUE

PATr:1

ROSIEELL

SILVER CITY

N.Y. ALEAMY

BINCHAMTON

BIIFF LLO

NEW YORKICENT.PK.)

NEW YORK(LA GUARDIA)

NEW YCRK (KENNEDY)

ROCHESTER

SCHFNF.CTADY
839. $\quad-4 \quad 74 \quad 3.64 \quad 20.33 \quad .05$

6696

9548

10000

ค 383

\&295

$223^{\circ}$

2289

$2 \pi 41$

5 C. 4 .

4711

5484

$490 \mathrm{C}$

4484

4 . C.

7049

8996

$775 \mathrm{C}$

$87 \mathrm{cC}$

8129

3191

7723

6125

6530

5864

$697^{\circ}$

6684

661 ?

6673

7433

7733

$270^{\circ}$

6332

6761

7383

4 ค1?

4589

$498 \mathrm{C}$

434 A

67.28

379.3

3705

6875

72.86

7062

4871

4811

5719

6748

$665 r$
$3.57 \quad 17.37 .06$

$3.70 \quad 21.05 \quad .05$

3.ค? 22.37.04

3.6421 .99 .05

3.6322 .87 .04

$3.5 \mathrm{C} \quad 13.14 \quad .08$

$3.5 n 13.14 .08$

$3.5 n \quad 12.57 \quad .08$

3.5C 18.29 .05

$3.5 r \quad 17.71 .06$

$3.50 \quad 19.14 .05$

3.517 .71 .06

$3.5 \mathrm{C} \quad 16.86 .06$

$3.5 \cap 17.14 .06$

3. hr. 21.11 .05

3.7024 .33 .04

3.6523 .89 .04

$3.6723 .16 \quad .04$

$3.61 \quad 22.97 \quad .04$

3.6720 .17 .05

$3.6 C \quad 23.61 .04$

3.6120 .21 .05

$3.55 \quad 20.26 \quad .05$

$3.50 \quad 20.00 \quad .05$

$3.60 \quad 21.40 \quad .05$

$3.5720 .18 \quad .05$

$3.56 \quad 19.94 \quad .05$

3.5720 .74

3.6021 .39

$3.6 \mathrm{C} \quad 20.50$

$3.50 \quad 12.57$

$3.53 \quad 17.8 .3$

$3.58 \quad 18.18$

$3.6 C 21.39$

3.5014 .96

$3.5 \mathrm{C} 15.71$

$3.5 \Gamma \quad 15.43$

$3.5 \cap \quad 15.14$

$3.52 \quad 19.30$

$3.50 \quad 14.57$

3.5014 .86

3.5919 .51

3.6018 .99

$3.60 \quad 17.78$

$3.50 \quad 15.71$

$3.5 C \quad 15.43$

3.5014 .50

3.5718 .19

3.5619 .92

.05
WALL

G $/ A \quad R$

$5.12 \quad 14.46$

4.7113 .17

$5.31 \quad 14.68$

$5.60 \quad 15.18$

5.1115 .64

$5.09 \quad 16.31$

$4.30 \quad 10.70$

$4.30 \quad 17.70$

$4.30 \quad 10.23$

$4.40 \quad 14.53$

$4.37 \quad 14.18$

$4.45 \quad 15.06$

$4.39 \quad 14.12$

$4.35 \quad 13.57$

$4.39 \quad 13.67$

4.8115 .80

$5.30 \quad 16.98$

$4.95 \quad 17.37$

5.2116 .31

$5.04 \quad 16.47$

$5.06 \quad 14.43$

$4.94 \quad 17.19$

5.0414 .49

$4.66 \quad 15.45$

$4.49 \quad 15.60$

$4.79 \quad 16.06$

4.7115 .30

$4.68 \quad 15.16$

$4.70 \quad 15.74$

$4.89 \quad 15.76$

4.9514 .56

$4.30 \quad 10.23$

$4.60 \quad 13.70$

$4.73 \quad 13.75$

$4.88 \quad 15.79$

$4.38 \quad 11.87$

$4.36 \quad 12.62$

$4.40 \quad 12.28$

4.3312 .23

$4.57 \quad 14.88$

4.3011 .86

$4.30 \quad 12.09$

$4.76 \quad 14.70$

$4.86 \quad 14.00$

4.8113 .30

$4.39 \quad 12.54$

$4.38 \quad 12.33$

4.4211 .08

$4.72 \quad 13.76$

4.6915 .12
$\mathrm{U}$

.07

.08

.07

.07

.06

.06

.09

.09

.10

.07

.07

.07

.07

.07

.07

.06

.06

.06

.06

.06

.07

.06

.07

.06

.06

.06

.07

.07

.06

.06

.07

.10

.07

.07

.06

.08

.08

.08

.08

.07

.08

.08

.07

.07

.08

.08

.08

.09

.07

.07 


\begin{tabular}{|c|c|c|c|c|c|c|c|c|c|c|}
\hline \multirow[t]{2}{*}{ STATE } & \multirow[t]{2}{*}{ STATION } & \multirow{2}{*}{$\begin{array}{c}\text { DEGREE } \\
\text { DAY }\end{array}$} & \multirow{2}{*}{$\begin{array}{l}\text { DESIGN } \\
\text { TEMP. }\end{array}$} & \multirow{2}{*}{$\begin{array}{c}D E S I G N \\
\Delta T\end{array}$} & \multicolumn{3}{|c|}{ CEILING/ROOF } & \multicolumn{3}{|c|}{ WALL } \\
\hline & & & & & $0 . / A$ & R & $u$ & $Q / A$ & $R$ & $u$ \\
\hline & SYRACUSE. & 6756 & 2 & 68 & 3.58 & 19.02 & .05 & 4.73 & 14.39 & .07 \\
\hline \multirow[t]{6}{*}{$N \cdot C}$. & ASHEYILLE & $4 \Pi 42$ & 17 & 53 & 3.50 & $15 \cdot 14$ & .07 & $4 \cdot 30$ & 12.31 & .08 \\
\hline & CHAPLOTTE & 3191 & 22 & 48 & 3.50 & 13.71 & .07 & $4 \cdot 30$ & 11.16 & .09 \\
\hline & GREFHSBORO & 3805 & 17 & 53 & $3.5 n$ & 15.14 & .07 & $4 \cdot 30$ & 12.33 & .08 \\
\hline & RALEIGH & 3393 & 20 & 5.0 & 3.50 & 14.29 & .07 & 4.30 & 11.63 & .09 \\
\hline & MLITNGTON & 2347 & 27 & 43 & 3.50 & 12.29 & .08 & $4 \cdot 30$ & 10.00 & .10 \\
\hline & "INSTON-SALEM & 3595 & 17 & 53 & $3.5 n$ & 15.14 & .07 & $4 \cdot 30$ & 12.33 & .08 \\
\hline \multirow[t]{4}{*}{ N. D. } & Q I SMARK. & $8 B 51$ & -19 & 9.9 & 3.69 & $24 \cdot 15$ & .04 & 5.26 & 16.94 & .06 \\
\hline & DEVILS LAKE & 9991 & -19 & २9 & 3.79 & 23.48 & .04 & 5.57 & 15.98 & .06 \\
\hline & $F A R C_{B} 0$ & 9226 & -17 & 87 & 3.72 & 23.37 & .04 & 5.37 & 16.21 & .06 \\
\hline & MLLISTON & 924.3 & -17 & P7 & 3.72 & 23.36 & .04 & 5.37 & 16.19 & .06 \\
\hline \multirow[t]{9}{*}{$0+10$} & AKRON-CANTON & 6037 & 6 & 64 & 3.50 & 18.27 & .05 & 4.51 & 14.19 & .07 \\
\hline & CINCINNATI & $441 ?$ & 12 & 58 & $3.5 n$ & 16.57 & .06 & $4 \cdot 34$ & 13.36 & .07 \\
\hline & CLEVFLAND & 6351 & 7 & 63 & 3.54 & 17.82 & .06 & 4.61 & 13.68 & .07 \\
\hline & COLIMRUS & $566 \mathrm{C}$ & 7 & 63 & 3.50 & 18.00 & .06 & 4.47 & 14.11 & .07 \\
\hline & DAYT TN & 5627 & 6 & 64 & 3.50 & 18.29 & .05 & 4.46 & 14.34 & .07 \\
\hline & MANSFIELD & 6403 & 3 & 67 & 3.54 & 18.97 & .05 & 4.62 & 14.50 & .07 \\
\hline & SANDISKY & 5796 & 8 & 62 & 3.50 & 17.71 & .06 & 4.48 & 13.84 & .07 \\
\hline & TOLFด & 6494 & 5 & 65 & 3.55 & 18.31 & .05 & 4.65 & 13.98 & .07 \\
\hline & YOUNGSTOWN & 6417 & 6 & 64 & 3.54 & 18.07 & .06 & 4.63 & 13.84 & .07 \\
\hline \multirow[t]{2}{*}{ OKLA. } & OKLAHDMA CITY & 3725 & 15 & 55 & 3.50 & 15.71 & .06 & $4 \cdot 30$ & 12.79 & .08 \\
\hline & TULSA & 3860 & 16 & 54 & $3.5 n$ & 15.43 & .06 & 4.30 & 12.56 & .08 \\
\hline \multirow[t]{7}{*}{ OREGON } & $A S T O R I A$ & 5186 & 30 & 40 & $3.5 n$ & 11.43 & .09 & 4.42 & 9.05 & .11 \\
\hline & SUGFVE & 4726 & 26 & 44 & 3.50 & 12.57 & .08 & $4 \cdot 37$ & 10.06 & .10 \\
\hline & MEDFORD & 550 & 23 & 47 & $3.5 n$ & 13.43 & .07 & 4.40 & 10.68 & .09 \\
\hline & PENOLFTON & 5127 & 10 & 60 & 3.50 & 17.14 & .06 & 4.41 & 13.60 & .07 \\
\hline & PORTLAND & 4635 & 24 & 46 & 3.50 & 13.14 & .08 & $4 \cdot 36$ & 10.54 & .09 \\
\hline & ROSERURG & $449 !$ & 29 & 41 & $3.5 n$ & 11.71 & .09 & $4 \cdot 35$ & 9.43 & .11 \\
\hline & SALEM & $475^{4}$ & 25 & 45 & 3.50 & 12.86 & .08 & $4 \cdot 38$ & 10.28 & .10 \\
\hline \multirow[t]{8}{*}{ PEN!N. } & ALLENTOWN & 5 मी & 5 & 45 & $3.5 n$ & 18.57 & .05 & 4.48 & 14.51 & .07 \\
\hline & ERIF & 6451 & 11 & 59 & 3.55 & 16.64 & .06 & 4.64 & 12.73 & .08 \\
\hline & HARFISRURT & 5251 & 13 & 57 & $3.5 n$ & 16.29 & .06 & 4.43 & 12.88 & .08 \\
\hline & PHILADFLPHIA & 5144 & 15 & 55 & 3.50 & 15.71 & .06 & $4.4 i$ & 12.46 & .08 \\
\hline & PITTSRURGH & 5987 & 9 & 61 & $3.5 n$ & 17.43 & .06 & 4.50 & 13.56 & .07 \\
\hline & $P E A D I N G$ & 4945 & 9 & $A_{1}$ & $3.5 C$ & 17.43 & - 26 & 4.39 & 13.89 & .07 \\
\hline & SCRAVTOM & 6254 & 6 & 64 & 3.53 & 18.15 & .06 & $4 \cdot 58$ & 13.99 & .07 \\
\hline & MILLIAMSPORT & 5934 & 5 & 65 & $3.5 n$ & 18.57 & .05 & 4.49 & 14.47 & .07 \\
\hline P. I. & DROVIDENCE & 5954 & 10 & 60 & 3.50 & 17.14 & .06 & 4.50 & 13.35 & .07 \\
\hline \multirow[t]{4}{*}{ s.r. } & CHATLESTON & 2.733 & 27 & 43 & $3.5 n$ & $12 \cdot 29$ & .08 & $4 \cdot 30$ & $1 n .00$ & .10 \\
\hline & COLUMBIA & 2484 & 23 & 47 & 3.50 & 13.43 & .07 & 4.30 & 10.93 & .09 \\
\hline & FLORENCE & 2387 & 25 & 45 & $3.5 \pi$ & 13.96 & .08 & $4 \cdot 30$ & 10.47 & .10 \\
\hline & GREENVILLE-SPARTENBURG & 2980 & 23 & 47 & 3.50 & 13.43 & .07 & $4 \cdot 30$ & 10.93 & .09 \\
\hline \multirow[t]{3}{*}{ s.n. } & $4 U 80 N$ & 8223 & -17 & $8 ?$ & $3 \cdot 6 ?$ & $22 \cdot 44$ & .04 & $5 \cdot 07$ & 16.18 & .06 \\
\hline & RAPIO CITY & 7345 & -6 & 76 & $3 \cdot$ So & $21 \cdot 11$ & .05 & 4.87 & 15.61 & .06 \\
\hline & SICUY FALLS & $783 ?$ & -10 & 80 & 3.60 & 22.22 & .04 & 4.97 & 16.10 & .06 \\
\hline \multirow[t]{5}{*}{ TENIN. } & BP ISTDL & 414.3 & 16 & 54 & $3.5 \pi$ & 15.43 & .06 & $4 \cdot 31$ & 12.52 & .08 \\
\hline & CHATTANOOGA & 3254 & 19 & 51 & $3.5 n$ & 14.57 & .07 & $4 \cdot 30$ & 11.86 & .08 \\
\hline & KNOXVILLE & 3494 & 17 & 53 & $3.5 n$ & 15.14 & .07 & $4 \cdot 30$ & 12.33 & .08 \\
\hline & MEMPHIS & 3232 & 21 & 40 & 3.50 & 14.00 & .07 & $4 \cdot 30$ & 11.40 & .09 \\
\hline & NASHVILLE & 3578 & 16 & 54 & 3.50 & 15.43 & .06 & $4 \cdot 30$ & 12.56 & .08 \\
\hline
\end{tabular}




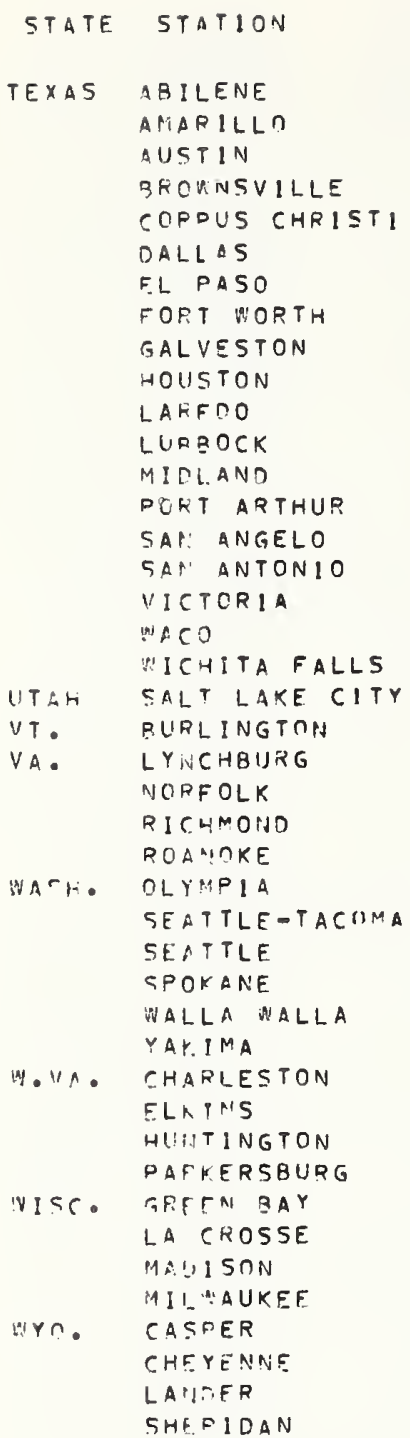

\begin{tabular}{|c|c|c|c|c|c|}
\hline DFGREE & JESIGN & DES I GN & $C E$ & $\| L \backslash N G / F$ & OF \\
\hline DAY & TEMP. & $\Delta T$ & $n / A$ & $\mathbf{R}$ & $u$ \\
\hline 2624 & 21 & 49 & $3.5 \pi$ & 14.07 & .07 \\
\hline 3955 & 12 & 58 & 3.50 & 16.57 & .06 \\
\hline 1711 & 29 & 41 & 3.56 & $11 \cdot 52$ & .09 \\
\hline 600 & 40 & 30 & 3.90 & 7.69 & .13 \\
\hline 914 & 36 & 34 & 3.74 & 9.08 & .11 \\
\hline 2363 & 24 & 46 & $3.5 n$ & 13.14 & .08 \\
\hline 2700 & 25 & 45 & 3.50 & 12.86 & .08 \\
\hline 2435 & 24 & 46 & 3.50 & 13.14 & .08 \\
\hline 1274 & 36 & 34 & 3.65 & 9.33 & .11 \\
\hline 1396 & 32 & 38 & 3.62 & 10.49 & .10 \\
\hline 797 & 36 & 34 & 3.80 & 8.94 & .11 \\
\hline 3578 & 15 & 55 & 3.50 & 15.71 & .06 \\
\hline 2591 & 23 & 47 & 3.50 & 13.43 & .07 \\
\hline 1447 & 33 & 37 & 3.61 & 10.75 & .10 \\
\hline 2235 & 25 & 45 & 3.50 & $12.8 h$ & .08 \\
\hline 1546 & 30 & 40 & 3.59 & 11.14 & .09 \\
\hline 1173 & 32 & 38 & 3.67 & 10.37 & .10 \\
\hline 2039 & 26 & 44 & 3.50 & 12.57 & .08 \\
\hline 2832 & 19 & 51 & 3.50 & 14.57 & .07 \\
\hline 6052 & 9 & 61 & 3.51 & 17.49 & .06 \\
\hline 8269 & -7 & 77 & 3.63 & 21.23 & .05 \\
\hline 4166 & 19 & 51 & 3.50 & 14.57 & .07 \\
\hline 3421 & 23 & 47 & 3.50 & 13.43 & .07 \\
\hline 3865 & 18 & 52 & 3.50 & 14.86 & .07 \\
\hline $415 ?$ & 18 & 52 & $3.5 \pi$ & 14.86 & .07 \\
\hline 5236 & 25 & 45 & 3.50 & 12.86 & .08 \\
\hline 5145 & 74 & $4 h$ & 3.50 & 13.14 & .08 \\
\hline 4424 & 32 & 38 & 3.50 & 10.96 & .09 \\
\hline 6655 & 4 & 66 & 3.57 & 18.51 & .05 \\
\hline 4805 & 16 & 54 & $3.5 n$ & 15.43 & .06 \\
\hline 5941 & 10 & 60 & 3.53 & $17 \cdot 14$ & .06 \\
\hline 4476 & 14 & 56 & 3.50 & $16 \cdot 00$ & .06 \\
\hline 5675 & 5 & 45 & 3.50 & 18.57 & .05 \\
\hline $44+6$ & 14 & 56 & 3.50 & 16.00 & .06 \\
\hline 4754 & 12 & 58 & 3.50 & 16.57 & .06 \\
\hline 8029 & -7 & 77 & 3.40 & $21 \cdot 37$ & .05 \\
\hline 7589 & -8 & 78 & 3.60 & 21.57 & .05 \\
\hline 7863 & -5 & 75 & 3.60 & 20.83 & .05 \\
\hline $7 h 35$ & -2 & 72 & 3.60 & 20.50 & .05 \\
\hline 7410 & -5 & 75 & 3.60 & 20.83 & .05 \\
\hline $73 E 1$ & -2 & 72 & 3.60 & $20 \cdot 90$ & .05 \\
\hline 7970 & -12 & A 2 & 3.65 & 22.79 & .04 \\
\hline 7657 & -7 & 77 & 3.42 & $21 \cdot 39$ & .05 \\
\hline
\end{tabular}

$\begin{array}{lcc} & \text { WALL } & \\ Q 1 A & R & U \\ 4.30 & 11.40 & .09 \\ 4.30 & 13.49 & .07 \\ 4.36 & 9.41 & .11 \\ 4.70 & 6.38 & .16 \\ 4.54 & 7.48 & .13 \\ 4.30 & 10.70 & .09 \\ 4.30 & 10.47 & .10 \\ 4.30 & 10.70 & .09 \\ 4.45 & 7.65 & .13 \\ 4.42 & 8.60 & .12 \\ 4.60 & 7.39 & .14 \\ 4.30 & 12.79 & .08 \\ 4.30 & 10.93 & .09 \\ 4.41 & 8.39 & .12 \\ 4.30 & 11.47 & .10 \\ 4.39 & 9.11 & .11 \\ 4.47 & 8.51 & .12 \\ 4.30 & 10.23 & .10 \\ 4.30 & 11.86 & .08 \\ 4.52 & 13.51 & .07 \\ 5.08 & 15.16 & .07 \\ 4.32 & 11.81 & .08 \\ 4.30 & 10.93 & .09 \\ 4.30 & 12.09 & .08 \\ 4.31 & 12.05 & .08 \\ 4.42 & 10.17 & .10 \\ 4.41 & 10.42 & .10 \\ 4.34 & 8.75 & .11 \\ 4.70 & 14.05 & .07 \\ 4.38 & 12.33 & .08 \\ 4.49 & 13.35 & .07 \\ 4.35 & 12.88 & .08 \\ 4.47 & 14.55 & .07 \\ 4.34 & 12.89 & .08 \\ 4.38 & 13.26 & .08 \\ 5.01 & 15.37 & .07 \\ 4.92 & 15.86 & .06 \\ 4.97 & 15.08 & .07 \\ 4.93 & 14.61 & .07 \\ 4.88 & 15.36 & .07 \\ 4.88 & 14.77 & .07 \\ 4.97 & 16.49 & .06 \\ 4.94 & 15.60 & .06\end{array}$


HEATING, VENTILATING, AND COOLING SYSTEM REQUTREMENTS

HEATING AND COOLING LOADS

\subsection{REQUIREMENT}

Heating and cooling loads shall be determined for the purpose of sizing heating, ventilating and air conditioning, (HVAC) systems and components for efficient utilization of energy.

\section{CRITERIA}

Note: The following items, 6.0.1 through 6.0.2.6, refer only to parameters for use in calculating heating/cooling loads. For equipment and system requirements refer to 6.1 through 6.5 .

6.0.1 Procedures -- Heating and cooling loads shall be determined in accordance with procedures described in the American Society of Heating, Refrigerating, and Air Conditioning Engineers (ASHRAE) Handbook of Fundamentals, Chapters 21 and 22, or procedures for which similarity to ASHRAE procedures can be demonstrated.

6.0.2 Design Parameters -- The following design parameters shall be used in the heating and cooling load determination: (If for special cases other design conditions are selected, heating and cooling load calculations shall be based on the selected conditions.)

6.0.2.1 Outdoor Design Conditions -- Winter and summer outdoor design conditions shall be the 97-1/2 and 2-1/2 percent values, respectively, as given in Chapter 33, Weather Data and Design Conditions, of the ASHRAE Handbook of Fundamentals, 1972.

6.0.2.2 Indoor Design Conditions -- Winter indoor design conditions shall be $70^{\circ} \mathrm{F}$ dry-bulb temperature, with humidification, if provided, to not more than 30\% relative humidity. Summer indoor design conditions shall be $78^{\circ} \mathrm{F}$ dry-bulb temperature, with controlled dehumidification, if provided, to not less than $60 \%$ relative humidity.

\section{COMENTARY}

ASHRAE procedures will be used to determine the adequacy of submitted calculations.

The winter and summer design temperature levels selected for load calculations were chosen to discourage oversizing in the selection of HVAC equipment. 
6.0.2.3 General Ventilation -- For load design of all building types except one- and two-family dwelling units, mechanical ventilation with outside air, for the purpose of meting normal respiratory and odor control needs shall be taken as $5 \mathrm{cfm}$ per person for certain spaces or two air changes for other spaces (see 6.0.2.4 and 6.4.15 for description and criteria).

6.0.2.4 Special Ventilation -- For load design, mechanical ventilation capacity in excess of $5 \mathrm{cfm}$ per person (or two air changes per hour) for the purpose of controlling smoking contaminants, toxic gases, or other contaminants, shall be the actual amount included in the design (see 6.4.15).

\section{EVALUATION}

Examination and evaluation of engineering calculations.

\section{CRITERION}

6.0.2.5 Infiltration -- For load design, infiltration shall be taken as 0.7 air change per hour for one- and two-family dwellings and mobile homes, and 0.5 air change per hour for all other buildings. (s ee 5.0.6.1)

\section{EVALUATION}

See Evaluation for 5.0.6.

\section{CRITERION}

6.0.2.6 Heat Gains -- Internal heat gains shall be included in both heating and cooling loads as appropriate.

\section{EVALUATION}

Examination and evaluation of engineering calculations.

\section{COMMENTARY}

In buildings that have a reasonably steady internal heat release of appreciable magnitude from sources other than the heating system, a computation of this heat release under design conditions should be made for deduction from the total of the computed heat losses.

1/ Wherever the term cfm is used in this document it shall be interpreted as standard cubic feet per minute, unless the immediate context indicates another meaning. 


\section{I REQUIREMENT}

Manufacturers of building equipment defined as energy-significant equipment shall make available to prospective building owners or their representatives the full-load energy-utilization efficiency of such equipment, taken by itself.

\section{CRITERIA}

6.1.1 Full-load Efficiency -- The manufacturer shall make available to prospective purchasers the full-load energy-utilization efficiency ( $\boldsymbol{n}_{\text {f }}$ ) of the specific models to be furnished based on equipment in new condetion. Furnishing of certified test data is deemed to satisfy the requirements of this paragraph.

6.1.2 Rounding-Off -- For the purpose of publication, the energy-utilization efficiency shall be rounded off to the nearest even whole number within a range of two percentage points, e.g., $72 \pm 1$ percent.

\section{COMMENTARY}

The "two percent" criterion effectively allows an actual spread of up to four percent and is an arbitrary value based on engineering judgment.

\section{CRITERIA}

6.1.3 Procedure -- A document shall be furnished to prospective equipment purchasers, upon request, summarizing the methods used to determine the efficiency, or referencing a national consensus voluntary standard test procedure. Publication of such test methods or references by commercial data services or trade organizations is deemed to satisfy the requirements of this paragraph.

6.1.4 Availability of Data -- Where the data specified in 6.1.1 are not immediately available, the manufacturer shall obtain and fumish the data specified in 6.1.1.

6.1.5 Multi-Mode Operation -- Where equipment is designed for multi-mode operation (e.g., multi-speed forced warm air furnace with provision for a cooling coil), full-load energy-utilization efficiency ( $n / f$ ) data shall be provided for each separate mode of operation applicable to the proposed system. 
6.1.6 Full-Load Efficiency Data -- Full-load efficiency data shall be furnished as required under 6.1.1 for each different basic model and subtype numbered energy-significant equipment, except that a typical unit may be selected to represent a group of units, each of which meets all the following criteria:

(1) The function, capacity, and performance characteristics are similar.

(2) The basic model numbers are the same.

(3) The units are all manufactured at the same plant.

(4) The units are sold to the same class of market. Examples of different classes of market include residential, commercial, contractor, retail, etc.

6.1.7 Identify Test Model -- Where full-load energy-utilization efficiency data are published for a group of similar units based on testing or analysis of a typical unit, the actual unit type number tested or analyzed shall be clearly identified.

\subsection{REQUIREMENT}

Energy-significant equipment used in building systems shall be designed for efficient utilization of energy.

\section{CRITERION}

6.2.1 Minimum Full-Load Energy-Utilization Efficiency -- No equipment shall be specified in the design of new buildings which has a full-load energy-utilization efficiency less than the equivalent of that presently specified in nationally recognized voluntary standards.

\section{EVALUATION}

Verification that selected energy-significant equipment meets fullload efficiency requirements of applicable national consensus standards.

\subsection{REQUIREMENT}

Energy-significant equipment which requires periodic routine maintenance actions to maintain efficient operation shall be fumished complete with the necessary maintenance information.

\section{CRITERION}

6.3.1 Required Maintenance Actions -- Required routine maintenance actions shall be clearly stated as required and incorporated on a permanent label affixed to a normally visible, external surface of the equipment. The label may be limited to identifying required actions explained in greater detail in a service manual. The label should identify by title and/or publication number the service manual for that particular model and type of product. 


\subsection{REQUIREMENT}

HVAC systems shall be energy-efficient.

\section{CRITERIA}

6.4.1 System Design Heating/Cooling Capacity -- The heating system(s) for spaces in buildings intended to provide comfort for human occupancy shall be designed with capacity to heat such spaces to $70^{\circ} \mathrm{F}$ at the winter outdoor design temperature (see 6.0.2.1). Similarly, the cooling system(s), if provided, shall be designed with capacity to cool such spaces to $78^{\circ} \mathrm{F}$ at the summer outdoor design temperature (see 6.2.2.1). Heating/cooling systems shall be capable of functioning to accomplish the requirements for the control system in $6.4 .2,6.4 .3,6.4 .4,6.4 .5$ and 6.5 .9 , as applicable.

\section{EVALUATION}

Review of HVAC system plans and specifications. Comparison of system capacity design and building load calculations.

\section{COMMENTARY}

The design criteria of Chapter 6 do not limit the operation of HVAC systems in buildings to the design indoor temperatures specified in the criteria. For special cases such as hospitals or homes for the elderly, requiring higher indoor temperatures, designers may wish to size systems toward the high end of the 120 percent capacity range allowed in 6.4.10.

\section{CRITERIA}

6.4.2 Temperature Control -- Each space heating/cooling system shall be provided with at least one readily adjustable automatic control for the regulation of interior temperature. Each separate zone served by space heating/cooling system shall be equipped with readily adjustable automatic control or conveniently located manual means for temperature regulation as required in 6.4.1,6.4.3, and 6.5.9. Automatic comfort space temperature controls shall be capable of being set to control heating at least from $55^{\circ} \mathrm{F}$ to $70^{\circ} \mathrm{F}$ and to control cooling (if cooling is provided) at least from $78^{\circ} \mathrm{F}$ to $85^{\circ} \mathrm{F}$. For space (or zone) temperatures between $70{ }^{\circ} \mathrm{F}$ and $78^{\circ} \mathrm{F}$ the automatic control system shall be capable of being set such that neither heating or cooling is provided. Combination, separate or multiple heating/cooling thermostats used to control heating and cooling in any one room or zone shall be interlocked or the systems otherwise controlled to avoid simultaneous heating and cooling in any one room or zone except for reheat as allowed in 6.4.7. Means for shutting off the heating or cooling to each zone shall be provided at a convenient location, either within the zone or at an appropriate central building supervisory monitoring station. 
Central supervisory/monitoring systems can be used to meet the requirements of 6.4 .2 .

\section{CRITERIA}

\subsubsection{Multiple-Zone Temperature Control}

6.4.3.1 Single-Family Dwelling Units, Attached or Detached, and Mobile Homes -- At least one automatic temperature control as required in 6.4 .2 shall be provided for each single-family dwelling unit and mobile home. Each separate heating/cooling system in a single-family dwelling unit shall be equipped with an automatic temperature control. Each separate zone in a single-family dwelling unit or mobile home shall be provided with either a readily adjustable automatic temperature control or sufficient conveniently located manually-adjustable devices capable of being adjusted to both partially restrict and shut off the heating or cooling input to the rooms or spaces in that zone. For single-family dwelling units or mobile homes, there shall be at least one separate zone in each cumulative full story height of the complete dwelling unit, excluding non-conditioned basements and garages. Intermediate floor levels in split-level construction are not considered full stories under this criterion.

6.4.3.2 Multi-Family Occupancies -- For multi-family occupancies, each individual living unit shall be considered separately for zoning purposes and shall be provided with automatic space temperature control as required in 6.4.2. For any single living unit, there shall be at least one separate zone in each cumulative full story height of the complete living unit, and each zone shall be provided with controls as required in 6.4.3.1. Intermediate floor levels in split level construction are not considered full stories under this criterion. Spaces other than living units in multi-family buildings shall be treated as in 6.4.3.3.

6.4.3.3 Other Buildings -- For other buildings, each space or group of spaces to be conditioned for comfort and having different demands for heating or cooling (because of varying solar loads, changing occupancies, or other internal heat gains) shall be considered as a separate zone, and shall be provided with automatic space temperature control as required in 6.4.2. Each floor shall be considered as at least one zone. For buildings greater than $2000 \mathrm{ft}^{2}$ of floor area per story, at least each cumulative $2000 \mathrm{ft}^{2}$ of floor area or fraction thereof of conditioned space(s) on each floor adjacent to each major orientation of exterior exposure shall be considered as a separate zone and shall be provided with automatic space temperature control as required in 6.4.2. At least each cumulative $3000 \mathrm{ft}^{2}$ of floor area or fraction thereof of conditioned space(s) on each floor having no exterior exposure shall be considered as a separate zone and shall be provided with automatic space temperature control as required in 6.4 .2 . 
Review of control systems plans and specifications.

\section{COMMEITTARY}

Areas or spaces within a building having different and varying demands for heating and cooling (called zones) each need a means for controlling its temperature to prevent overheating (or overcooling) which could be caused by having the system control in another space. In addition, large open spaces require multiple zoning to provide ability to operate the heating and cooling in only those areas being utilized. Multiple zone control can be accomplished by modulating or varying the heating or cooling effect being delivered to each zone or by using separate systems for each zone. The $2000 \mathrm{ft}^{2}$ of floor area adjacent to an exterior exposure would accommodate, for example, 13 offices $10 \mathrm{ft}$ by $15 \mathrm{ft}$ or equivalent spaces.

\section{CRITHRIA}

6.4.4 System Design for Humidity Control -- This document does not require that heating/cooling systems be designed for or equipped with controls for maintaining selected relative humidities in spaces or zones to provide comfort for human occupancy.

If the heating system is equipped with means for adding moisture to maintain selected relative humidities in spaces or zones during heating operation, the capacity of the humidifying function shall be designed to produce relative humidities not higher than 30 percent at winter design conditions, and the system shall be equipped with automatic humidity control(s) capable of being set to control indoor relative humidity to 30 percent or lower.

If automatic control of indoor space humidity is provided as a part of the cooling system design, the minimum indoor design relative humidity shall be 60 percent. Means for raising humidity during cooling operation is not required. The automatic humidity control system shall be capable of being set such that cooling apparatus shall not operate for the sole purpose of lowering the space (or zone) relative humidity below 60 percent. See 6.4.7 Reheat for limitations on use of new and recovered energy. The control system shall be capable of being set such that neither the humidifying or dehumidifying functions of the HVAC system shall operate for the sole purpose of space (or zone) humidity control in the range from 30 to 60 percent relative humidity. 
6.4.5 Control Set-Back -- All heating and cooling systems shall be equipped with manually adjustable automatic timing or other devices capable of reducing the energy for heating and cooling during periods of non-use or alternate uses of the building spaces or zones served by such systems. Buildings designed for continuous manual or automatic supervisory control are considered to meet this criterion. The change in setting required to reduce the heating or cooling effect (set-back) shall not cause energy to be expended to produce the set-back conditions.

\section{COMMENTARY}

"Set-back" as used in 6.4.5 means the ability to change the automatic temperature control setting to a value which will reduce the heating or cooling produced during periods of reduced needs. Night set-back

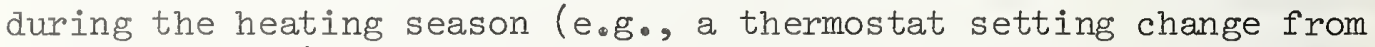
$70^{\circ} \mathrm{F}$ to $\left.55^{\circ} \mathrm{F}\right)$, should not cause the cooling system to operate to cool the building to the set-back temperature of $55^{\circ} \mathrm{F}$. Similarly, under cooling conditions a set-back of the thermostat should not cause the heating system to raise the indoor temperature.

6.4.6 Simultaneous Heating/Cooling - HVAC systems serving one or more rooms or zones in a building shall be so arranged that no one room or zone can be heated and cooled simultaneously by the HVAC system except for reheat as permitted in 6.4.7.

\section{COMMEIVTARY}

Separate heating and cooling systems should be interlocked or otherwise controlled to prevent simultaneous operation for one room or zone. See Criterion 6.4.7 for limitation on reheat.

\section{CRITERIA}

6.4.7 Reheat - Energy for reheat to accomplish either humidity or temperature control in any HVAC system shall be limited to the following conditions:

a. The total amount of new energy for either humidity or temperature control used for reheat shall not exceed 5 percent of the cooling system design capacity.

b. Recovered energy shall not be used for reheat for control of temperature in excess of 10 percent of the cooling system design capacity.

c. Recovered energy may be used as needed for humidity control in accordance with 6.4 .4 . 


\section{EVALUATION}

Review of HVAC system plans and specification.

\section{COMMENTARY}

Use of excessive amount of either new or recovered energy for reheat purposes for temperature control only (as opposed to reheat for required humidity control purposes) is wasteful, and can be eliminated by suitable distribution design. Use of small amounts of energy for reheat for either temperature or humidity control in isolated areas may be more economical than providing a separate system.

\section{CRITERIA}

6.4.8 Energy Recovery - Each air exhaust-makeup system having more than 4000 cfm capacity which imposes non-beneficial heat gains or losses on space conditioning systems shall employ energy recovery equipment if either the winter or summer outdoor design temperature is $15^{\circ} \mathrm{F}$ or more lower or higher, respectively, than the indoor design temperature. This equipment shall be capable of recovery of at least 50 percent of the potential heating or cooling effect in the exhaust air, whenever the temperature difference between the exhaust air and makeup air is $10{ }^{\circ} \mathrm{F}$ or greater. This requirement does not include contaminant-laden process exhaust systems such as kitchen range hoods. Energy recovery systems shall be capable of intermittent operation to accomodate beneficial outdoor air conditions and the exhaust-makeup system shall be designed to operate in accord with the design requirements whether the energy recovery system is functioning or not.

\section{COMMENTARY}

Possible proximity of the air intakes and outlets can create a need in design to assure the effective separation of the two air streams.

\section{CRITERIA}

6.4.9 Cooling with Outdoor Air -- Each HVAC system with cooling capacity greater than 120,000 Btu/hr in buildings not equipped with internal/external zone heat recovery equipment shall be designed to use outdoor air for cooling whenever cooling is needed at an outdoor temperature of $65^{\circ} \mathrm{F}$ or lower, and when the enthalpy of the outdoor air is lower than that of the indoor air.

6.4.10 System Sizing - HVAC systems and subsystems for a building shall be selected such that the aggregate capacity at design conditions shall not be more than 120 percent of the design heating, cooling, humidifying, and dehumidifying loads, standby equipment not included. The cooling equipment in heat pumps may exceed the 120 percent requirement. The heating equipment in heat pumps shall not exceed the 120 percent requirement. 
Examination of HVAC system plans and specifications. Comparison of load requirements and system capacity data.

\section{COMMENTARY}

The 20-percent over-design in system capacities indicated by this criterion is an allowance for additional capacity that may be needed following night-time change in thermostat setting and weather conditions above or below design levels. Generally, excessive oversizing of system capacities results in less efficient operation. Standby equipment as used in 6.4.10 refers to equipment designed and irtended for use when primary equipment is off-line due to maintenance or repair.

In order to minimize inefficiencies due to oversized system designs, it shall be a design objective that the HVAC system be sized so as to be capacity limited at the stated design conditions. At outdoor temperature extremes, the conditioned space temperature may drift from the normal control point, and at or near extreme conditions, the heating/cooling system may recover slowly after temperature control setting change.

\section{CRITERIA}

6.4.11 Special Zones -- Individual zones in large buildings or groups of buildings served by a central HVAC system which (1) must maintain zone operation when main building loads are minimal or are shut down, or (2) comprise unusual heating or cooling loads different from main building loads, shall be served by the central system only if the central system is designed to accommodate efficiently this special zone conditioning by such means as efficient capacity reduction of refrigerating units and boilers, adequate distribution zoning and zoning control, and use of multiple subsystem elements (compressors, heaters, fans and pumps, etc); otherwise, these special zones shall be equipped with separate space conditioning systems. For cumulative special zone loads equal to one-half or more of the total system design load, the system shall be energy efficient to at least 85 percent of the full-load efficiency (see 6.4.13).

\section{EVALUATION}

Examination of plans and specifications with particular regard to system design related to special zones and capacity reduction. Comparison of computed load requirements with selected equipment performance data.

\section{CRITERION}

6.4.12 System Performance Instrumentation - Central heating and cooling systems in buildings of more than $10,000 \mathrm{ft}^{2}$ of floor area shall be equipped with instruments or other indicating devices from which a deter- 
mination can be made of need for adjustment or service to maintain energyefficient operation.

EVALUATION

Examination of plans and specifications

COMMENTARY

The indicating devices envisioned by this criterion include but are not limited to pressure gages, water level devices on boilers, flow meters for various critical fluids, thermometers for flue and other temperatures, etc.

\section{CRITERIA}

6.4.13 Half-Load Efficiency -- HVAC systems operating at $1 / 2$ rated load at design conditions shall have an efficiency not less than 85 percent of the system efficiency at full load operation at design conditions. HVAC systems shall be designed and equipped with means for operating at highest available system efficiencies as loads are reduced.

\section{EVALUATION}

Certification by designer or manufacturer of HVAC systems or major subsystems.

\section{CRITERION}

6.4.14 Interzone Heat Recovery -- Each HVAC system with a cooling capacity greater than $240,000 \mathrm{Btu} / \mathrm{hr}$ and which simultaneously provides heating to one or more zones and cooling to one or more different zones shall be designed to recover heat rejected by the cooling unit whenever the heat rejected is equal to at least 50 percent of the heat required by that system at that time. In such systems, new energy shall be used only for supplemental heating needed in excess of the recoverable heat.

\section{EVALUATION}

Comparison of design heating/cooling loads and system design capacities. Examination of plans and specifications.

\section{CRITERIA}

6.4.15 Ventilation by Mechanical Means -- Outdoor air for mechanical ventilation designed as a part of an HVAC system, for the purpose of meeting normal respiratory and odor control needs in conditioned offices, stores, meeting rooms, auditoriums, schools, living units and similar spaces, shall be limited to $5 \mathrm{cfm}$ per person. Outdoor air for mechanical ventilation of conditioned corridors, lobbies, stairways, halls, laundries, storage areas and similar public spaces in multi-family and other buildings 
shall be limited to 2 air changes per hour for normal respiratory and odor control needs. Special ventilating capacity in excess of $5 \mathrm{cfm}$ per person (or 2 air changes per hour) for the purpose of controlling smoking contaminants, toxic gases, or other contaminants in the two classes of conditioned spaces listed above shall be equipped with volume or cyclic controls capable of remote adjustment if necessary, so that the ventilation rate can be readily adjusted to the amount needed for actual occupancy conditions and shut of when not required.

These ventilation-limiting requirements do not apply to intermittentlyoperated locally-controlled ventilation units such as kitchen vent fans, range hoods, bathroom fans, or to attic ventilating fans, or to the sizing of ventilation systems using outdoor air for temperature control in the occupied spaces, or to ventilation of non-conditioned spaces.

ASHRAE Standard 62-73, Standards for Natural and Mechanical Ventilation, recommends special ventilation rates.

All mechanical ventilation systems shall be equipped with conveniently located means for volume reduction or shut-off when ventilation is not required.

\section{COMMENTARY}

If outdoor air ventilation rates in conditioned spaces greater than shown are desired, consideration can be given to use of heat recovery apparatus to minimize adverse loads on the space conditioning system (see 6.4.8.) The criteria values for outdoor ventilation rates were were selected to save energy and yet provide needed ventilation. For unusual non-toxic odor control, consideration should be given to odor removal devices in lieu of increased ventilation rates. 


\subsection{REQUIREMENT}

Components of HVAC systems shall be energy-efficient.

\section{CRITERIA}

6.5.1 Fluid Transport Thermal Losses/Gains -- See 6.5.2 and 6.5.3 for minimum insulation requirements. In addition, the non-beneficial heat gain/loss to/from each separate subsystem of piping and ductwork transporting liquids, vapors, or gases used for space heating/cooling shall be limited to 3 percent of the heating/cooling thermal transfer design capacity for the fluid in that subsystem. In any case, the aggregate total non-beneficial gain/loss shall not exceed 5 percent of the total system design capacity including all piping, ductwork, and unit casings, etc., forming the entire heating/cooling system within the building. A subsystem is a section of the entire system which contains only one type of transfer fluid, such as hot or chilled water, steam, refrigerant, brine, air, etc. Non-beneficial heat gain/loss means heat transfer into/ from non-conditioned space(s) or heat transfer into/from conditioned space(s) in excess of or opposition to the energy requirement of that space.

\section{EVALUATION}

Examination of plans and specifications. Review of heat loss/gain calculation.

\section{COMMENTARY}

A simple heating/cooling system may have only air ducts to consider under 6.5.1. More complex systems may have chilled water lines, steam or hot water lines, primary and secondary air ducts, etc, for which the several subsystem losses or gains must be determined for comparison with the design heating/cooling loads served by that subsystem, and the total losses/gains compared with the total system design capacity.

\section{CRITERIA}

6.5.2 Thermal Resistance of Ducts, Plenums, and Other Enclosures for Air Systems-Heating -- Air ducts and other surfaces installed in nonheated spaces (e.g., attics, garages, crawl spaces, etc.) shall be thermally insulated to provide a surface-to-surface thermal resistance of not less than $\mathrm{R}=\Delta \mathrm{T} / 20 \mathrm{hr} \mathrm{ft}^{2}{ }^{\circ} \mathrm{F} / \mathrm{Btu}$, where $\Delta \mathrm{T}$ is the maximum temperature difference between the air in the duct or enclosure and the surrounding air, or shall be insulated to a value of $R=4 \mathrm{hr} f t{ }^{\circ} \mathrm{F} / \mathrm{Btu}$, whichever is greater.

\section{COMMENTARY}

Examination and evaluation of engineering calculations. 
6.5.3 Thermal Resistance and Condensation Control, Ducts, Pipes and Surfaces - Cooling - For air ducts and surfaces installed in non-cooled spaces, the thermal resistance criteria of 6.5 .2 shall apply. Additionally, all ducts, pipes, and cool surfaces shall be insulated sufficiently to prevent surface condensation under operating conditions. The insulation shall be protected by a vapor barrier, maximum permeance 0.1 perm, and all joints shall be sealed against vapor penetration.

\section{EVALUATION}

Engineering examination and evaluation of the design and design calculations. ASTM recommended practice E241-68 for general design information, ASTM Test Methods E96-66 (Procedures A, dry cup) for materials such as paper, plastic films and other sheet materials that are less than 1/8-inch thick shall be used for the purpose of evaluation.

\section{COMMENTARY}

Access doors and similar removable panels in duct system enclosures should be tight fitting (see 6.5.4) and insulation at joints of such doors should be adequately sealed to minimize moisture entering the insulation.

6.5.4 Duct Air Leakage -- The entire duct system for HVAC systems shall not leak more than 5 percent of the design air flow at design duct pressure.

\section{EVALUATION}

Review of duct plans and specifications. Tests patterned after SMACNA procedures.

\section{COMMENTARY}

Medium and high pressure ducts are customarily designed for duct leakage of 1 percent or less. Duct air leakage in any system defeats the intended function of the system. Leakage in non-conditioned areas is a total loss and in addition, leakage even in conditioned areas may prevent adequate delivery to intended locations.

\section{CRITERION}

6.5.5 Automatic Ignition -- Automatically controlled gaseous or liquid fuel-fired devices providing space heating shall be equipped with means for fuel ignition which operates only when the burner is required to operate. Automatic ignition devices shall conform to life safety standards, such as:

ANSI Z21.20 Automatic Burner Ignition and Safety Shut-off Devices ANSI Z226.1 Primary Safety Controls for Gas and Oil Fired Appliances 
Certification or listing of selected ignition devices.

6.5.6 Off-Cycle Air Flow Heat Loss -- Combustion heating equipment with greater than 250,000 Btu/hr input shall be equipped with devices to minimize air flow through the combustion chamber during burner off-cycles. These devices shall be safety listed. All vented fireplaces shall be equipped with tight closing dampers or other comparable draft closures.

\section{EVALUATION}

Examination of proposed heating system design. Certification or listing of stack or combustion chamber off-cycle air flow control devices.

\subsubsection{Cooling Efficiency - Electric Motor-Driven Cooling Systems --} Electric motor-driven cooling systems rated at standard rating conditions as listed in ARI 210-67 and including all system fan and pump motors shall have a ratio of net system cooling capacity to energy input of not less than 8.0 Btuh/watt for cooling capacities of 60,000 Btuh or greater and $7.0 \mathrm{Btuh} /$ watt for cooling capacities less than 60,000 Btuh. All cooling systems with rated output greater than 240,000 Btuh shall have a ratio of system capacity to energy input of not less than 8.5 Btuh/watt.

\section{EVALUATION}

Certification of selected equipment.

\section{COMMENTARY}

The term "Btuh/watt" is used here as a means of expressing efficiency of electric motor-driven cooling equipment because of its adoption by the industry. As used it means (Btu/hr)/watt, where "Btu/hr" is the net cooling capacity of the complete system at its defined rating condition, and "watt" is the electrical input rate to the complete system at the same conditions. The values of "Btuh/watt" do not include correction for electric power generation, transmission and distribution efficiency for either the compressor motor or for other auxiliary electrically-operated elements. If electric power generation transmission and distribution requires $12000 \mathrm{Btu} / \mathrm{kwh}$, the values of $7.0,8.0$ and 8.5 "Btuh/watt" indicate net cooling capacity-toenergy source input COP values of $0.58,0.67$, and 0.71 respectively. Net cooling as used here includes both sensible and latent heat.

\section{CRITERIA}

6.5.8 Cooling Efficiency - Heat-0perated Cooling Systems - - Heat-operated cooling systems with a COP of less than 0.5 at standard rating conditions including all system auxiliaries, and fan and pump motors (determined in accordance with Appendix 2 of Chapter 6) shall not be used to provide more than 25 percent of the design cooling requirement unless recovered energy, solar energy or energy derived from waste processes is used as the principal energy source. 
Comparison of selected system performance data and efficiency of energy source. Review of calculated overall system COP.

\section{COMMENTARY}

Pending availability of standard industry rating procedures for determining the overall system net cooling capacity-to-system energy input COP, a procedure is given in Appendix 2 of Chapter 6. Net cooling as used here includes both sensible and latent heat. Using the procedure in Appendix 2, as an example, a heat-operated cooling system with a unit $\mathrm{COP}$ of 1.0 or more, energized by a steam supply of at least 70 percent efficiency, and with system control, condenser and cooling circuit power inputs equal to not more than 20 percent of the chiller capacity would. satisfy the requirement of 6.5 .8 for use of "new" energy. 
6.5.9 Flectric Resistance Heating-- This document does not limit the use of electric resistance heating systems as the principal means of comfort space heating in the following buildings:

-all buildings in geographic areas having 2000 heating degreedays or less annually

-buildings utilizing electric energy for heating which is generated either by solar or wind-produced energy, by combustion of waste materials, by recovery of waste energy, or by a total energy system conforming to the definition in Chapter 3.

-buildings smaller than $500 \mathrm{ft}^{2}$ of floor area.

-mobile homes

For all other buildings the use of electric resistance heating as the principal means for comfort space heating shall be limited to the following conditions:

1. Buildings shall have a design heat loss at least 15 percent lower than permitted in Chapter 5

2. In addition to the minimum temperature control requirements for any heating system in 6.4 .2 and 6.4 .3 , (a) one or more readily-adjustable automatic temperature controls as required in 6.4.2 shall be provided for control of each zone described in $6.4 .3 .1,6.4 .3 .2$, or 6.4 .3 .3 as applicable, and (b) at least one readily-adjustable automatic temperature control as required in 6.4 .2 , or sufficient readily-adjustable manual devices capable of being set to both partially restrict and shut off. Such heating input controls shall be provided (I) in each separate heated room or other enclosed spaces of more than $100 \mathrm{ft}^{2}$ of floor area which has one or more exterior walls, and (2) in ęach heated room or other enclosed space of more than $500 \mathrm{ft}^{2}$ of floor area, having no exterior walls. If in response to $2(b)$, each separate heated space in a zone is provided with automatic control, $2(a)$ is satisfied, and a separate zone control is not required.

EVALUATION

Examination of plans and specification.

COMMENTARY

Electricity is a highly refined source of heat which, in typical generating plants, has already lost about two thirds of the available potential energy of the fuel used in the generating process by the time it reaches the electric heating load in a building. Because of this loss in energy potential, logic indicates that a highly refined form of energy should be applied more carefully at the point of use. 6.5 .9 (2) is intended to eliminate unnecessary input of this highly refined heat energy when solar or other heat gains reduce the demand for heating. 
Central electric resistance warm air or hydronic systems can satisfy the automatic zone temperature control requirements by using individual automatically-controlled heat outlets or fixtures in all the spaces in a zone.

The rationale for not recommending a differential reduction of heat loss even greater than 15 percent for electric resistance heating is based on the following:

(1) The thermal resistance criteria in Chapter 5 may already be equal to or greater than previously existing guidelines for electrically heated buildings, and the technical/esthetic feasibility of requiring thermal resistance differential requirements much greater than 15 percent is in doubt for some climatic regions.

(2) The criteria of 6.5 .9 do not limit using forms of electrically energized heating other than the resistance type. In many applications, an electric driven heat pump system uses electricity more efficiently than does electric resistance heat, and its use should be encouraged.

(3) Depending upon the application, anywhere from one-fifth to one-half of the source potential energy is lost in direct heat conversion systems using fossil fuels. The 15 percent criteria brings the efficiency of electric resistance heat within the same general area as that of the low end of the range for fossil fuels.

The exception made for mobile homes is based on two factors:

(1) Dimensional space and weight limitations due to transportation requirements.

(2) Mobile homes typically use central forced warm air heating systems because this type of system is adaptable to various fuels used at different installation sites. The specific site (and fuel) is unknown at the time of manufacture. Under these conditions, it is usually unfeasible for the mobile home manufacturer to use those forms of electric resistance heating that readily lend themselves to zone control.

\section{CRITERIA}

6.5.10 Heat Pumps -- Electric motor driven vapor compression heat pumps with supplemental electric resistance heat shall be sized to provide by compression at least 60 percent of the calculated annual heating requirement for the building or space served. A control shall be provided which can be set to prevent use of supplemental electrical resistance heat at outdoor temperatures above 32 \% F. Air-source heat pumps shall have seasonal performance factors (S.P.F.), including supplemental heating of: 
Design Temperature, ${ }^{\circ} \mathrm{F}$

$\begin{aligned} &> 35 \\ & 20 \text { to } 35 \\ & 0 \text { to } 20 \\ &-20 \text { to } 0\end{aligned}$

S.P.F.

$>2.25$

$>? .0$

$>1.5$

$>1.25$

$$
S \cdot P \cdot F \cdot=\frac{X}{Y+Z}
$$

where:

$\mathrm{X}=$ heat delivered to space during heating season, $\mathrm{kWh}$.

$Y=$ energy to motors during the heating season, kWh.

$\mathrm{Z}=$ supplemental heat during heating season, $\mathrm{kWh}$.

\section{EVALUATION}

Comparison of calculated annual heat loss and certified seasonal performance factors. Review of design calculations, plans, and specification.

\section{COMMENTARY}

Heat pump seasonal performance factors (S.P.F.) can be computed as shown below from building heat loss, heat pump performance characteristics, including supplemental heat, and seasonal heating hours below $65^{\circ} \mathrm{F}$ for outdoor air temperature increments of 5 F. Engineering Weather Data AFM 88-8, Chapter 6, lists heating season hours at $5{ }^{\circ} \mathrm{F}$ intervals for many locations in the U. S. This information is also available from the U. S. Weather Bureau. Using data such as is furnished by several heat pump manufacturers, the analytical procedure may consist of a summation by $5^{\circ} \mathrm{F}$ increments of the building heat loss, the varying steady-state heat pump performance characteristics and hours of operation, and hours of required supplementary heat operation. A computerized dynamic analysis is not necessarily required. The S.P.F. shall take into account all system energy requirements, including defrost operation and supplementary heat. Specifically, the items, X, Y, and Z necessary for determining S.P.F. can be calculated in tabular form from the following information:

A - Outdoor temperature range, ${ }^{\circ} \mathrm{F}$ outdoor air temperature increments of $5^{\circ} \mathrm{F}$ below $65^{\circ} \mathrm{F}$

$B$ - Seasonal heating hours for $A$, hrs

C - Average building heat loss for A, Btu/hr

D - Heat pump capacity for A, Btu/hr

$E$ - Percent running time for heat pump, \% If $C>D, E=100$; otherwise $E=100 \times \mathrm{C} / \mathrm{D}$

$F$ - Rate of energy input to heat pump for $A, k W$

G - Energy input to heat pump, kWh $\mathrm{G}=\mathrm{B} \times \mathrm{E} \times \mathrm{F} / \mathrm{I} 00$

H - Energy input to building from electric resistance heaters, kWh. If $\mathrm{C}<\mathrm{D}, \mathrm{H}=0$; otherwise $\mathrm{H}=\mathrm{B} \times(\mathrm{C}-\mathrm{D}) / 3412$.

$J$ - Energy input to building from heat pump, $\mathrm{kWh}$. $J=E \times D / 341200$ 
Summing over the outdoor air temperature increments gives

$Y=\Sigma G$

$\mathrm{Z}=\Sigma \mathrm{H}$

$X=\Sigma J+\sum H$

for substitution in the definition for S.P.F.

The purpose of the control to prevent use of supplemental electric resistance at outdoor temperature above $32^{\circ} \mathrm{F}$ is to eliminate unnecessary use of the less efficient supplemental heating at times when the heat pump can supply adequate heating. It also assures that failure of the heat pump will be detected if it occurs. The temperature of $32{ }^{\circ} \mathrm{F}$ will permit use of supplemental heating to prevent freezing damage in the event of heat pump failure. The $32{ }^{\circ} \mathrm{F}$ temperature is not intended as a balance point requirement for determining heat pump size. 
APPENDIX 1

LISTING OF STANDARDS FOR HVAC

EQUIPMENT WHICH INCLUDE EFFICIENCY

ANSI Z21.11 - 1971

Gas-Fired Room Heaters

Volume I (Z21.11.I) Vented Room Heaters - Efficiency 70 percent based on total volume of gas.

Volume II ( 221.11 .2$)$ Unvented Room Heaters - 1971 -

Performance - No number for efficiency.

ANSI Z21.13 - 1972

Gas-Fired Steam and Hot Water Boilers

Shall have a thermal efficiency of 75 percent based on total heating value of the fuel.

ANSI $221.34-1971$

Gas-Fired Duct Furnaces

Thermal efficiency of 75 percent based on total heating value of

fuel.

ANSI Z21.43 - 1968

Unvented Gas-Fired Infrared Radiant Heaters

Radiant efficiency of at least 35 percent.

ANSI $221.44-1971$

Gas-Fired Gravity and Fan Type Sealed Combustion System Wall Furnaces

Gravity type - Efficiency 70 percent based on total heating value of fuel.

Fan type - Efficiency 75 percent based on total heating value of fuel.

ANSI 221.47 -

Gas-Fired Gravity and Forced Air Central Furnaces

Thermal efficiency gravity 70 percent based on total heat value of gas.

ANSI Z21.48 - $1976(48 a-1968$

Gas-Fired Gravity and Fan Type Floor Furnaces

Gravity type - Efficiency 65 percent based on total heating value of fuel.

Fan type - Efficiency 70 percent based on total heating value of fuel. 
ANSI Z21. $51-1971$

Vented Gas-Fired Infrared Radiant Heaters

Efficiency - shall have a radiant efficiency of at least 35 percent.

ANSI Z21.52 - 1971

Gas-Fired Single Firebox Boilers

Steam and hot water boilers shall have efficiency 75 percent based on

total heating value of fuel.

ANSI Z21.53 - 1967

Gas-Fired Heavy-Duty Forced Air Heaters

Shall have thermal efficiency of not less than 75 percent based on total heating value of fuel.

ANSI Z91.1 - 1972

Oil-Powered Central Furnaces

Performance - Output capacity in Btu/hr 0.75 times input. 
At the present no standard industry rating conditions have been promulgated for heat-operated cooling units. Unit performance shall be based on the following rating conditions which shall be considered "standard" for this document:

Leaving chilled-water temperature
Chilled water $\Delta \mathrm{T}$ across chiller
Temperature of condensing water
entering unit
Condenser water flow

Steam inlet pressure (single efiect)

Entering hot water temperature (single effect)

Hot water $\Delta T$ across unit (single effect)

Steam inlet pressure (double effect)

Entering hot water temperature (double effect)

Hot water $\Delta T$ across unit (double effect)

Outdoor air Temperature, DB

Outdoor air temperature, WB

Indoor air temperature, DB

Indoor air temperature, WB $44^{\circ} \mathrm{F}$

$10^{\circ} \mathrm{F}$

$85^{\circ} \mathrm{F}$

$3.6 \mathrm{gpm} / \mathrm{ton}$ of condenser load

12 psig

$270^{\circ} \mathrm{F}$

$40^{\circ} \mathrm{F}$

123 psig or 144 psig

$370^{\circ} \mathrm{F}$

$40^{\circ} \mathrm{F}$

$95^{\circ} \mathrm{F}$

$75^{\circ} \mathrm{F}$

$80^{\circ} \mathrm{F}$

$67^{\circ} \mathrm{F}$

The COP of the proposed system based on the above conditions shall be determined by:

$$
\operatorname{COP}=\frac{\text { net refrigerating effect }}{\text { rate of total energy input }}
$$

where the net refrigerating effect is the rate of heat removal from the chilled water passing through the chiller minus the power input to all cooling circuit fans and pumps, and the rate of total energy input is the sum of all power used by the unit accessories, the condenser water cooling process pumps, fans, etc plus the product of the rate of fuel consumption and the higher heating value of the fuel used as the source of heat energy to the absorption unit itself, all expressed in consistent units. For the COP determination, energy input to all auxiliary devices (other than the absorption unit) such as controls, fan and pump motors shall be based on the power input to the various devices. Where steam or hot water is used as the unit energy source, the rate of energy input to the unit shall be based on the fuel used to produce the steam or hot water. If the unit is direct-fired, the rate of energy input to the unit shall be the product of the rate of fuel consumption and the higher heating value of the fuel. 


\subsection{REQUIREMENT}

Hot water for domestic and sanitary purposes shall be generated and delivered in a manner conducive to saving energy.

\section{CRITERIA}

7.0.1 Insulation -- All service hot water storage tanks and pipes containing heated water shall be insulated. Minimum insulation. values for storage tanks and piping shall be $\mathrm{R}=6$ and $\mathrm{R}=4$, respectively.

\section{EVALUATION}

Review of system plans and specifications.

\section{COMMENTARY}

The heat loss of domestic hot water systems due to intermittent use and from the piping or recirculating systems is significant, and adds to the cooling loads in spaces requiring cooling.

\section{CRITERIA}

7.0.2 Pump Operation -- Circulating service hot water systems shall be so arranged that the circulating pump(s) can be turned off when the portion of the building served by that pump is not in use.

7.0.3 Combination Service Water Heating/Space Heating Boilers -- Service water heating equipment shall not be dependent on year-round operation of boilers otherwise required only for winter space heating if the boiler capacity is more than 120 percent of the design service water heating demand load.

\section{COMMENTARY}

A boiler may operate at low efficiencies during summer months if used to provide domestic hot water under conditions where the water heating load is small in relation to the space heating load.

\section{CRITERIA}

7.0.4 Temperature Control -- Service water heating systems shall be equipped with automatic temperature controls capable of adjustment to the lowest acceptable temperature setting for the intended use. These settings shall be $120^{\circ} \mathrm{F}$ or less for domestic dishwashing/clothes washing machines and $180^{\circ} \mathrm{F}$ or less for commercial application. 
7.0.5 Electric Resistance Service Water Heating - For systems serving more than four single-family living units, service water heaters shall not use electric resistance heating unless 1) electricity is used as the principal means for heating the building, or 2) the electric power used for water heating is generated either by solar or wind-produced energy, by combustion of waste materials, by recovery of waste energy, or by a total energy system conforming to the definition in Chapter 3.

\section{CRITERIA}

\subsubsection{Fossil-Fuel-Fired Service Water Heating - Fossil-fuel-fired} service water heaters with input heating capacities greater than $250,000 \mathrm{Btu} / \mathrm{hr}$ shall be equipped with automatic ignition (which operates only when the burner is required to operate) and of $f-c y c l e$ air-flow heat-loss control devices. Each of these devices shall be safety listed. 
LISTING OF STANDARDS FOR SERVICE WATER HEATING EQUIPMENT WHICH INCLUDE EFFICIENCY

\section{ANSI A21.10 - 1971}

Gas Water Heaters

Volume 1 (Z21.10.1) Automatic Storage Type Water Heaters With Inputs Less Than 75,000 Btu/hr - Performance Test.

Volume II (Z21.10.2) Side-Arm Type Water Heaters

Volume III (Z21.10.3) Circulating Tank, Instantaneous and Large Automatic Storage Type Water Heaters - Thermal efficiency of not less than 70 percent based on the gas input. 


\section{ELECTRICAL DISTRIBUTION AND \\ POWER FACTOR REQUIREMENTS}

\subsection{REQUTREMENTT}

The electrical distribution system in a building shall be designed for efficient distribution of energy from the service entrance to the outlets, and shall not impose inefficient conditions on the electric utility distribution system.

\section{CRITERIA}

8.0.1 Power Factor -- In each building having one or more electric services aggregating 600 amperes or more, a graphic (recording) power factor meter shall be provided during the first year of operation and the power factor shall be continuously monitored. If the power factor falls below 0.9 lagging for periods accumulating one-half hour in any 24-hour period, power factor corrective devices shall be installed to raise the power factor to 0.9 or higher. If after the initial power factor correction additional reactive loading is introduced in the building, the power factor shall be continuously monitored again for a period of one year, and additional correction performed to meet the above criterion.

It is recommended that the electric utility be responsible for installation, upkeep, and removal of the graphic power factor meter.

\section{COMMENTARY}

Low power factor causes greater losses in transmission and distribution of electricity. Typically, most commercial and public buildings during the non-air conditioning season have a power factor of at least 0.9 , unless the power factor is reduced by reactive loads such as fluorescent lighting units and elevator motors. Where the loads of the building are such that they create a power factor at the building service of less than 0.9 lagging, capacitance corrective devices can be placed at those loads or at the feeders to those loads. Power factor correction at the generating plant does not prevent the losses associated with transmission of the reactive power component through the distribution network.

\section{CRITERION}

8.0.2 Power Factor Correction for Cooling Equipment -- In a building which is wholly or partly cooled with one or more units aggregating 120,000 Btuh or higher, power factor correction devices shall be provided so that the power factor of the entire air conditioning system, including fans, shall be not less than 0.9 lagging at any load condition.

EVALUATION

The designer shall indicate on the plans a calculation of the lagging kilovars of the air conditioning equipment, the corrective leading kilovars provided, and the resultant power factor of not less than 0.9 . 
Power factor improvement, especially during periods of peak summer load, will reduce peak demand in the public utility peak power output and reduce losses in the transmission and distribution system.

\section{CRITERIA}

8.0.3 Service Voltage -- In each building having one or more electric services aggregating 600 amperes or more, the service voltage shall be nominally 277/480 volts, 3-phase, 4-wire, or 480 volts, 3-phase, 3-wire. In such buildings, the portion of the lighting system defined as "efficient" under 9.1.1 shall be served directly at 277 volts or higher, and transformers shall be used only to serve appliance loads, or other loads not designed to operate at 277 volts. Manufacturers shall make available to prospective building owners or their representatives data on the full-load efficiency of such transformers.

\section{EVALUATION}

Verify by inspection of the plans submitted for approval. COMMENTARY

Higher service voltages mean lower losses in the distribution of electricity.

\section{CRITERION}

8.0.4 Voltage Drop -- In any building, the combined voltage drop in feeders and branch circuits shall not exceed 3 percent of the service voltage.

\section{EVALUATION}

The plans submitted for approval shall have a tabulation of feeders and branch circuit voltage drops. The voltage drop summation of the longest and the most heavily loaded feeder and branch circuits should not be more than 3 percent of the service voltage.

COMMENTARY

Articles 210-6(d) and 215-3 of the National Electric Code define the size of the feeders and branch circuits so that the total voltage drop does not exceed 5 percent of the service voltage. The energy lost in the distribution system principally goes into $I^{2} \mathrm{R}$ losses in the feeders, branch circuits, transformers and switch gear, and is converted into heat which is generally not credited to useful effect, and adds to the comfort cooling load.

The above criterion reduces the voltage drop loss by up to 2 percent, and to that extent, energy will be conserved. 
8.0.5 Light Switching -- In any space requiring two or more branch circuits for lighting, switching shall be provided for each circuit or for portions of each circuit, so that a portion of the lighting system adequate for custodial or maintenance purposes or for effective complemertary use of natural and artificial lighting may be operated without switching on/off all of the lighting in that space.

\section{EVALUATION}

The plan examiner shall look at the diagrams to make sure that there is enough switching provided. He should determine that there is at least one switch in each room.

\section{CRITERION}

8.0.6 Electric Meters -- In any multi-tenant building, the electric energy to each tenant shall be metered separately for energy consumed in his portion of the building. It is recommended that each tenant also be billed separately for the energy he uses. Condominiums shall be included as multi-tenant buildings. Hotels, college dormitories, and other transient facilities are excluded from the provisions of this paragraph.

\section{EVALUATION}

Examine plans to determine that each tenant has his own meter. COMMENTARY

There is some evidence that a significant reduction in energy usage occurs when tenants pay directly for the energy they consume. 
LIGHTING REQUIREMENTS

\subsection{REQUIREMENT}

In any space within a building, the permissible level of maintained illumination shall be based upon the use for which the space is intended.

\section{CRITERIA}

9.0.1 Task Lighting -- The design criteria for the level of illumination in the immediate area of a specific task shall be no greater than that recommended by the Illumination Engineering Society in the IES Lighting Handbook, 5th ed., for that task.

9.0.2 Local Lighting -- Task illumination shall be produced by luminaires arranged to illuminate the immediate task area, and such luminaires shall be individually switched. This requirement shall not apply where room occupancy is such that the averaged occupied space is $50 \mathrm{ft}^{2}$ or less per occupant.

9.0.3 General Lighting -- The general level of illumination in a space surrounding the task area shall be not more than $1 / 3$ of the task level. Where more than one task level occurs in a space, the general level shall be not more than 1/3 of the average level of task illumination in the adjacent task spaces.

9.0.4 Noncritical General Lighting -- In the areas within corridors, stairways, toilets, lobbies, and the like, where no specific visual task occurs, the level of illumination shall be no more than $1 / 3$ of the average level of general illumination in the adjacent task spaces, but not less than OSHA recommended levels for safety.

\subsubsection{Lighting Calculations}

9.0.5.1 Compliance with the requirements and criteria of 9.0 and 9.1 shall be determined by calculation of maintained illumination, following the procedure recommended by the Illuminating Engineering Society in the IES Lighting Handbook, 5th ed.

9.0.5.2 The following initial reflectances shall be used in calculation of maintained illumination:

1) Ceilings, $80 \%$

2) Walls, $50 \%$

3) Floors, 20\%

\section{COMMENTARY}

Where higher reflectances are provided, increased lighting levels will be permitted in proportion. Where lower reflectances are provided, no increase in wattage will be permitted for the purposes of bringing lighting levels up to those specified above. 
9.0.5.3 The following shall be used in calculating Light Loss Factors:

1) Area atmosphere to be "clean"

2) Time between cleaning, 12 months

3) Lamp burnout factor $=1.0$

4) All recoverable factors $=1.0$

9.0.5.4 Coefficients of utilization shall be no lower than those given in the IES Lighting Handbook, 5th ed., for the existing conditions and type of Iuminaires.

\subsection{REQUTREMENT}

Only efficient lamps shall be used for general illumination and local task illumination, except as provided below in 9.1.3 and 9.1.4.

\section{CRITERION}

9.1.1 Efficient Lamps -- Lamps shall be defined as those which produce at least 40 lumens per watt input, including ballast losses, at the rated initial output, defined herein as "efficient lamps". This definition is used in 9.1 .4 as a basis for determining lighting load.

\section{COMMENTARY}

Some lamps in common use operate with a relative efficiency as low as $1 / 4$ that of other commonly available lamps. The objective of the criteria of 9.1 .1 is twofold:

1) To provide a basis for computing the total wattage allowed for lighting under 9.1.4.

2) To restrict the use of inefficient lamps to special usages (9.1.3) and in a trade-off mode with more efficient lamps as provided under 9.1 .4 .

\section{CRITERIA}

9.1.2 Other Lamps - To the extent that lamps producing less than 40 lumens per watt are used, the general lighting in the space shall be reduced by an equal number of watts.

9.1.3 Exceptions -- The criteria of 9.1.1 and 9.1.2 shall not apply to the following:

1) Private residences, except for kitchens, bathrooms, and laundry areas.

2) Private apartments in apartment houses, except for kitchens and bathrooms in the apartments, and public spaces such as lobbies, halls, stairways, laundry and utility rooms, and basement areas generally.

3) Small spaces, such as closets, requiring only one lamp of not over 60 watts. 
4) Auditoriums and stages where dimming is essential to the use of the space.

5) Projectors.

6) Portable devices.

7) Luminaires for medical and dental diagnostic, surgical, or therapeutic purposes.

8) Highlighting applications, such as localized lighting of work stations, sculpture exhibits, art exhibits, and individual items of display merchandise.

9) Specialized lighting applications (color matchings; where electrical interference cannot be tolerated).

9.1.4 Lighting Alternatives -- The total watts used in a.building for interior lighting purposes shall be no more than that which would have been required had all spaces been illuminated with efficient lamps, efficient luminaires, and reflectances, as defined above. Performance specifications of lamps and luminaires shall be that given in the fifth edition of the IES Lighting Handbook.

\subsection{REQUIREMENT}

Use of luminaires providing for heat removal or heat recovery shall be encouraged.

\section{CRITERION}

9.2.1 Heat Removed/Recovered from Luminaires -- Where the heat from lamps is in part removed by a heat transfer medium which does not enter the occupied spaces, each Btu so removed may be offset by $1 / 2 \mathrm{Btu}$ of additional permitted energy input to the lighting system for illumination purposes, provided that at least $50 \%$ of energy so removed can be recovered for useful heating purposes elsewhere or for reheat in humidity-control equipment, and provided that the remainder of the energy removed is not transmitted as additional load to the cooling system.

\section{EVALUATION}

The evaluator may determine from standard procedures when available, or manufacturers! recommendations when industry or national standards are not available, the total Btu exhausted from luminaires.

\section{COMMENTARY}

All energy used for lighting ends up as heat, and energy saved by removing this load from the air conditioning load should be rewarded. The criteria of 9.5 is not intended to encourage the use of more energy in lighting for the purpose of heating building space. 


\subsection{REQUIRENENNT}

The energy expended for exterior lighting shall be minimized by basing the maximum level of maintained illumination upon the use for which the space is intended and by using efficient light sources as defined in 9.1 .1 .

\section{CRITERIA}

\subsubsection{Lighting Levels}

9.3.1.1 Maintained levels of illumination for exterior lighting shall be no greater than that recommended by the Illuminating Engineering Society in the IES Lighting Handbook, 5th ed., for that area classification.

9.3.1.2 Signs and facade lighting, 500 watts, or $1 \%$ of total interior lighting load of the building, whichever is greater.

9.3.1.3 Continuous burning gas lamps shall not be used to provide illumination or decoration.

9.3.2 Lighting Calculations -- Calculation of illumination shall follow the procedure recommended by the Illuminating Engineering Society (IES) Lighting Handbook, fifth edition. 


\section{ENERGY REQUIREMENTS FOR BUILDING}

DESIGNS BASED ON DYNAMIC ANALYSIS

\subsection{REQUIREMENTT}

Alternative building designs shall be accepted that can be shown to. save equivalent amounts of energy without following each and every detailed requirement of Chapters 5 through 9 of this standard.

\section{CRITERIA}

10.0.1 Equivalent Annual Energy Consumption -- Under the provisions of this chapter the designer may propose any design of building and energysaving systems for which the integrated annual energy use is equal to or less than the corresponding annual energy use of a similar system designed to meet the requirements of chapters 1-9 of this standard. Comparison of the two designs shall be based on annual energy profiles of both systems covering heating, ventilating, cooling, lighting, and service water systems. The criteria for this comparison process are illustrated in Figure $10-1$.

10.0.2 Documentation -- Building owners or their representatives who desire to use an alternative building design based on dynamic analysis shall provide detailed technical data and analyses as necessary to verify that the design complies with the requirements of this chapter. This report shall include details of the annual energy consumption analysis for the building service systems prepared by a registered professional engineer or architect, recognized as an expert in the design of the type of structure and systems submitted.

10.0.3 Basis for Comparison -- The building and service system design selected as a basis for the reference energy budget shall meet the requirements of Chapters 1 through 9 of this document and shall be one that is commonly employed for the proposed type of occupancy and geographical location.

10.0.4 Commonality -- The comparative analysis for evaluation shall include the building exterior envelope design, cormon climatic data, common operational occupancies and schedules, common energy systems characteristics, common efficiency assumptions, and comparable building shape and height.

10.0.5 Analysis Procedure -- The energy consumption analysis for the design forming the basis of comparison and for all energy-using systems considered as alternatives under the provisions of this chapter shall be conducted according to the following procedure: 
10.0.5.1 The building heating and cooling load analysis that is used as the basis for the energy consumption analysis shall be performed in accordance with the procedures recommended by the American Society of Heating, Refrigerating and Air Conditioning Engineers (ASHRAE) Task Group On Energy Requirements in the document entitled "Procedures for Determining Heating and Cooling Loads for Computerized Energy Calculation", or equivalent.

10.0.5.2 The simulation of the building and its systems shall cover the entire range of operation for a test year. Simulation of the HVAC system shall be performed in accordance with the ASHRAE Task Group publication entitled "Proposed Procedures for Simulating the Performance of Components and Systems for Energy Calculation". Operational characteristics of the building, including temperature and humidity levels, lighting schedule, occupancy schedule, and schedule of outside air being introduced through the ventilation system shall be included. The simulation of the compponent equipment shall include operation at part-load as well as fullload conditions. Manufacturers' data shall be used where available and all thermal performance characteristics of the energy-significant components as well as thermal characteristics of the building shall be given in the report specified in 10.0 .2 .

10.0.5.3 The particular computer program or calculation procedure that is used to estimate annual energy consumption shall be reviewed and evaluated by the registered professional engineer or architect referenced in 10.0.2. An analysis procedure which deviates from the criteria of 10.0.5.1 and/or 10.0.5.2 shall be allowed provided that it is approved.

\section{COMMENTARY}

These criteria allow maximum flexibility to the designer to provide performance solutions without necessarily complying with the detailed criteria for the building envelope, mechanical, electrical, lighting, service water, or other systems within a building. 


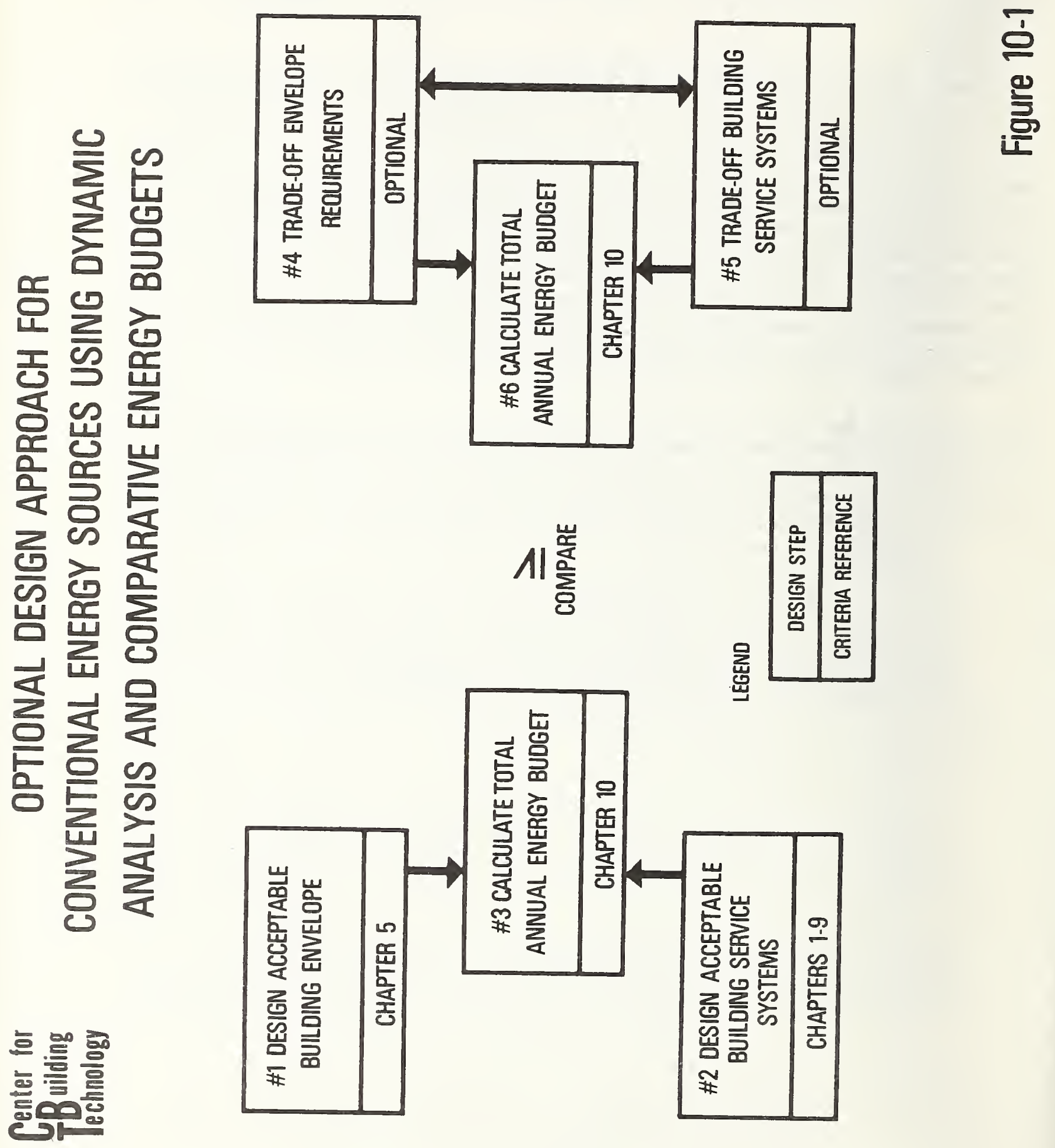


REQUIREMENTS FOR BUILDINGS UTILIZING

SOLAR OR WIND POWERED ENERGY SOURCES

\subsection{REQUIREMENT}

An energy bonus shall be granted to buildings designed to reduce usage of mineral or hydroelectric energy sources by using solar or wind powered energy sources to supply part of all of the building energy requirements.

\section{CRITERIA}

11.0.1 Energy Estimate - The computed annual energy consumption of a building and its service systems when employing part or all solar or wind powered energy sources according to the Criteria of this chapter shall be allowed to exceed the reference energy budget obtained by computing the annual energy consumption of a system employing only mineral or hydroelectric energy sources by the amount of 50 percent of the energy obtained from solar or wind powered sources. The criteria for claiming such an energy bonus is given in this chapter and the steps illustrated in Figure 11-1. Windows shall not be considered a solar energy source for the purposes of this chapter. Use of windows to make more effective use of solar energy car be recognized under Chapter 10.

11.0.2 Documentation -- Building owners or their representatives desiring to claim the energy bonus that is permitted in 11.0 .1 shall provide a report giving detailed technical data and analysis as necessary to verify that the design complies with the requirements of this chapter. This report shall include details of the energy consumption analysis for the building service systems prepared by a registered professional engineer or architect, recognized as an expert in the design of the type of structure and systems submitted.

11.0.3 Basis for Comparison -- The building and service systems design using mineral or hydroelectric energy source(s) and selected as a basis for the reference energy budget shall meet the requirements of Chapters 1 through 9 of this document and shall be one that is commonly employed in the proposed type of occupancy and geographical location.

11.0.4 Commonality -- In designing the service systems using part or all solar or wind energy sources, only those components of the building and service equipment that must be modified to utilize such energy may be different from those used to calculate the total annual energy budget. Common climatic data, common occupancies and use schedules, and common efficiency assumptions for identical components shall be used in the two cases.

11.0.5 Analysis Procedure -- The energy consumption analysis for both the mineral or hydroelectric and the solar or wind powered energy-using systems shall be conducted according to the following procedure. 
11.0.5.1 The building heating and cooling load analysis that is used as the basis for the energy consumption analysis shall be performed in accordance with the procedures recommended by the American Society of Heating, Refrigerating and Air Conditioning Engineers (ASHRAE) Task Group on Energy Requirements in the document entitled "Procedures for Determining Heating and Cooling Loads for Computerized Energy Calculation," or equivalent.

11.0.5.2 The simulation of the building and its systems shall cover the entire range of operation for a test year. Simulation of the HVAC system shall be performed in accordance with the ASHRAE Task Group publication entitled "Proposed Procedures for Simulating the Performance of Components and Systems for Energy Calculation". Operational characteristics of the building, including temperature and humidity levels, lighting schedule, occupancy shcedule, and schedule of outside air being introduced through the ventilation system shall be included. The simulation of the component equipment shall include operation at part-load as well as fullload conditions. Manufacturers' data shall be used where available and all thermal performance characteristics of the energy-significant components as well as thermal characteristics of the building shall be given in the report specified in 11.0 .2 .

11.0.5.3 The particular computer program or calculation procedure that is used to estimate annual energy consumption shall be reviewed and evaluated by the registered professional engineer or architect referenced in 11.0.2. An analysis procedure which deviates from the criteria of 11.0.5.1 and/or 11.0.5.2 shall be allowed provided that it is approved by the organization using this document.

\section{COMMENTARY}

The intent of Chapter 11 is to encourage the development and use of solar or wind powered energy sources so as to conserve extracted energy sources and reduce pollution. For example, assume a design that meets the criteria of Chapters 1 thnough 9 and that has an annual consumption of energy from mineral sources of 100 units. The designer can elect to use the criteria of Chapter 11 instead of Chapters 1 through 9 and design his building to supply, say, 50 units of the energy requirement from solar energy sources. Using the formula in Figure 11-1, block 非6, he will then be permitted to design his building and service systems to consume a total of 125 units of energy annually with 75 coming from mineral fuel and 50 units coming from solar energy. The net saving will be 25 units of mineral fuel and the building will be allowed a bonus of 25 units of energy over and above the reference energy budget of 100 units. 
The rationale for Chapter 11 and the related definition of solar energy sources is as follows:

1) All forms of extracted energy sources commonly in use today are in short supply, will apparently remain so for the near future, and have finite limits of economic recovery and ultimate depletion.

2) The AEC has stated that nuclear electrical power generation cannot reasonably be expected to carry a major fraction of the electric energy load until after the turn of the century.

3) Limitations on the total quantity of thermally generated energy as we know it today will ultimately be determined by the effects of various forms of pollution, including thermal pollution. The effects of thermal and other forms of pollution are already measurably significant.

4) Conserving energy is an essential element of the Federal Government's goal to achieve energy self-sufficiency.

It follows that the Nation's finite energy sources and particularly those in short supply should be conserved and used in the most efficient manner available, and that extra incentives are neither needed nor should be used to stimulate the exploitation of energy sources which add pollution to the air or waterways. 

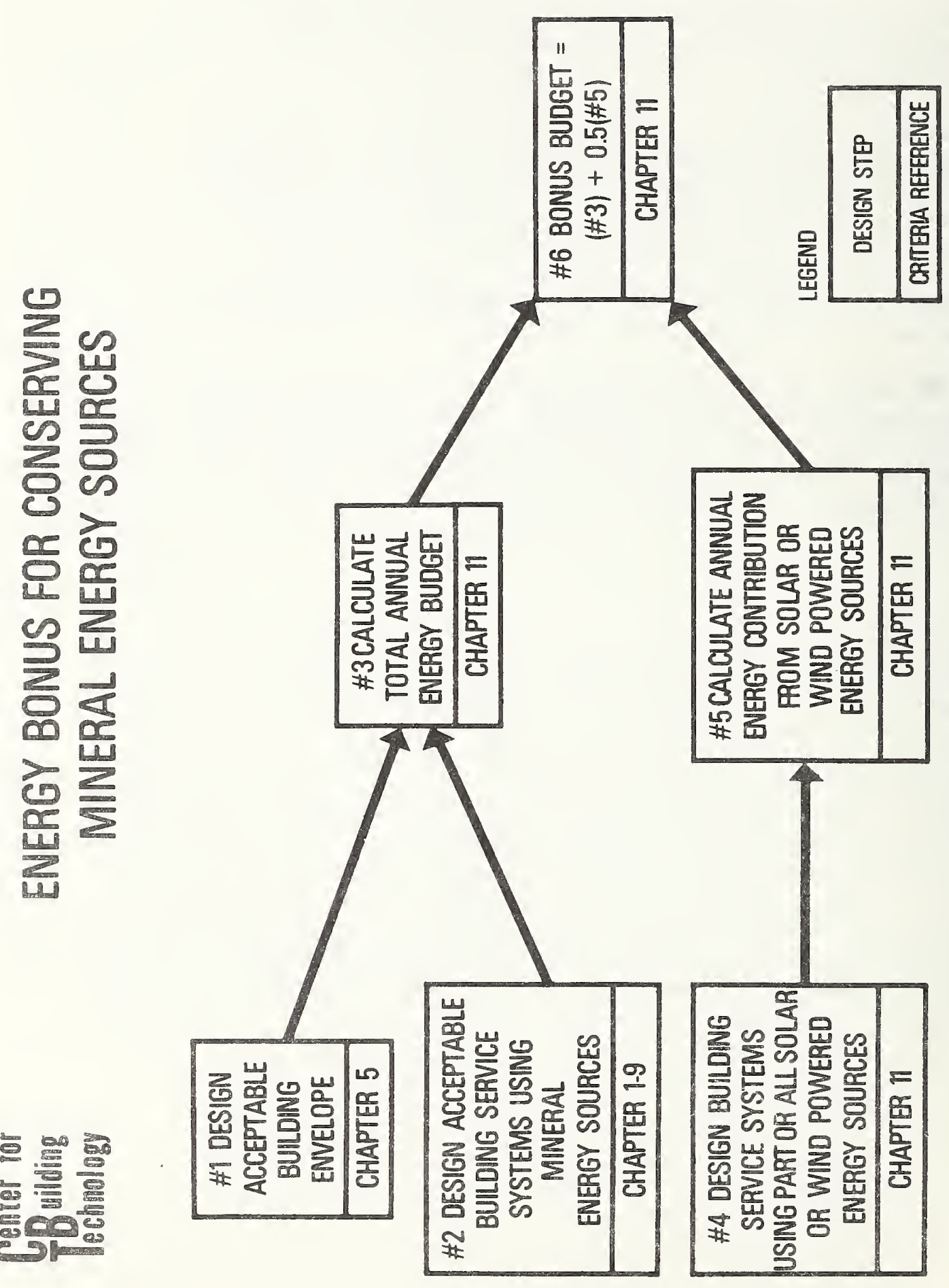
Physical

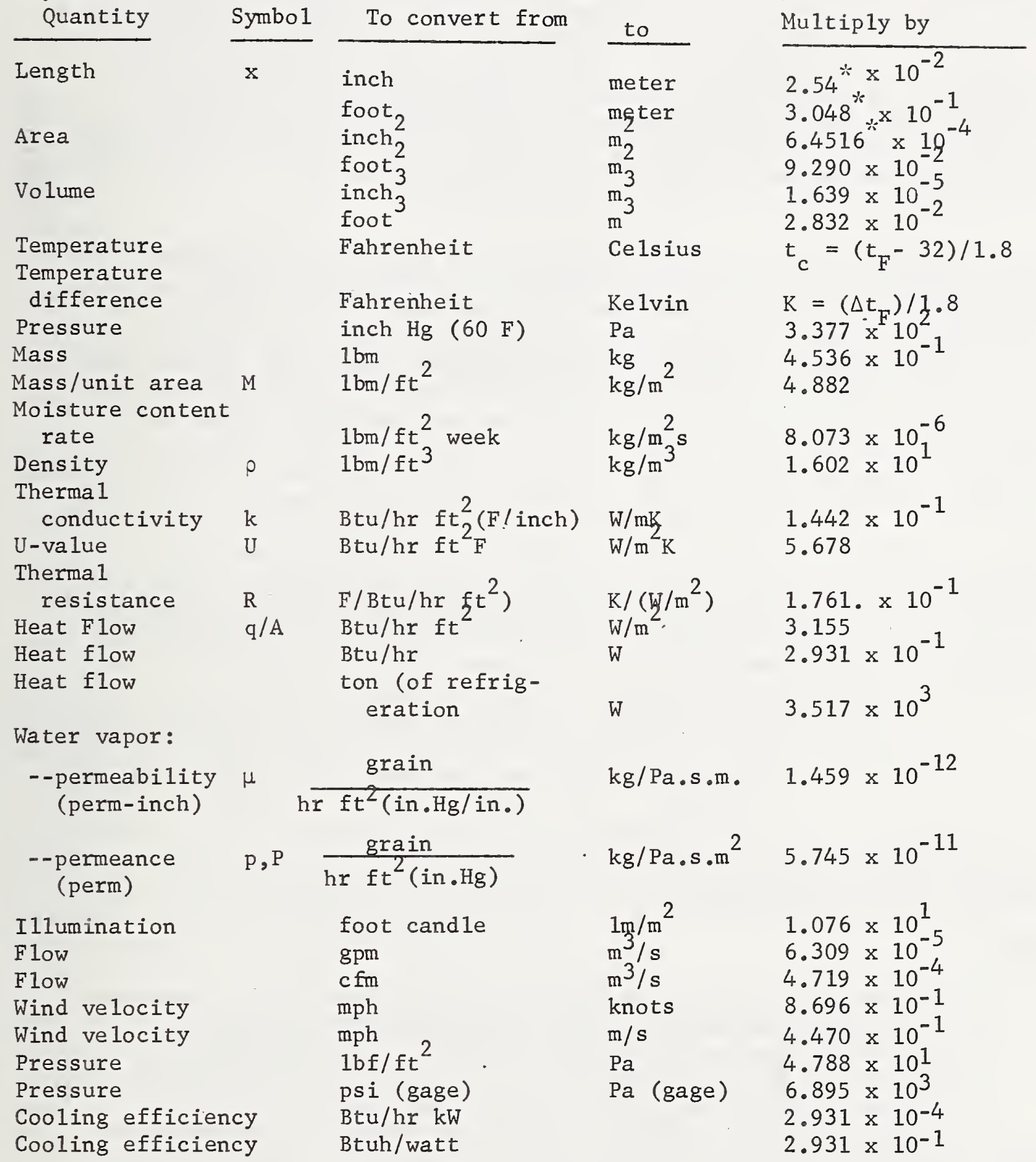

* Exact value: others are rounded to fourth place. 
In order to avoid the possibility that any requirement of these criteria might be counterproductive in an economic efficiency sense, it may become necessary to determine whether a requirement is economically efficient. To determine economic efficiency, the present worth of life-cycle energy savings must be compared to the present worth of the extra life-cycle costs incurred to achieve the energy savings. This section describes one acceptable method for calculating the present worth of energy savings and extra costs, and it specifies a relationship between these two magnitudes in order for economic efficiency to be determined.

For the purpose of these calculations, the building life (L) and the real annual discount rate (D) must be assumed. The life-cycle energy savings, resulting from the use of a required subsystem rather than a specific alternative, consist of the estimated yearly difference in electrical and fossil fuel consumption valued at present prices, which grow, in real terms, at an annual rate of $P$. The extra life-cycle costs consist of additional initial costs, additional maintenance operations, and replacement costs through the life of the building. Real discount rates and real rates of fuel price increases (i.e., rates of change apart from general price increases) are used to eliminate the need to estimate the rate of general inflation.

A given requirement in the document should be considered economically efficient if the present worth of energy savings (B) is greater than the present worth of the extra costs (C). A requirement should be considered economically inefficient if the present worth of energy savings (B) is less than the present worth of the extra costs (C). The calculation of $\mathrm{B}$ and $\mathrm{C}$ is described as follows:

$$
\begin{array}{ll}
B=\frac{1+P}{D-P} \cdot\left[1-\left(\frac{1+P}{1+D}\right)^{L}\right] \cdot S & D \neq P \\
B=L \cdot S & D=P
\end{array}
$$

where

$S=$ the annual value of energy saving by incorporating a subsystem or component required in the document rather than using a specific alternative.

$\mathrm{S}=\mathrm{p}_{1} \mathrm{~s}_{1}+\mathrm{p}_{2} \mathrm{~s}_{2}$, etc.,

where $\mathrm{p}_{1}=$ the present unit price of fuel 1 , and $s_{1}=$ the number of
units of fuel 1 saved annually. 
Simply stated, B is equivalent to the present value of a stream of dollar energy savings over $L$ years which grow at the real rate of fuel price increase, $P$, while being discounted to present value at the real discount rate, $D$.

where

$$
C=I+\left[\frac{1-\frac{1}{(1+D)^{L}}}{D}\right] \quad(M+0)+\sum_{y=1}^{L} \frac{R_{y}}{(1+D)^{y}}
$$

$D=$ real annual discount rate in decimal form.

$P=$ annual rate of change in the real price of energy in decimal form.

$I$ = extra initial cost incurred by incoporating a subsystem or component required by these criteria rather than using a specific alternative.

$\mathrm{L}$ = building life in years.

$\mathrm{M}=$ extra annual maintenance cost at present prices.

$0=$ extra annual operations cost at present prices.

$\mathrm{R}_{\mathrm{y}}=$ extra replacement costs in year $\mathrm{y}$ at present prices.

I, $M, O$ and $R_{y}$ may be negative. A negative value indicates that the particular cost component of the required subsystem is lower than that for the alternative being considered. If this is the case, the negative sign should be retained in the computation.

In selecting specific values for $D$ and $L$, lower values of $L$ and higher values of $D$ will reduce $B$, thereby increasing the chance that the requirement will appear to be economically inefficient. It is recommended that a building life of no less than 30 years be used (12 years for mobile homes) and a discount rate of no more than .08 be used.

As increasingly costly energy sources are utilized, e.g., North Sea and North Slope oil rather than Oklahoma oil, the real price of energy can be expected to rise during the life of the building (barring an innovation such as the commercial generation of electricity by fusion at favorable cost). Therefore, it appears overly conservative to say that $P$ equals zero. As an attempt to capture the effect of rising real energy prices, it is suggested that $P$ be assumed to equal .01 . This assumption means that the nominal price of energy is expected to rise annually at a rate one percent greater than the general level of prices over the appropriate lifetime. 


\section{ENERGY ANALYSIS DATA}

The amount of energy consumed by building service systems is strongly affected by the dynamic interplay of structure heat transfer characteristics and mechanical systems for heating and cooling, both of which are usually changing with respect to time depending upon the outdoor weather conditions and the use patterns of the building spaces such as lighting, energy consuming equipment and occupancy.

Even with similar mechanical systems in similar types of building in the same general locality, the energy consumption between buildings may differ considerably depending upon the design of the central system and the specific types of system components used.

Accurate evaluation of building energy consumption, therefore, requires detailed mathematical simulation of the system dynamics. Such a simulation technique has been illustrated in a document entitled, "Proposed Procedures for Simulating the Performance of Components and Systems for Energy Calculations", published by the American Society of Heating, Refrigerating and Air-Conditioning Engineers.

Although the methodology to perform dynamic simulation analysis is well defined, the validity of such calculation is limited by the lack of adequate technical information such as the following:

Part-Load Efficiency Data -- Most of the HVAC equipment manufacturers publish efficiency data for major energy consuming components in terms of output capacity and input power requirement at a specified design point so that consulting engineers can select equipment to meet the heating and cooling load of the building under steady state design conditions. The efficiencies of components are commonly available only at a specific design point, often 100 percent of design rated load, which seldom occurs during the course of building operation throughout the year. During most of the year the equipment operates under part load conditions. Yet the energy efficiency data for the part load condition are seldom available from the manufacturer. In some cases such data are not easy to obtain and may require considerable one-time expenditure. In order for energy analysis to become an effective adjunct of building design, however, part load efficiency data is essential.

Control Characteristics - The dynamic response of a heating and cooling system with respect to changing requirements in the space is influenced by the manner in which the system and its equipment are controlled. If the control is out of phase with the space heating and cooling needs, 
much of the energy used to heat and cool the space will be wasted. This phenomena is especially acute for the terminal reheat system and double duct system whereby the primary energy is used to simultaneously heat and cool the supply fluid to attain the desirable condition. The parameters that describe the performance of the control function are usually expressed in such terminology as throttling range, time constant, transfer function and LaPlace transform, details of which are found in most control textbooks. Availability of this type of information for different types of controls would make it possible to estimate the energy consumption of system components as reflected in the drooping of the modulating control or the cycle frequency, percent-on time and anticipation characteristics of the on-off controls. However, very little information has been made available by the manufacturers as to these parameters, nor are comprehensive algorithms available to take these factors into account for the energy analysis.

Air Distribution To Multiple Zones From Central Fan-Plants-- The amount of chilled or heated air to be delivered to the various zones from a central fan plant is in many instances very much different from that predicted by zone heat balance equations. Present engineering practice for air distribution design is aimed at the sizing of the air duct, and not suitable for evaluating the air delivery performance under actual operating conditions. Moreover, a large amount of fan power is wasted by overpressurizing supply air and subsequent throttling of it through dampers. More comprehensive and accurate methodology for designing and evaluating the air distribution system, such as that based upon network analysis, is available and its use should be encouraged.

Standard Weather Data For The Energy Analysis -- Weather data required for the energy analysis is not the same as the steady state design weather data used for the selection of heating and cooling equipment and system design. The design weather data are basically specified as preventive measures so that occupants can be protected from the results of inadequate capacity of heating and cooling equipment. Such weather design criteria are not suitable for the dynamic evaluation of energy consumption by the equipment, since extreme weather conditions seldom prevail during the year. The weather data needed for energy analysis must satisfy the following requirements :

- Must contain coincidental values of temperature, humidity, wind data and solar radiation data including percent of sky cover by clouds.

- Must be conducive to dynamic analysis of building thermal performance and system responses.

- Must be readily obtainable and usable for each locality.

- Must be consistent. 
Engineering Data For Nonconventional Systems -- Design and performance analyses data are needed for nonconventional systems, such as solar and/ or wind power utilization systems, engine driven heat pumps, and heatoperated refrigeration cycles (Rankine, absorption, adsorption and fuelcell).

Simplified And Reliable Energy Calculation Procedures - - Although the energy calculation methods based upon the dynamic simulation of buildings and building service systems fulfill a need, they require considerable effort and a comprehensive computer program which may not be warranted in many applications of small or simple buildings. Simple energy estimate methods and versatility for evaluating different mechanical systems or innovative designs are necessary. What is needed is an energy analysis procedure more comprehensive than the degree day method yet less difficult to use than dynamic analysis. One such attempt was made recently at the National Bureau of Standards to estimate heating and cooling load(I). Approaches similar to this effort need to be further developed so that the energy consumption of less complicated buildings may be determined by a simple arithmetic manipulation of climatic factors, energy usage patterns and indoor conditions with respect to energy response factors, which will be predetermined for several typical buildings by the detailed dynamic analyses.

\section{TESTING PROCEDURES}

Most of the testing procedures published today for the HVAC equipment are for the rating or safety labeling/listing of equipment under specified design conditions. Due to standby losses (standing pilots, stack losses, compressor crankcase heaters, circulating pumps, etc.) energy converting equipment may operate with higher efficiency under the design test condition, than the part load conditions typical of day by day operation. In addition, conventional testing procedures are usually under steady loading conditions whereas the actual load is usually fluctuating. For the purpose of energy-based evaluation of building service systems and equipment, new testing procedures must be developed for evaluating efficiency performance under realistic operating conditions. General requirements for energy based testing may be stated as follows:

1. For the purpose of evaluating energy utilization efficiency, equipment shall be subjected to standardized, non-steady load conditions which represent the changing climatic and internal building load patterns common to the building.

(I) Kusuda, T., Tsuchiya, T., Powell, F.J., "Prediction of Room Temperature by Using Equivalent Thermal Mass Response Factors", Proceedings for the 5th Symposium on Temperature, National Bureau of Standards, Wash., D. C. 1971. 
2. Accurate instrumentation for determining integrated energy consumption as well as the peak power demand should be used.

3. Methodology to translate the test results to actual operating condition through mathematical simulation must be prescribed.

\section{INFILTRATION}

One of the greatest causes of building energy waste is due to unwanted air leakage, which is usually affected by the way the buildings are constructed and by the outdoor weather conditions, particularly the temperature and wind. Yet the present technology for estimating the heat gain and heat loss due to infiltration is relatively weak as compared to other modes of heat transfer such as conduction and solar radiation.

Methods of testing and evaluating building air infiltration under field conditions are presently available, but such methods need to be further developed and reduced to consensus standard procedures. 






